\title{
COMMUNITY-BASED CONSERVATION AND CROSS-CULTURAL RELATIONSHIPS
}

\section{Growing Connections Through \\ Growing Ecologies}

By
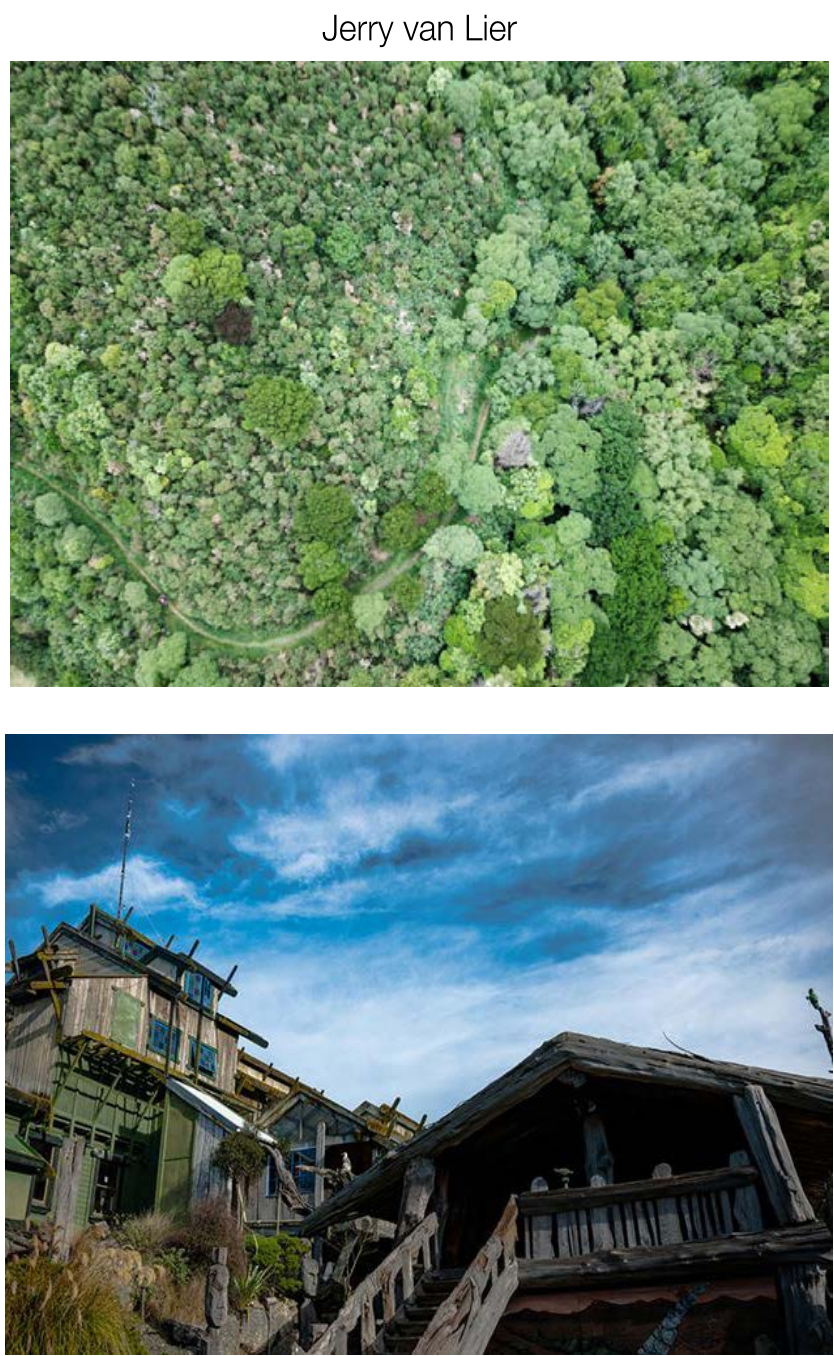

A 120-point thesis submitted to Victoria University of Wellington as a partial fulfilment of requirements for the degree of Masters of Environmental Studies 
Title image; Arial view of Manawa Karioi, the Tapu Te Ranga marae

(Photo credit; the Manawa Karioi Society) 


\section{Abstract}

Conservation is a well-established concept which exists in diverse forms based on diverse meanings and environmental values. The role which communities play in local resource management addresses many challenges in regards to top-down state management over natural resources. Communities' ability to act as environmental agents is contingent on how willing nation-states are to devolve power and decisionmaking to communities. Co-management relationships between community and state is one means of devolving power and increasing community agency. Where Indigenous communities are involved, co-management is a way of shifting power, knowledge and resources away from Western centred norms towards Indigenous worldviews and institutions. In Aotearoa New Zealand, co-management emerges across conservation efforts, from state managed levels to locally managed levels. Community-based conservation is one type of local co-management.

This research aims to analyse the different experiences and perspectives of community volunteers at the Manawa Karioi Ecological Restoration project in Island Bay, Wellington. The Manawa Karioi Ecological Restoration project is first and foremost a collaborative relationship between the volunteers of the Manawa Karioi Society and the whānau (family) of the Tapu Te Ranga marae. The land on which conservation occurs belongs to the Tapu Te Ranga marae, and therefore the longstanding relationship that the two groups have with one another goes a long way to explaining the effectiveness of restoration at Manawa Karioi. This research focuses on interviews from twelve different participants, both from the Tapu Te Ranga marae and the Manawa Karioi Society.

Through the conceptual lens of poststructuralism and political ecology, the key themes of this research will bring to light how the relationship between the Tapu Te Ranga marae and the Manawa Karioi Society enables process towards decolonisation of community-based conservation, wider societal understandings of nature and sense of place in nature. This research will explore the relationship between Manawa Karioi and the Tapu Te Ranga marae, with an aim to provoke further thought for other community organisations who wish to engage with, or already have a form of relationship with, Iwi, hapu or whānau. In doing so this research can be offered as a frame of reference for such organisations. 
Key words; Community-based conservation, co-management, relationships, natural resource management, decolonisation, poststructuralism, political ecology, social constructivism. 


\section{Thesis Acknowledgements}

To my wonderful Mum and Dad. You have supported me right from the start of my university career. Your belief and support has guided me all the way, and there will never be enough words to express my gratitude. Thank you from the bottom of my heart.

Thank you Amanda for your supervision throughout this thesis. You have pushed me to be the best researcher possible. Thank you for helping me through the challenges of the research process, but also acknowledging hard work and effort. Geography has and always will be my favourite topic.

To the Milne family: Jamie, Grant and Stella. Thank you for your constant love and support and for providing a safe space to write this thesis. To Kelly, Scotty, James and Claudia. Living with you for my whole undergraduate degree was the best flat whānau I could have wished for. Growing with all of you through those years will always be some of my fondest memories. To my dear friends from the Bungalow: Kent, Ben and Oscar. The love and support from you through my first year of Master's was great. I love you guys, and living with another close whānau means the world to me.

To Finn and Thom. Finn I can never truly tell you how great it was to have you back. Thank you for all your hard work and support to help me over the line. Thank you Thom for being right there next to me through nearly all my years of study. And also helping me pass statistics. I knew once I passed stats, everything else was in the bag ;)

Laila. I could not have finished my university degree, let alone do a Master's without you. You saw me in times where I thrived, but also when I was completely broken, and always pulled me back up. Thank you for always giving me not just your time, but your kindness and compassion. I will think of you for inspiration when times are tough, as you always helped me believe I would get through.

To my wider but ever so close group of friends and whānau: Harry, Clint \& Nikki, Stu \& Nat, Jae Barrett, Nick and Karena Goodall, Duncan, Benn \& Grace, Dave Graham, Cleo, Willow, Jackie Ryder, all close friends at the Table of Knowledge, and so many more. You are my closest friends and have supported me in different ways right 
throughout this thesis. Words will never truly express my gratitude. There are many others, so please know that I have always been grateful for the people who have thought of me on this journey. Kia ora.

Thank you Allen Copeland and Ted for being great friends and flatmates, and for the calm and great home environment you created for me during my thesis year. You always were there for me at home. Thank you and I love you both very much.

To my Victoria University Geography and Environmental Masters cohort. It's been a pleasure to complete my studies with you all. I thank you for all your support through the ups and downs that we have been through together.

Lastly, a big thank you to the Manawa Karioi Society and the Tapu Te Ranga marae for their support, and for allowing me to work with them in my research. I am glad to be a part of this project, and as it is located in the area where I have grown up, it is a really special place for me. Kia ora 


\section{Pepeha}

Ko Tawatawa te Maunga

Ko ngā waka o ngā hau e whā Ngā Waka

Ko te Manawa Karioi te Puna

Ko Ūkaipo nō Mahinārangi me Pare Waaka ngā Whare Tīpuna

Ko Hirini te Tangata

Ko Tapu Te Ranga te Marae

Tawatawa is the mountain

The people of the four winds are the waka

Manawa Karioi is the spring

Ūkaipo of Mahinārangi and Pare Waaka are the ancestoral houses

Hirini is the Rangatira

Tapu Te Ranga is the Marae

(Citation -Tapu Te Ranga website) 


\section{$\underline{\text { Table of contents }}$}

ABSTRACT III

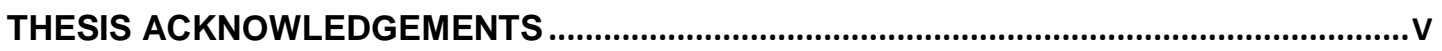

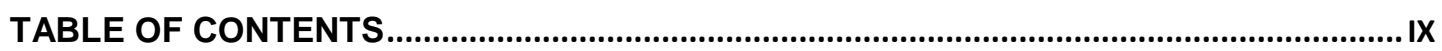

LIST OF FIGURES .................................................................................................................

LIST OF TRANSLATED TE REO WORDS........................................................................II

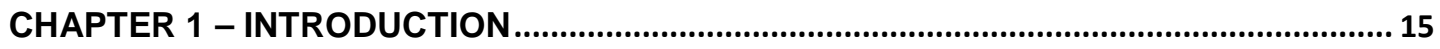

1.1 The Tapu Te Ranga marae And the Manawa Kario Society as a CaSe Study ............................... 16

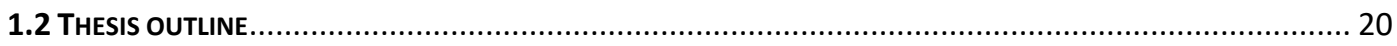

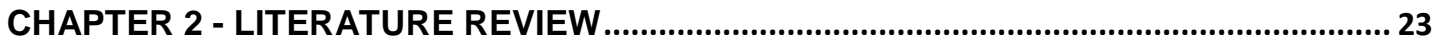

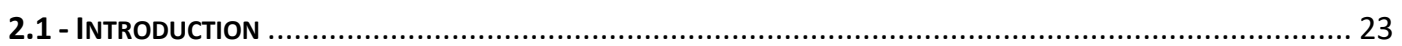

2.2 - Understandings of Nature - NatUre AS a Social Construction ............................................. 24

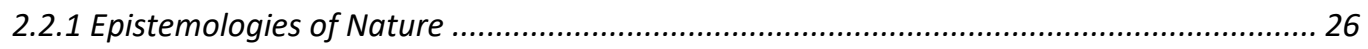

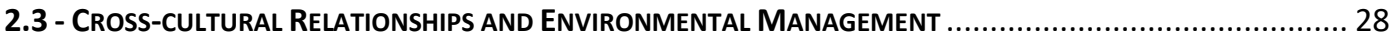

2.3.1 - History of Conservation in New Zealand; Colonial Environmental Knowledges \&

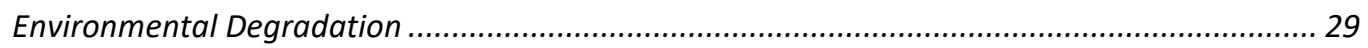

2.3.2 - Fortress Conservation and Protected Areas .............................................................. 30

2.3.3 - Co-management, Cross-cultural Relationships and Environmental Management.......... 31

2.3.3.1 - Power Relations within cross-cultural, co-management relationships ................................. 33

2.3.3.2 - Scale, Scope, \& Representation of Cross-Cultural Relationships ........................................ 35

2.3.3.3 - Cultural awareness in conservation co-management ........................................................... 36

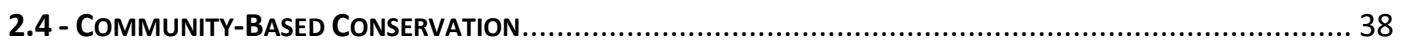

2.4.1 - Background to Community-based Conservation ...................................................... 39

2.4.2 - Volunteers and Participants for Community-based Conservation ................................. 41

2.4.3 - Community-relationships for Community-based Conservation ..................................... 43

2.4.4 - Wider Cross-cultural and Social Benefits Achieved through Community-based

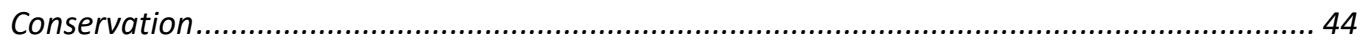

2.5 - Community-based Conservation in Aotearoa New Zealand - The Gap in the Literature............ 45

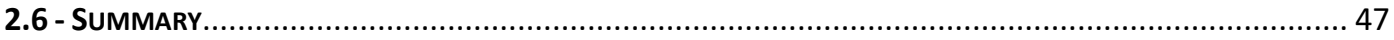

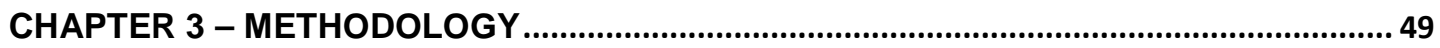

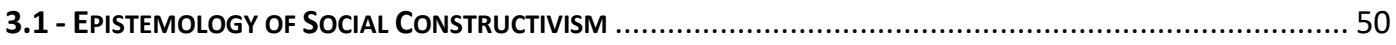

3.2 -The Case Study - The Manawa Kario Ecological Restoration Project ................................... 51

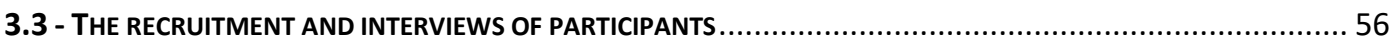

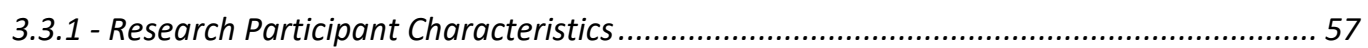




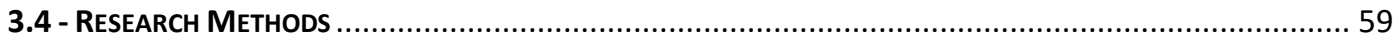

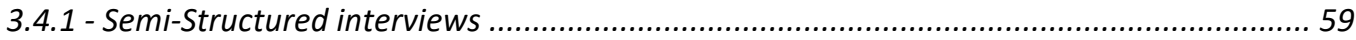

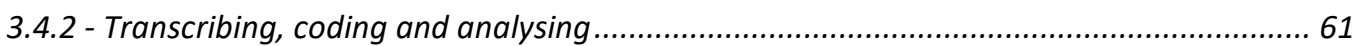

3.5 Reflexivity, Positionality and Relations of Power in Cross-Cultural Research .........................62 62

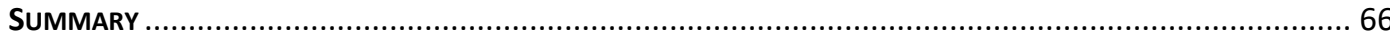

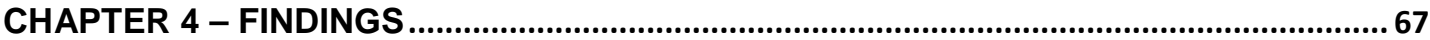

4.1 - The Relationship between the Tapu Te Ranga marae and the Manawa Karioi Society................ 67

4.1.1 - The Tapu Te Ranga marae - Manawa Karioi Kaupapa of Conservation: ......................... 68

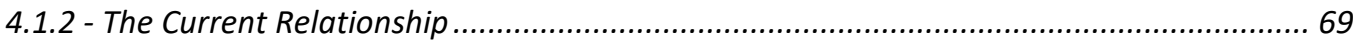

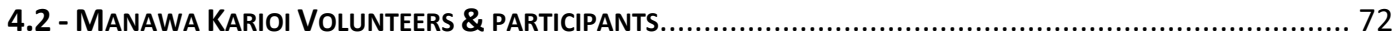

4.2.1 - Challenges and Successes of Volunteers ................................................................. 74

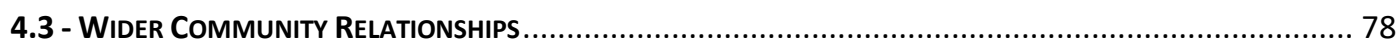

4.3.1 - Aligned Values - Sisters of Compassion \& Tapu Te Ranga.......................................... 78

4.3.2 - Community-based conservation groups in Island Bay.............................................. 81

4.3.3 Wellington City Council \& other institutions ........................................................... 83

4.4 - Wider COMmUNity BENEFITS FRom C.B.C AND CROSS-CULTURAL RELATIONSHIPS .............................. 85

4.4.1 - Cross-Cultural Engagement in Space and Place ........................................................... 85

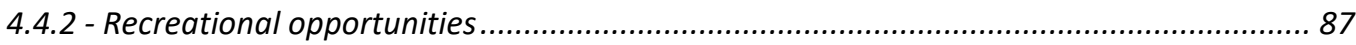

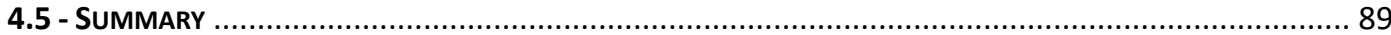

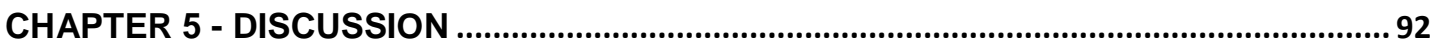

5.1 - Decolonising Practices: The Tapu Te Ranga - Manawa Kario Relationship............................. 93

5.2 - Poststructural and Political Ecology Analysis at Manawa Kariol ....................................... 98

5.3 - HOW DO THESE KEY FINDINGS CONFIRM OR CHALLENGE EXISTING LITERATURE? .................................. 100

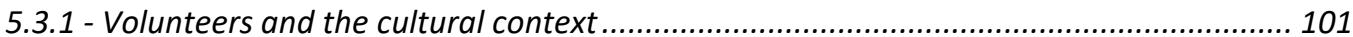

5.3.2 - Community relationships for conservation............................................................... 102

5.3.3 - Community Benefits for conservation ..................................................................... 103

5.4 - POSTSTRUCTURAL, POLITICAL ECOLOGY - RELATIONSHIP WITH EXISTING LITERATURE........................... 105

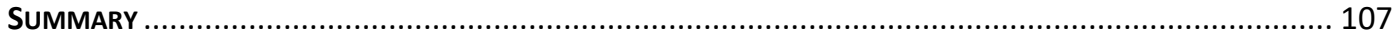

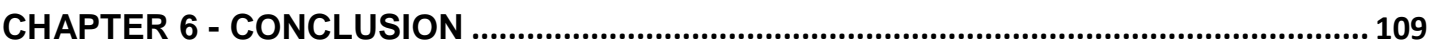

6.1 -REFLECTION OF THE RESEARCH PROCESS - StRENGTHS AND LIMITATIONS ...................................... 110

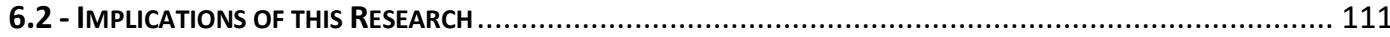

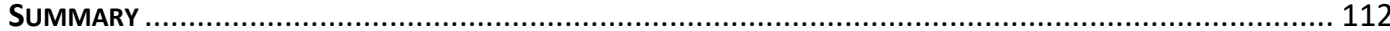

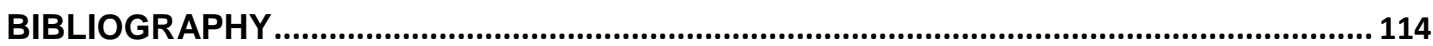

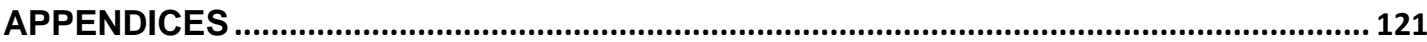

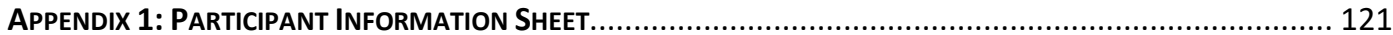


APPENDiX 2: PARTICIPANT CONSENT FORM

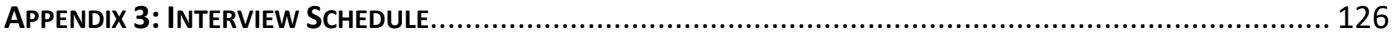

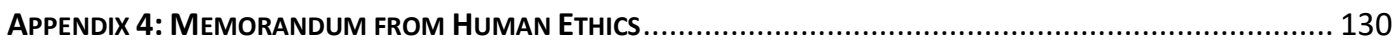




\section{List of Figures}

Figure 1: Tapu Te Ranga marae location in arial view of Wellington. 17

Figure 2: Arial view outlining the Tapu Te Ranga marae, Manawa Karioi and the Home of Compassion 18

Figure 3: Photo of Manawa Karioi taken in 2007 (Photo credit; the Manawa Karioi Society) .53

Figure 4: Photo of Manawa Karioi taken in 2018 (Photo credit; the Manawa Karioi Society) .53

Figure 5: Tapu Te Ranga marae, 2019. .54

Figure 6: Tapu Te Ranga marae, 2019. .55

Figure 7: Network Analysis Map (Attride-Stirling, 2001) .62

\section{List of Tables}

Table 1: Table of research participants. .57

\section{List of Translated Te Reo Words}

Hapu - Sub-tribe

Hui - To gather

Iwi - Tribe

Kaumātua - Senior elder, often a leader

Kaupapa - Vision

Kōrero - Discuss

Māoritanga - Māori practices and beliefs

Maunga - Mountain

Mokopuna - Children, grand children

Ngahere - Bush, forest

Rangatira - To be of high status

Rongoā - Medicinal (and other) uses of plants

Taha Māori - Māori identity

Tino Rangatiratanga - Self-determination, autonomy, self, governing

Te ao Māori - Māori worldview

Tipuna whare - Ancestral house often used for hui (meetings) at marae 
Tūrangawaewae - A place to stand

Urupā - Burial ground

Whānau - Family

Whenua - Land 


\section{Chapter 1 - Introduction}

Conservation is the concept of preserving and protecting the environment and all natural species (Mairi Jay \& Morad, 2009). However, there are numerous pressures on preservation, and many critiques of top down and market led efforts to conserve nature (Büscher \& Whande, 2007). Since the 1980s, localised conservation has been promoted as a better avenue to achieve positive outcomes for nature and people (Western, 1994). Communities have been managing their own environments for millennia (Western, 1994). However, colonial hegemony has had devastating consequences for many Indigenous or First Nations peoples around the world (B. Coombes, Johnson, \& Howitt, 2012). This has occurred where Western cultures have displaced Indigenous peoples from their land, and thus deprived them of their own environmental and social agency (B. Coombes et al., 2012).

The common belief that conservation through creating protected areas such as national parks can only be a positive way forward for managing natural resources does not address many of the complexities of displacement for many local communities (West, Igoe, \& Brockington, 2006). National parks, as asserted by (Colchester, 2004), have "denied Indigenous peoples' rights, evicted them from their homelands and provoked long-term social conflict" (p. 145). In recognising these pernicious effects of colonialism, many nation-states and other institutions now regard co-management between the state and local communities as a way to better manage common resources.

The World Bank defines co-management approaches to conservation as the sharing of responsibilities between key primary stakeholders, often in the form of local communities and the nation-state (The World Bank, 1999). Co-management, as described by Carlsson and Berkes (2005), is a constant problem solving process rather than a fixed answer or model. This perspective seeks to look beyond comanagement as a simplistic notion that involves the power-sharing of common pool resources (Carlsson \& Berkes, 2005). Instead, they view co-management as a process which recognises that state and community structures are complex and heterogeneous. Co-management is therefore also a contextual process involving diverse agents, cultures, communities and institutions, where deliberation, negotiation and joint learning need to be involved for problem solving to be effective (Carlsson \& Berkes, 2005). Collaborative partnerships which take all this into account not only 
open space for environmental advancements, but also allow for many social inequities to be addressed through shifts in power (Carlsson \& Berkes, 2005).

Discussions in Geography which address nature often cover two dominant and prevailing themes: the concern of space and spatial patterns in relation to social structures, and interactions between people and nature, environment or land (Sayer, 1979). The way in which different understandings of nature are constructed in society is influenced by worldviews.

The term 'Western' refers to cultures that stem from Eurocentric worldviews. Westernised perceptions of nature often tend towards seeing nature as a wilderness, which is ideally peopleless and pristine (Cronon, 1996). Western centred binaries such as this notion of a peopleless, pristine environment have created a separation of nature and culture as described by West et al. (2006). Understandings of nature are based on the idea of nature as separate to humans, and therefore subjective value is found when people engage with it (Sayer, 1979). Braun and Castree (2005) maintain that "[m]ore than ever before, then, nature is something made" (p. 3). Escobar (1999) also supports Castree and Braun (2005) by asserting that there "is a growing belief that nature is socially constructed (entirely different from saying 'there is no real nature out there')" (p. 325). Through a poststructural-informed political ecology, I will explore different constructions of nature through a community conservation initiative.

\subsection{The Tapu Te Ranga marae and the Manawa Karioi Society as a case}

\section{study}

This research was ethnographic and focused on community-based conservation and cross-cultural relationships. The case study was the Manawa Karioi Society, and the relationship which they have with the Tapu Te Ranga marae. Tapu Te Ranga marae is an urban, contemporary marae in Island Bay, Wellington. The case-study is unique as the space where the Manawa Karioi Ecological Restoration Project is located is owned by the marae. The society are invited to carry out community-based conservation in the marae space. 


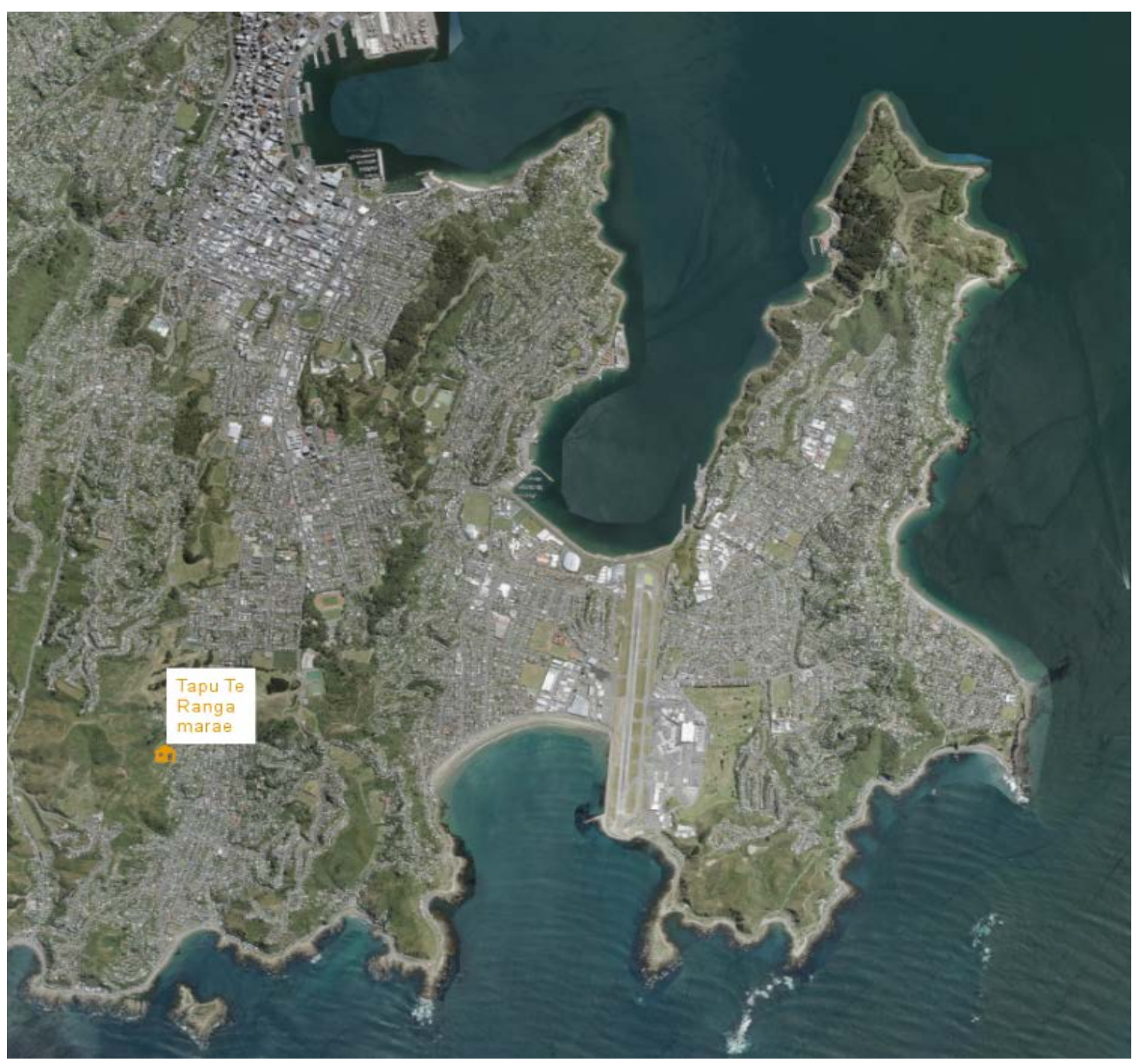

Figure 1: Tapu Te Ranga marae location in arial view of Wellington 


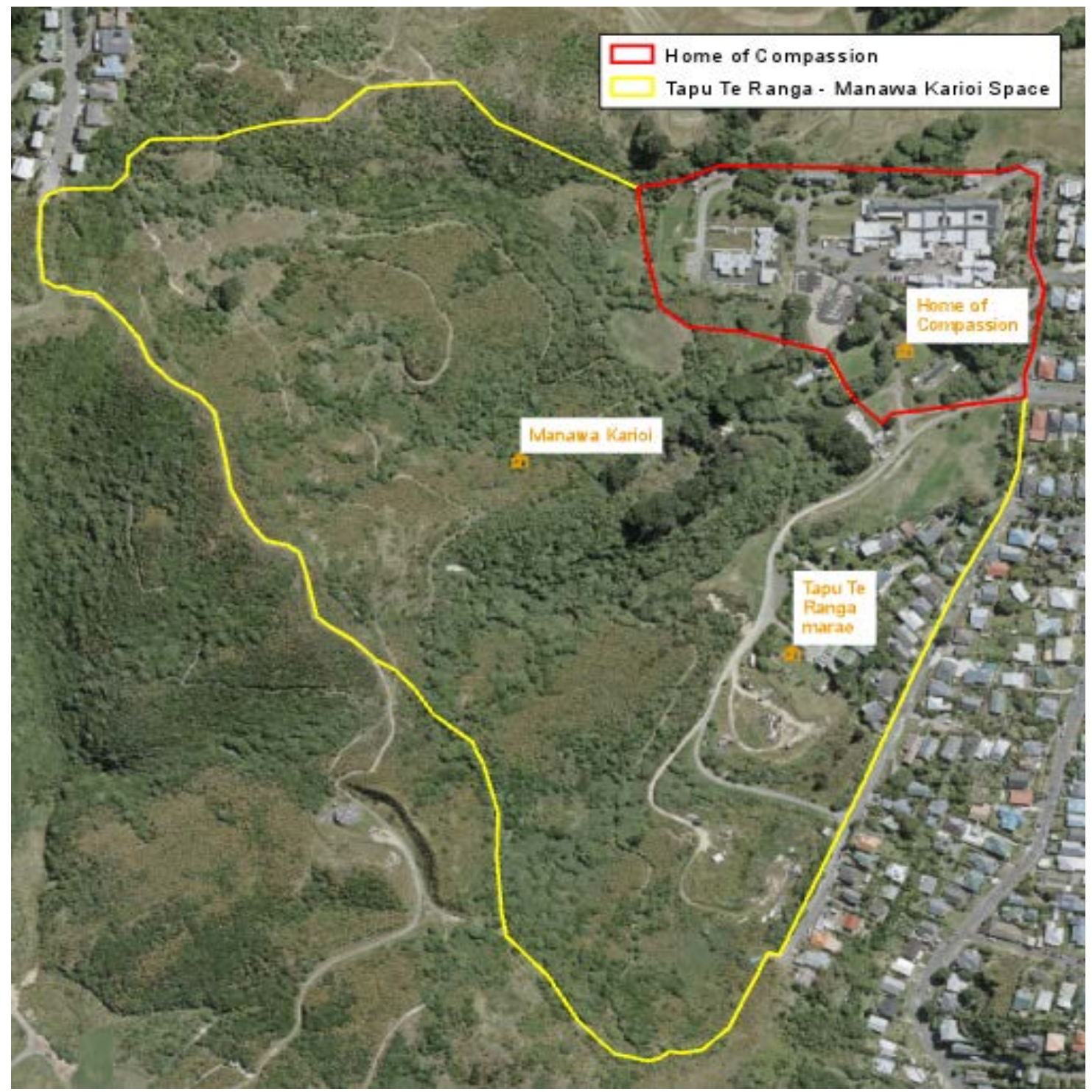

Figure 2: Arial view outlining the Tapu Te Ranga marae, Manawa Karioi and the Home of Compassion

This research was qualitative; I interviewed participants from both the Tapu Te Ranga marae and the Manawa Karioi Society. I will present an overview of how their relationship has been constructed within the space of the marae through communitybased conservation. With participants' insight, I hope to analyse how the maraeManawa Karioi space has been developed to form a sense of place.

The Manawa Karioi space is a part of the marae, where community volunteers from the society work to ecologically restore the hillside by the marae. This is done through the planting of eco-sourced native trees. Community perspectives of both the Manawa Karioi Society and the Tapu Te Ranga marae will highlight the nature of the relationship, as will the important events that have taken place to allow them to exist in the way they do today. However, this cannot be achieved without also 
understanding how community-based conservation might open greater opportunities for communities to engage with each other in collaborative decision making. As such, the following research question is addressed:

\section{What kinds of relationships form around community-based conservation on Māori land?}

For the Manawa Karioi Society, conservation occurs on land belonging solely to the Tapu Te Ranga marae. This means that a Western society actively volunteers their time to undertake conservation on Indigenous land. This is something which is rarely seen in Aotearoa New Zealand. This research question not only explores ways which communities and local Māori might work together, but also the key aspects that go into maintaining an effective cross-cultural relationship.

The cross-cultural relationship between Tapu Te Ranga marae and the Manawa Karioi Society allows for decolonising practices to occur. Decolonisation as described by Smith (1999) is an ongoing process where colonial power is divested back to Indigenous peoples through bureaucratic, cultural, linguistic and psychosocial means. At the Tapu Te Ranga marae, this is achieved in the way the Manawa Karioi Society recognises that they conduct their work on Māori land, and shows respect and gratitude. In the same light, the marae whānau demonstrates a strong appreciation for the work that the Manawa Karioi Society do. However, as relationships are fluid, the Tapu Te Ranga - Manawa Karioi relationship has changed over time. The relationship has been contingent on those who partake in it. For the Manawa Karioi Society and their volunteers, the effectiveness for building the relationship on their side has been based on the time they can give, and the ability to engage with the marae whānau. This is discussed as a sub-theme to emerge from this research, along with the wider community relationships which involve the marae space, and the wider community benefits of conservation at a local marae.

As the Tapu Te Ranga marae and the Manawa Karioi Society also act as a community driven initiative, this research will also explore the following sub-question:

How are these relationships for community-based conservation contributing to a decolonising understanding of nature? 
The findings from these research questions will be presented and used to discuss how community-based conservation promotes diverse understandings of nature and conservation. Additionally, I will explore how the decolonising practices go some way towards shifting power and resources away from Pākehā and Pākehā norms, towards Indigenous people, worldviews and institutions. Collectively, these two aspects highlight how the cross-cultural values applied at Manawa Karioi alter the conventional norms and constructs surrounding nature. This is illustrated in the wider community groups who engage with the marae and the Manawa Karioi Society, as well as the community benefits achieved through conservation in the marae space.

The relationships which exist within the marae space are complex, and it's important to be clear about the terms used in this thesis to refer to the various spaces and groups involved. Despite the land not belonging to the Manawa Karioi Society, the physical space in which community-based conservation takes place is named Manawa Karioi. Referring to the physical space as Manawa Karioi does not imply that the Manawa Karioi Society have land tenure rights to the space, rather that the society shares the name of the conservation space. In referring to the relationship between the two groups, I will refer to this as the Tapu Te Ranga - Manawa Karioi relationship.

\subsection{Thesis outline}

This introduction chapter has introduced themes of conservation, co-management and how communities can play a significant role in the way natural resources are managed. It has also illustrated why community-based conservation and crosscultural relationships are important. The research questions will guide the direction of this thesis. The following chapter is the literature review, which will explore research related to cross-cultural relationships and community-based conservation. In it I will suggest where gaps in the literature may lie.

Chapter three, the methodology chapter, will provide detail about how this research was applied. This research was conducted in a qualitative manner, where data used were based on the experiences and perspectives of those involved at the Tapu Te Ranga marae and Manawa Karioi Society. Poststructuralism and political ecology will be the conceptual frameworks which will guide analysis of this research. Poststructuralism will shed light on how understandings of nature come to be stabilised as common perspectives in society, and subsequently how those perspectives affect the management of natural resources (Castree, 2001). Political 
ecology will provide insights into how power relations play a role in such relationships, and hence also play a role in how nature is constructed (Bryant, 2001).

Chapter four is the findings chapter. This chapter will detail the main findings to come out of the semi-structured interviews with the participants involved. I will discuss how the findings respond to the research questions. The fifth chapter is the discussion chapter, which will present analysis of the findings, state why they are significant, and connect them to existing literature. It will show how the relationships the marae have with the neighbouring Sisters of Compassion and the Manawa Karioi Society have enabled diverse ways of viewing nature over time. Additionally, discussion will also focus on the cross-cultural relationship and the inputs which are required to maintain successful engagement with respective groups. Chapter six will conclude this thesis, and discuss how it may be applicable to other community organisations. This research aims to be applicable to contexts outside of conservation, with a view to adding value to local communities by acknowledging cultural diversity. 


\section{Chapter 2 - Literature Review}

\section{1 - Introduction}

Various forms of conservation exist which aim to conserve the environment in different ways. Community-based conservation is one of these forms. The literature surrounding community-based conservation states that it has emerged as a social movement in both the Global North and South, as a response to larger state and institutionally lead conservation (Berkes, 2004). For this thesis, the Global North and South refer to nation-states which are considered developed (North) and those that are still in phases of development (South). This distinction will be important to provide context where nation-states of the Global South who have historically been colonised by countries of the Global North have often faced large struggles for geopolitical, economic and environmental development. The literature covered in this review will address different aspects of cross-cultural relationships for collaborative conservation. An additional focus will be the literature on the relationships that enable, and are enabled by conservation.

Igoe and Brockington (2007) state that institutions such as state governments, nongovernmental organisations (NGOs) and Trans-National Corporations (TNCs) have produced neoliberal policies when dealing with conservation or the environment. These policies often undermine broader social and economic policies for communities and their environments. Corbeil (2015) defines institutions for conservation as government and NGOs who ensure the protection and preservation of natural and national heritage. Agrawal and Gibson (1999) have also written on communities and natural resource management, and identify market and economic forces as prominent obstacles to community-based conservation. Today, large conservation institutions are in positions of influence on key decisions that impact capital and economic markets, while also effecting social, economic and environmental aspects of communities (Corbeil, 2015). As community-based conservation has emerged as a movement, critiques of many forms of institutionally led conservation have become more prominent.

Poststructural and political ecology perspectives have contributed substantially to such critiques of conservation. Poststructural and political ecology perspectives highlight how perceptions of nature are formed, and how power relations between actors shape relationships with nature (Braun \& Castree, 2005). Aotearoa New Zealand's colonial history has a significant role in shaping contemporary power 
relations in natural resource management. Colonial relations have also had significant impacts on Māori, particularly through violent dispossession of land and culture (B. Coombes, 2003). In this context, some literature on community-based conservation may offer a platform to address these power inequalities, and enable greater crosscultural management of natural resources and decision making.

This chapter will explore community-based conservation in relation to ideas of protected areas, the co-management of natural resources between nation-states and Indigenous and non-Indigenous communities. Literature covered will include a history of conservation in a global context, and in Aotearoa New Zealand. In particular, I will explore literature that analyses how knowledge, language and discourses play a role in conceptualisations of nature. Literature on how governments and institutions impact conservation will also be addressed. Additionally, this chapter will explore shifts in the way community based conservation is theorised. Finally, I will address literature which highlights key aspects to community-based conservation and reasons why communities are often more suited to making decisions for their own environments rather than the state, or state institutions. The first section of this literature review chapter will detail the diverse ways in which nature is constructed.

\section{2 - Understandings of Nature - Nature as a Social Construction}

Many scholars have queried the ways in which the concept of 'nature' is perceived and what it means for society. Braun and Wainwright (2001) explore how nature has evolved through history. There are many different ways of understanding nature, and these are often underpinned by different cultures and worldviews (Demeritt, 2002). Nature therefore has different values for different societies or communities (Castree, 2003). Such values and views are associated with diverse epistemologies.

Within a poststructural approach to conservation, nature is always something which is constructed: "It is something made - materially and semiotically, and both simultaneously" (Braun \& Castree, 2005, p. 4). A poststructural approach asks: how do certain understandings of nature stabilise at different times to become widely accepted knowledge? What are the consequences of such processes (Braun \& Castree, 2005)? These questions interrogate how notions of nature become stabilised through sets of discursive structures and practises. Discursive structures are what shape our experiences and perspectives. These come in the form of language, 
knowledge and discourses, and shape social and environmental outcomes (Braun \& Castree, 2005).

A poststructural approach also enables questions about how perceptions, or understandings, of nature become enveloped into spheres of political, economic, cultural and social debates (Castree, 2001). This approach "is not to deny the materiality of the world" (Braun \& Wainwright, 2001, p. 45), but acknowledges the physical substance of the world does exist. However, realities based on this material world, and the meanings given to it, are constructed, leading to diverse realities for many. Braun and Wainwright (2001) go further to state that in this regard "there is no pre-discursive metalanguage for us to describe that 'reality"' (p.45). Michel Foucault, one of the significant contributors to poststructural thinking, describes how discursive practices stem from power, and in turn, argues that knowledge is controlled through power (Braun \& Wainwright, 2001). Foucault (1990), in History of Sexuality, describes how sets of discursive practises are often tied to the work of institutions such as prisons, schools, hospitals and governments. The ideas that Braun and Wainwright (2001), Braun and Castree (2005), and Foucault (1990) present on the links between discursive practices and the way people interact with nature is key in deconstructing the ways in which Western philosophical traditions have been formed around, and therefore interact with, nature.

Relational geography provides some of the fundamental elements for poststructural thinking. Themes of relationality are embedded within poststructuralism as 'space' and 'place' are related to each other (Murdoch, 2005). Relational geographies underpin poststructuralism through analysis of spatial and social processes (Murdoch, 2005). Massey (2005) maintains that the nature of space is a constant process, where interrelations occur within spaces and scales. If space is actively fluid, then it is relational geographies that seek to be informed by the relationships that flow within spaces to create relational concepts of place (Cresswell, 2012). Therefore, through space, place is formed by the politics of relationality, the flows of networks and connections, and thus relationships which occur (Hetherington, 1996). Place therefore holds identity which is also fluid, and is also often an indicator of broader environmental relationships and politics within space. How place becomes a stabilised object of space through diverse relationships with nature makes a significant contribution to how people identify with their natural environment which surrounds them. 
Nature is often the reflection of a person's environmental relationship, based on their cultural view of the world. For many developed countries, relationships with nature often stem from a Western cultural perspective, where discursive colonial practices have contributed greatly in forming common understandings of nature (Braun \& Castree, 2005). Western Society tends to perceive nature as a pristine, people-less, and an undisturbed environment (Cronon, 1996). What stems from this kind of environmental relationship is a view of nature as something that can be controlled. Holling and Meffe (1996), describe such relationships as a 'command and control' pathology of nature. This is based on an understanding of nature and society as separate entities. As natural resources have declined and populations continue to grow, environments have become viewed as entities that can be managed through top down institutions (Holling \& Meffe, 1996). Therefore, it can be said that Western relationships with nature are socially constructed epistemologies, formed by discourses which inform people's environmental values.

\subsubsection{Epistemologies of Nature}

Epistemologies play a key role in the way that nature is understood. Epistemologies shape the way in which our worldview perceives nature, and are therefore a key way in which discursive practises are produced (Sayer, 1979). Nature is often framed in scientific and technocratic forms that support constructed versions of Western epistemologies (Sayer, 1979). Such epistemologies influence the way in which public decision makers describe nature. Since technologies and science are dominant in capitalist societies, Western peoples tend to overlook their constructed view of nature (Bryant, 2001). Technology and science therefore not only have a tendency to provide an outlook in society that capitalist market forces will overcome prominent environmental issues, but also that natural resources should be utilised for production and capital gain (Sayer, 1979). In doing so, technocratic policy and decision making are most often informed through an emphasis of Western knowledge.

Braun (2002) emphasises how certain knowledges are privileged in the case study of the intemperate rainforests in British Columbia, Canada. Intemperate rainforests in British Columbia hold value for many different peoples. For the nation state of Canada, privileged knowledge has been exemplified in the way decision makers allocated large blocks for industrial forestry which in turn provide capital and economic gain (Braun, 2002). For the Indigenous peoples of the British Colombia region, the use of Western science and technocracy has overshadowed their values and beliefs 
surrounding the intemperate rainforests. Stevenson (2004) supports the idea that epistemologies play a large role in privileging knowledges by stating that "management structures are processes entrenched in the institutional and epistemological values, assumptions and structures of Canadian and European cultural traditions" (p.2). Therefore, Western knowledge has become privileged through the institutionalisation of environmental decision making.

Traditional knowledge for Indigenous peoples has become located on the periphery of what is considered valid for state institutions. This is due to discourses and perceptions of the West which frame Indigenous knowledge as being limited in what it can offer to natural resource management. The effects of dominant epistemologies within state and global Western institutions for environmental decision making is that dominant discourses are formed within society. Nadasdy (1999) asserts how dominant Western discourses for the Ruby Range sheep steering committee in the Yukon, Canada, played a large role in the knowledge which was utilised for comanagement between the Kluane First Nations people of the committee and the Yukon Territorial Government. Traditional ecological knowledge was overlooked in this instance. Instead, scientists and the people who represent the Yukon Territorial Government privileged dominant Western ideas for managing the Dall sheep on the Ruby Range (Nadasdy. P, 1999). Although this example is based in Canada, Aotearoa New Zealand has similar examples of natural resource management where Māori knowledge is often left on the discursive outside. The way in which understandings of nature are held in Aotearoa New Zealand will be further explored in the case study for this research.

As traditional epistemologies and knowledge are placed further on the margins of what Western decision makers consider valid, co-management relationships become imbalanced. Nadasdy (1999) describes the power relations which are entangled within the co-management relationship between the Klaune First Nations people and the Yukon Territorial Government:

[A]ll knowledge - including science - embedded in a larger social process which give it meaning. Indeed, some have contested even the assumption that science is an epistemologically distinct system of knowledge, preferring instead to see legitimatization of scientific artefacts (theories, data and instruments) as a result of active social manipulation, rather than some elite epistemological status they happen to possess (p. 11). 
Discourses of knowledge trickle down through societal structures to inform conventional social norms. Western forms of knowledge become legitimised through social norms and discourses and are privileged over traditional knowledge (Sayer, 1979). However, there is a shift away from integrating traditional knowledge to acknowledging and sharing epistemologies and knowledge in co-management relationships. Nadasdy (1999) critiques the Ruby Range Sheep Steering committee for the integration knowledge which is hand-picked to suit the committee's Westerncentric agenda. Therefore, knowledge which is utilised in co-management relationships must be underpinned by shared epistemologies, to foster equal power relations between Western and Indigenous communities.

Poststructuralism and political ecology seek to understand what is missing in constructions of nature. In the following section, I discuss themes from Aotearoa New Zealand's colonial history, and how dominant ideas of environmental management and conservation have developed over time.

\section{3 - Cross-cultural Relationships and Environmental Management}

Over the past decades, environmental management literature has increasingly focussed on cross-cultural relationships and their importance in conservation efforts (Spaeder \& Feit, 2005). Berkes (2009) states that the way forward for Western and Indigenous cultures is collaborative decision making with regard to environmental resource management. Tipa and Welch (2006) state that environmental resource management is gaining in volume as a critique of colonialism, particularly its legacies and persistence. Many areas of environmental management now focus on remedying the detrimental effects of colonial histories in many diverse forms (Nash, 2002). Conservation has become a prominent area of debate within environmental resource management, in regard to protected areas which exclude Indigenous peoples from their land (Brockington, Duffy, \& Igoe, 2012).

To begin this section, I briefly outline a history of Aotearoa New Zealand's environmental management and conservation story. I detail how colonialism in Aotearoa New Zealand has influenced many areas of environmental management. Therefore, interactions with resources and conservation are often implemented through Western understandings of knowledge. Because of this, Māori have been 
greatly disadvantaged. Not only have Māori had to regain rights to environmental land management through Te Tiriti o Waitangi (Treaty of Waitangi), conservation has often been underpinned by Western knowledges and values (Ruru, 2008). The remainder of the chapter will look to detail some key inputs for building effective cross-cultural relationships for environmental management, and will provide Aotearoa New Zealand-based examples of cross-cultural relationships becoming more widely accepted.

\subsection{1 - History of Conservation in New Zealand; Colonial Environmental}

\section{Knowledges \& Environmental Degradation}

Aotearoa New Zealand has a unique history of environmental land management that has influenced the way society perceives and interacts with the environment today. During the colonial settlement period of the eighteenth and early nineteenth century, vast amounts of land were taken from Māori, the Indigenous people of Aotearoa New Zealand (Brooking \& Pawson, 2010). As colonial settlers and the Crown took more control over the environment, Westernised 'command and control' perspectives began to dominate. Command and control methods are described by Holling and Meffe (1996) as "resource management efforts to reduce natural bounds of variation in ecological systems to make them more predictable, and more reliable for human needs" (P.329). Consequently, conservation that arose during the colonial-settler period of Aotearoa New Zealand's history is an important context for many of the environmental issues that are identified in conservation today, both at a community level and national governance level.

Wynn (1979), describes the first British settler societies of Aotearoa New Zealand as a pioneer society and states that "[c]haracteristically, pioneers have an exploitive attitude towards nature" (p.171). Consequently, ideas of settler land management included examples of environmental impacts of seal and whale hunting, the cutting down of native forests including Kauri and other significant Aotearoa New Zealand tree species, and the draining of wetlands. Many instances of forest clearing, and the draining of wetlands were to make way for agriculture and farming purposes (Wynn, 1979). Environmental land use practises and ideas of nature have evolved since the settler period. However, Westernised ideas of the environment are still very prominent, and set a context to how conventional nature is viewed in today's society. 
The long-term effects of settler environmental impacts in Aotearoa New Zealand have led to extremely fragile environmental ecosystems. British settlers and the Crown also realised the extent of land degradation that was occurring in Aotearoa New Zealand and responded to a global protectionist trend in conservation in the late $19^{\text {th }}$ century (Brooking \& Pawson, 2010). In Aotearoa New Zealand, fortress conservation was introduced by means of conserving areas of natural and national significance. National parks are the primary example of illustrating such areas of significance (Blue \& Blunden, 2010). Aotearoa New Zealand's first protected area, Tongariro National Park, was established in 1894 (Brooking \& Pawson, 2010). This protectionist movement, enforced through 'fortress conservation' by way of protected areas, became a standard practice for governments in order to conserve areas of natural and national significance (Brockington et al., 2012). The next section will describe fortress conservation and protected areas. Explanation will be given to how Aotearoa New Zealand has implemented protected areas by way of national parks and therefore the consequences for Māori.

\subsection{2 - Fortress Conservation and Protected Areas}

Brockington et al. (2012) describe protected areas through fortress conservation as a way to conserve the wilderness from human interference. This view of conservation stems from a romanticised perspective of nature and the environment where "advocates insist that wilderness heals society and people; that we need these places to provide the counterpoint to the destruction and management of the rest of our lives" (Brockington et al., 2012, p. 48). Conservation movements in the United States, Aotearoa New Zealand and Australia are all underpinned by such thinking of the wilderness (Brockington et al., 2012). However, fortress conservation can also be described as the idea of exclusion, expulsion and external control to parks which serve to protect many diverse aspects of flora and fauna (Hartter \& Goldman, 2011). With the exclusion of people from the wilderness through fortress conservation, many local communities around the world have been displaced. Moreover, protected areas have reinforced the idea of state management for conservation, which in turn has further increased the marginalisation of displaced communities from natural resource management (Heatherington, 2012). The introduction of protected areas in Aotearoa New Zealand supported Western understandings of nature and conservation (Blue \& Blunden, 2010). National parks have operated as a way to preserve what is considered natural and nationally significant landscapes by the Aotearoa New 
Zealand Government, as well as driving tourism, and marketing Aotearoa New Zealand as 'pure' and 'pristine' (Blue \& Blunden, 2010).

It is often Indigenous communities who experience displacement from protected areas. Māori have endured this exact kind of forced migration. Areas of displacement for Māori have traditionally been utilised for cultural practices (Blue \& Blunden, 2010). Protected areas have been utilised globally by Western countries to allow for state control of resource management and conservation (Brockington, Igoe, \& SchmidtSoltau, 2006). Heatherington (2012) states that "[t]he displacement of residents from homelands designated as parks has often increased poverty and marginality, escalating social tensions and resource conflicts" (p. 166). In Aotearoa New Zealand many Māori have had to fight for recognition, for land that was taken from them and for their culture that has been marginalised as a result of colonialism (Blue \& Blunden, 2010). Today, in Aotearoa New Zealand, social tensions and conflicts still exist. Te Tiriti o Waitangi (the Treaty of Waitangi) between Māori and the Crown has meant that Māori are able to self-govern aspects of resource management and conservation (Blue \& Blunden, 2010). However, many Māori Iwi (tribes) continue to fight an ongoing struggle for complete self-determination in administering natural resource management.

Today, Indigenous peoples in colonised states continue to experience inequality as a result of dispossession. Environmental resource management and conservation are often understood through the lens of the colonisers, and therefore Western knowledge is a dominant form of knowing in such societies (Craig, Moller, Saunders, \& Williams, 2013). Aotearoa New Zealand is an example of where Indigenous people have been displaced and continue to fight for self-determination. Aotearoa New Zealand is therefore a small reflection of the larger global picture of nature's significant link with histories of environmental development through colonial regimes (Blue \& Blunden, 2010). In the next section I will detail how co-management for environmental resource management has emerged, contesting some of these colonial dynamics.

\subsection{3 - Co-management, Cross-cultural Relationships and}

\section{Environmental Management}

Recent literature by Berkes and Ross (2013) emphasise cross-cultural comanagement as best practice for natural resource management and conservation. Carlsson and Berkes (2005) describe cross-cultural relationships as collaborative 
decision-making and the sharing of responsibility and resources between governments and local resource users. Co-management is further described as a governance system which combines state control with local decision making (S. G. Singleton, 1998). Although there are various forms of co-management, decentralisation is a key theme as local users share responsibilities for decision making with state governments. In order for this to occur, governments must devolve power to local resource users (Carlsson \& Berkes, 2005). Decentralisation is a factor for any co-management partnership, as governments allow agency for local communities to not only express their own needs and desires, but have equal power in decision making (Carlsson \& Berkes, 2005). Self-determination for Indigenous communities is achieved through decentralised methods in cross-cultural, comanagement relationships, and therefore provides equal power relations for decision making around natural resource management and conservation.

As co-management for conservation and natural resource management has grown more prevalent, discourses have also emerged concerning idealistic and disenchanted notions of conservation from local communities who are or have been involved in co-management relationships (Agrawal \& Gibson, 1999). Poor conservation and natural resource management outcomes have prompted decisionmakers to reconsider the way in which such co-managed relationships operate (Agrawal \& Gibson, 1999). Debates in literature on co-management are based around how well decentralisation actually occurs, and how much autonomy local resource users have within a co-managed relationship. Subjects of these debates include: how governments acknowledge environmental factors, political regimes, cultural traditions and power which generates and shapes such relationships (Spaeder \& Feit, 2005). Traditional state structures of co-managed relationships are seen as barriers for effective collaboration. The structures which formulate roles and responsibilities for co-management relationships must reflect the diverse cultural values involved, and acknowledge historical and political situations (Natcher, Davis, \& Hickey, 2005). Nadasdy (1999) states that issues around the integration of knowledge are problematic under formal co-management structures. An example of this is that knowledge supporting Western science and technocratic decision making is often privileged over the knowledge of other cultures and alternative ways of viewing the world (Nadasdy, 1999).

Despite discourses that both advocate for and critique cross-cultural and comanagement relationships, co-management is regarded as a progressive way of 
providing equality and equity to communities who have been previously been placed on the margins of environmental governance (Natcher et al., 2005). Academic analysis of co-management relationships suggests that state governments and institutions succeed or fail to recognise historical occurrences, local or common property rights, and providing equity in relations of power between local communities and state institutions (Spaeder \& Feit, 2005). Governments or state institutions who fail to recognise such considerations with Indigenous communities create possibilities of unequal power relations within relationships (Natcher et al., 2005). Self-determining qualities are based around autonomy for Indigenous communities in cross-cultural, co-management relationships and is therefore underpinned by equal power.

Power relations which exist in such cross-cultural relationships, however, also have the ability to produce further inequalities for Indigenous communities. Commentators in this field can often have an idealised view of co-management. However, although theoretical notions of co-management describe equity and empowerment, reality shows that power relations between major stakeholders may play out otherwise (Natcher et al., 2005).

Indigenous scholarship has detailed themes of decolonisation, seeking reparation from historical grievances and claims of rights to environmental management. These themes mentioned have played a large role in inspiring cross-cultural relationships (B. Coombes et al., 2012). Cross-cultural relationships are most often between the state, state institutions and Indigenous communities. Yet B. Coombes (2007) states that many Indigenous scholars are critical of ambivalent attitudes from many colonial governments, where Indigenous relationships still often see an imbalance of power relations. Indigenous struggles for self-determination still remain, however, crosscultural relationships are ways in which Indigenous peoples can increase their power and self-determination in land management. Collaboration in this form with Indigenous peoples is becoming widespread (B. Coombes et al., 2012). The following section will examine literature which deals with the themes of cross-cultural relationships for environmental land management, while outlining some the challenges, but also successful inputs for equitable relationships.

\subsubsection{1 - Power Relations within cross-cultural, co-management relationships}

Relations of power are often one of the most important factors to consider for building effective cross-cultural relationships. Natcher et al. (2005), state that co-management is more about managing relationships, rather that managing natural resources. Such 
statements are based on large amounts of research which champion cross-cultural, and co-management relationships with Indigenous communities and Western states (Colchester, 2004). As many co-management relationships exist between nationstates and Indigenous peoples, relationships often exist as formal co-management agreements (Carlsson \& Berkes, 2005). While formal co-management agreements are seen as a means for Indigenous peoples to enhance their power over land management, it does not mean that governments are often willing to give up sovereignty over land management. Thus, collaborative power sharing of land may not lead to equitable outcomes but strengthen state control over resource decision making, policy, management and allocation (Castro \& Nielsen, 2001).

Carlsson and Berkes (2005) assert that in environmental and conservation resource management, regardless of the scale in which the relationship exists, the sharing of power depends on both groups' willingness to recognise possible cultural barriers and to build strong, long-lasting partnerships. Cultural barriers include what epistemologies and knowledge are considered valid between the two groups, value differences over natural resources, and power differences (Nadasdy, 2005). Where power often becomes unequal within cross-cultural relationships, is where state governments have been intent on retaining final approval for co-management decisions which take place (Brockington et al., 2012). Often, this means that power and overall authority resides with state officials, who make political decisions which may not reflect the interests of Indigenous stakeholders involved (Stevenson, 2006).

Governments and state institutions who demonstrate ambivalence towards obligations to Indigenous partners have been greatly criticised by those Indigenous communities involved. B. Coombes (2007) expresses concerns towards stateIndigenous relationships, as governments have often been seen to ignore demands for equity of power. Stevenson (2006) states an Australian example:

[b]oth Aboriginal and non-Aboriginal parties to co-management must critically examine current management policies and practices in order to develop innovative approaches that will create the space required for the meaningful and equitable inclusion of Aboriginal peoples in decisions taken in respect to their lands and resources (p.167).

A re-evaluation of cross cultural relationships has found that increased community agency in co-management reduces state involvement, and allows for interactions 
between other stakeholders and actors across multiple scales (Carter \& Hill, 2007). Co-management is therefore a way in which power is redistributed to communities who are involved with natural resource management creating social and environmental equity (Stevenson, 2006). Complex power relations within crosscultural, co-management relationships are not the only important considerations for parties involved. The following section will address conceptions of scale, scope and representation and the role they serve for effective cross-cultural relationship building.

\subsubsection{2 - Scale, Scope, \& Representation of Cross-Cultural Relationships}

Scale, scope and representation are significant factors in shaping collaborative processes (Armitage et al., 2009). Scale refers to the level at which a co-management relationship exists; local, national or international (Adger, Brown, \& Tompkins, 2005). Scope is the extent of a co-management project and representation is the different stakeholders who are involved (Armitage et al., 2009). Governments are often considered large scale, however, the scale at which they engage in collaborative relationships can be at a range of levels (Adger et al., 2005).

The politics of scale are important to recognise for co-management relationships. Adger et al. (2005) assert that cross-scale interactions are "determined by both the power relations inherent within them and the transaction costs associated with them" (p. 4). Armitage et al. (2009), refer to collaborative relationships which build trust through "collaboration, institutional development, and social learning" as adaptive comanagement (p. 95). Adaptive co-management looks to address considerations of power through an awareness of scale and through the interactions between stakeholders (Armitage et al., 2009). However, Carter and Hill (2007) express that relations of power between cross-cultural partners might have less potential for equality. Natcher et al. (2005) argue that local scale, cross-cultural partnerships hold more potential to deal with contemporary resource management issues than relationships between governments and larger homogenous community groups. For this reason, local scale relationships with larger scale stakeholders are often favoured by communities, as such interactions have more potential for them to gain tangible benefits (Natcher et al., 2005). The politics of scale hold significant outcomes for local stakeholders in co-management agreements and therefore must be considered when shaping collaborative processes.

Communities and how they participate in cross-cultural relationships have the ability to better provide local knowledge to environmental decision making (Natcher et al., 
2005). For example Carter and Hill (2007) assert that "[c]ommunity groups and public agencies establish dialogue exchanges rather than competition and mistrust; when agencies value and support community and when community understands agency objectives and systematic change process" (p.44). Local scale cross-cultural relationships allow for all worldviews to be recognised, rather than adhering to formal structures of the state which often do not align with cultural values and interests of Indigenous communities (Berkes, 2002). It is in this way that the scope and scale of cross-cultural relationships affect how parties contend with the complexities of resource management and promote the knowledge and interests which all stakeholders may bring to light (Natcher et al., 2005).

Representation of communities is integral for community interests to be properly communicated, and therefore appropriately acknowledged. Formalised state structures are often based around particular management plans or projects (Adger et al., 2005). However, cultural concerns for Indigenous peoples often extend much wider, and over longer temporal periods (Wyatt, 2008). Because of a separation of scale between stakeholders', governments often misconceive communities as being homogenous entitles. This is known as the politics of scale (Armitage et al., 2009). Armitage et al. (2009) suggest that building effective cross-cultural relationships involves cultural awareness between stakeholders. The way diverse knowledge is represented is important to recognise and consider in balancing power relations.

\subsubsection{3 - Cultural awareness in conservation co-management}

Carter and Hill (2007) argue that language and knowledge within cross-cultural relationships are essential to building effective partnerships. Western knowledge and language can often dominate this sphere (Escobar, 1998). The way in which scientific language, and technocracy is utilised when engaging with co-management partners must be considered by state and institution representatives (Carter \& Hill, 2007). Comanagement agreements should clearly state issues and potential outcomes in language which all stakeholders may understand. Furthermore, such agreements should also demonstrate an understanding of Indigenous viewpoints and concerns (Carter \& Hill, 2007). Where Indigenous communities must withdraw their own cultural understandings, concerns and interests, their self-determination and agency in collaborative environmental decision making is impeded.

Indigenous ecological knowledge and values for environmental management are equally important as Western ones for holistic understanding of the environment for 
ecologists (Berkes, 2009). Indigenous relationships with environments often span long temporal periods, where close contact has led to holistic understandings of the interrelated ecologies of flora and fauna (Menzies, 2006). Western imperialism, global forces of economic development and climate change have often forced Indigenous ecological knowledge to the periphery of accepted wisdom (Gadgil, Berkes, \& Folke, 1993). This has been mentioned in section 2.2.1 of this chapter, however, what was not addressed are areas where colonial or neo-colonial influence is still prevalent in society, which must be confronted so that Indigenous knowledges are no longer marginalised (B. Coombes et al., 2012). Co-management relationships are areas where colonial traits can be eliminated through redistributions of power.

Such views of science and language in co-management relationships have become contentious among many Indigenous communities (Nadasdy, 2005). Sallenave (1994), identifies three areas where the linking of knowledges can present obstacles for collaborative cross-cultural resource management. These are: societal perceptual barriers, where cultural and colonial historical structures hold different values; scientific scepticism, where scientific methodologies differ to Indigenous ecological knowledge through notions of 'hard data'; and political barriers where relations of power are imbalanced and therefore policy and decision makers are less likely to take into account Indigenous environmental values (Sallenave, 1994). As a result, such barriers to linking Indigenous knowledge with science are predominantly held around the notion that scientific knowledge is the 'only' measure, as it strives for universal truth determined through positivists logic (Sallenave, 1994). Nadasdy (1999) states that through the compartmentalisation of scientific knowledge, a reductionist process is created. Nadasdy (1999) further states "[t]his compartmentalization has profound effects on how people can think about knowledge and the ways it can be used" (p. 5). 'Deficit theorising' is a concept which describes how public understandings of science and knowledge are considered objectively true, and leads to understandings of alternative knowledge being rejected (Irwin \& Michael, 2003). Such compartmentalising of Indigenous knowledge falls within the definition deficit theorising, and therefore must be critiqued accordingly.

Nadasdy (1999) asserts there are risks in regard to knowledge sharing. Berkes (2009) and Nadasdy (1999) express concerns surrounding cultural appropriations and a misuse of culture. However, there are also a number of additional strategies explored in literature for overcoming barriers, such as educational strategies, academic program reform, and Indigenous autonomy within them. Many of the ideas here are 
still contested and debated. However, a common theme is that cross-cultural relationships for environmental resource management and conservation are positive steps going forward (Berkes, 2009). Not only is it positive for biodiversity and ecologies, but also for addressing many issues surrounding social, economic and political spheres of development (Berkes, 2009).

So far in this chapter, I have shown how the literature has covered aspects of how society perceives nature through diverse epistemologies. I have also detailed how comanagement relationships are avenues for collaborative natural resource management. In the following section, I will define the concept of community-based conservation. I will describe why community-based conservation, as a social movement, allows communities to be self-determining in regard to resource management. I will also detail some of the fundamental inputs for constructing effective cross-cultural relationships.

\section{4 - Community-Based Conservation}

Co-management has emerged out of a broader push towards community led conservation. In the Global North, communities partaking and becoming more involved in conservation began as grass-roots movements in the 1980s (Little, 1994). Many Indigenous communities in the Global South, however, have always engaged in their own local environments (Agrawal \& Bauer, 2005). Many who conduct research in these areas state that communities have the potential to act as a panacea to many biodiversity and ecological issues which concern conservation (Berkes, 2007). Natcher et al. (2005), also go further to assert that community-based conservation has the potential to champion co-management relationships too. Considerations for co-management relationships are in areas of decentralised conservation governance, creating more meaningful participation within communities, and opening space for community and cultural self-determination (Agrawal \& Gibson, 2001). Communities are complex entities constructed from diverse structures: political and economic powers, race, gender, culture and social dynamics (Agrawal \& Gibson, 2001). Thus it is difficult to assign a single definition to communities without taking into account such factors.

Community-based conservation is therefore also a problematic term to define. At one end of the spectrum, it is about the protection of parks and reserves. Such protection 
efforts often-are in developing countries, where Indigenous populations look to gain more autonomy over areas they have been removed from (Western, 1994). On the other end of the spectrum, community-based conservation is managing natural resources, biodiversity and ecologies (Berkes, 2009). This is exemplified in developed countries where environmentally minded communities look to undertake conservation. In its broadest sense, community-based conservation may be defined as conservation where the benefits go back into communities who contribute to them (Otto et al., 2013). In the following section I will detail how community-based conservation exists both in the Global North and the Global South, and is influenced through different political, economic and social forces (Berkes, 2004).

\subsection{1 - Background to Community-based Conservation}

The appropriate balance between community and state led governance of natural resource management is a continual question raised in academia and politics (S. Singleton, 2000). Advocacy for community-based conservation often takes the form of contesting state resource and environmental management, as well as privatised corporate or institutionalised management (Agrawal \& Gibson, 2001). In continuing to describe community-based conservation, I will state how community aspirations are also often linked to community interests. Some of these include volunteers and other participants, community relationships which also contribute to conservation and wider cross-cultural and social benefits which may be achieved (Agrawal \& Gibson, 2001). In describing such community aspirations in relation to conservation, I give a nuanced view of community-based conservation as a set of institutions and practices which are complex and exist differently based on diverse community inputs.

Often neoliberal policies influence and promote environmental management for state and corporate institutions. Proponents of community-based conservation advocate for decentralised autonomy for communities, away from neoliberal interventions (Agrawal \& Gibson, 2001). Berkes (2007) states that although that there has been an emergence in community-based conservation, debate continues over what is the best form of managing resources and conservation. "The question of whether communitybased commons management can lead to conservation and whether conservation can be entrusted to communities is hotly debated" (Berkes, 2007, p. 15189). Community-based conservation has emerged as a reaction to discourses which promote centralised state resource management. Environmental management which advocates for institutional power in conservation are often opponents to community- 
based conservation (Agrawal \& Gibson, 1999). The theory of the 'Tragedy of the commons' was described by Hardin (1968) as over-exploitation and environmental degradation of common pool natural resources. Centralised state management is argued to be one form of regulating common pool resources to prevent externalities which occur due to over-exploitation.

The tragedy of the commons has become an economic and scientific doctrine for resource economists and those interested in fair and equal distribution of natural resources. One of Hardin's final suggestions to avoid such tragedy is for the commons to be either privatised or kept in the public domain with government regulation (Hardin, 1968). Today, research applies the tragedy of the commons, more generally regarded as 'common property theory', for institutional economics in relation to natural resources. Research in these areas looks at how common property resources hold two solutions: the commons controlled by private social enterprise, or state control (Feeny, Berkes, McCay, \& Acheson, 1990). Challenges brought about by private or state led governance of common property resources are twofold. Firstly, such governance, particularly by the private sector, has the potential for exclusion of other users. Secondly, there is the issue of managing resources as they become more depleted (Feeny et al., 1990). It is the former challenge of privatisation or state led governance over common property that has been a central critique to many who advocate for community-based conservation.

Community-based conservation seeks to engage community participation for management of the commons. Critiques of commons management today is often centred around the commodification of nature through resource environmental management (Büscher, Sullivan, Neves, Igoe, \& Brockington, 2012), Büscher et al. (2012) assert that "literatures explore ways in which the natural realms are transformed through and for capital accumulation" (p.4). They also go further to state that neoliberal views of nature may be defined as "the politics of transforming and governing nature under neoliberalism" (p.4). Neoliberalism is an ideology and development model which has seen a large transformation since its global inception in the 1980s (Castree, 2006). Today, neoliberal policy allows for governments to work with large institutions to drive economic and capital gain from natural resource management. The ascendency of neoliberal development has seen a pushback in the form of social movements, as social inequalities have increased with less government regulation over natural resources (Büscher et al., 2012). The desire for communities 
to have more autonomy over their environments has been a major goal of these insurgences.

Community-based conservation as a social movement has focused its pushback against the new world economic order, by calling for a redistribution of wealth (Fletcher, 2010). Western (1994), states that "Community-based conservation reverses top-down, centre-driven conservation by focusing on the people who bear the costs of conservation" (p.7). For Indigenous communities, the agenda is to regain power over their environments and natural resources through asserting their own cultural practises, as well as improving their own economic well-being (Western, 1994). Devolution of power for centralised resource management allows for community interests to be met in this way.

Community-based conservation is not without its critiques. Many question the notion of devolving power to communities for natural resource management. They question the appropriateness of community management in which there is potential for even more environmental degradation (Agrawal \& Gibson, 2001). This is related to a more central argument of whether or not communities are able to resolve resource conflicts and slow environmental degradation (Western, 1994).

For the remainder of this section, I will outline some key inputs with regard to community-based conservation. These include: the links between local participation and improving conservation outcomes, the importance of partnerships and deliberative decision making, and lastly, the wider cross-cultural and social benefits achieved through community-based conservation.

\subsection{2 - Volunteers and Participants for Community-based Conservation} Participation and engagement by communities for community-based conservation is another form of producing decentralisation. Little (1993) states that "decentralisation of resource-management activities means devolution of authority from the centre to the periphery" (p. 363). For local communities, this often requires further participation for resource management as institutional policies limit the power of authority for such communities (Little, 1993). Policies and wider political institutions can play a large role in communities' ability to participate in community-based conservation. 
Placing a definition on the concept of participation is troublesome due to the variation in communities involved. Two themes are consistent in diverse definitions of participation however. Little (1993) identifies two main motivations consistent throughout all participation for community-based conservation: participation as a goal for communities allows for greater power in management and therefore, resources for their communities (Little, 1993). The second is participation as an objective to shape greater social and economic outcomes for communities (Little, 1993). The difference between the two motivations is that participation as a goal, looks to promote community participation as a means of building a sense of community to further community investment and therefore control over local resources (Little, 1993). Whereas participation as an objective, looks to utilise community participation for holistic outcomes relating to environmental, economic and social factors (Little, 1993). The two however are not mutually exclusive and it could be argued that second motivation for participation cannot occur without out the first (Little, 1993). The two motivations for participation highlight that the devolution of power is necessary for community-based conservation to occur effectively.

Much of the exploration around participation within community-based conservation stems from rural development literature. Working within this literature, Little (1993) writes that participation for community-based conservation requires "local level, voluntary, people-centred, participatory, decentralised, village-based management" (Little, 1993, p. 351). Definitions within the literature change based on diverse community objectives, and participatory involvement; from conservation as protecting or preserving resources, through to conservation as a balance of environmental management among social and economic improvements for communities (Little, 1993). Participation is one of the critical elements. It plays a large role in achieving decentralised management.

Brooks, Waylen, and Mulder (2013) argue that community-based conservation projects are more likely to succeed when there is a focus on community participation. This includes the whole spectrum from project initiation and establishment to the dayto-day running of conservation projects. Schroeder (2000) asserts that, through a shift towards more holistic thinking around environmental issues, there is an increasing acknowledgement that people, human values, behaviours and experiences must be taken into account for objectives in planning and management, not just meeting ecological targets. Oakley (1991) affirms this as different examples of communitybased conservation projects differ through contexts of culture, ethnicity, economic and 
social means to implement projects. Participation in community-based conservation, throughout the literature, is a critical element to successful management and ecological outcomes. The next section will detail community relationships as another critical input for community-based conservation, as many projects rely on horizontal linkages for support in resource management.

\subsection{3 - Community-relationships for Community-based Conservation}

Often communities who undertake Community-based conservation also rely on external inputs from outside partnerships. Time, funding and resources are limited for many communities and their projects. Partnerships with local organisations frequently provide extra assistance for such communities who rely on volunteer participation (Campbell \& Vainio-Mattila, 2003). Vermeulen and Sheil (2007) define partnerships by stating "[s]trong partnerships entail shared decision making, shared risks and balance of rights and responsibilities between external conservation agents and local interest groups" (р. 434). Time, funding and resources are often limited for communities and their projects. Although partnerships with local institutions are fluid due to the many diverse contexts and influences that exist within community-based conservation, the literature states that such additional relationships are required for resource management or conservation support (Brooks et al., 2013). Having said this, it does not explicitly state that relationships for community-based conservation directly lead to successful conservation initiatives. So far, the literature in this review has covered aspects of cross-cultural relationships for collaborative conservation. However, this section will look beyond cross-cultural aspects to identify the importance of communities partnering with other local organisations to develop the social, economic and environmental objectives they might have.

Many researchers say caution is required for partnerships with local organisations, as they have the potential to remove agency from community-groups (Castro \& Nielsen, 2001). Local community groups need to take care and assess "whether organizations are truly representative of local interests" (Little, 1993, p. 364). Where communities have opportunities to develop healthy relationships with local organisations, literature suggests that attempts should be made to take them. Relationships with local organisations may provide additional support for community-based conservation through social, economic and environmental equity. Such organizations may also contribute expertise in areas where community-based conservation groups lack certain skills (Otto et al., 2013). This could be in the areas of management, 
administration, ecological knowledge, or could even be the knowledge sharing of challenges and successes with other conservation groups.

\subsection{4 - Wider Cross-cultural and Social Benefits Achieved through}

\section{Community-based Conservation}

Linking community aspirations to conservation objectives may provide for wider beneficial community outcomes. As communities are heterogenous entities, community aspirations exist in diverse forms. These can be social or economic aspirations, or the desire to be self-determining; all are consistent within literature (Western, 1994). An Indigenous conservation ethic through cross-cultural relationships is a rising trend for biodiversity conservation and management. Such ethics have become romanticised as it is often assumed that they have more of an environmental focus (Kleymeyer, 1993). However, global social movements have also used traditional cultural knowledge to promote Indigenous rights and to raise awareness about environmental (and other) inequalities. Such practices remove predetermined, and often colonial or Western, perceptions of nature (Kleymeyer, 1993). This promotion of alternative ways of viewing the environment instils and stabilises Indigeneity within the spaces which communities are looking to conserve.

Another benefit of community-based conservation is that it instils a sense of vested ownership and a sense of belonging that have positive social effects: they increase participation (Grese, Kaplan, Ryan, \& Buxton, 2000), sociological issues are shown to be more easily overcome, and an agreed sense of identity, agreed goals and custodianship are also shown to be increased (Grese et al., 2000). Participation is also shown to provide significant psychological benefits for volunteers through recreations and stewardship (Grese et al., 2000). Participants say the value gained from community-based conservation comes from various factors: helping the environment, learning new skills, achieving a heightened sense of spirituality, the personal benefits of spending time in green spaces as well as meeting and socialising with other participants (Grese et al., 2000). Where dominant institutions such as governments or large entities devolve power to the communities, such benefits are available for communities to achieve (Berkes, 2004).

Berkes (2002) asserts that commons literature is full of examples where state intervention in community-based conservation projects has constrained local participation by communities. By contrast, examples of where governments support 
local institutions in collaborative relationships with communities have, through less stringent policy and regulation, seen projects progress successfully (Berkes, 2002). Community-based projects which are less bounded by centralised institutions find themselves less involved in a socio-economic political realm, and therefore are able to self-organise (Berkes, 2002). Community groups who are able to work towards their aspirations and conservation goals individually and collectively achieve greater ecological benefits.

\section{5 - Community-based Conservation in Aotearoa New Zealand - The}

\section{Gap in the Literature}

In Aotearoa New Zealand there are many different examples of communities taking ownership over their environments. As Aotearoa New Zealand is a developed country of the Global North, issues and struggles around conservation exist differently to those of other regions of the world. Aotearoa New Zealand is a colonial state derived from British settlement; the Māori people of Aotearoa New Zealand have had to contend with many of the typical issues which colonialism brings about. Although community-based conservation is now a dominant concept, there are specific gaps in the literature regarding cross-cultural relationships between Māori and Pākehā communities.

Co-management between Māori Iwi and the Aotearoa New Zealand Crown is a large part of the conservation state. In recent years, progressive policy around conservation of national parks or other resources has seen what was the Te Urewera National Park in the central North Island disestablished (B. L. Coombes \& Hill, 2005). Power for management has been negotiated between Ngāi Tūhoe, the Māori tribe of $\mathrm{Te}$ Urewera and the Department of Conservation. Furthermore, the Aotearoa New Zealand government legislated Te Urewera as its own legal entity, and granted the forest its own legal personhood status (Warren, 2016). Thus Te Urewera forest is not owned by any person or entity; it owns itself. The concept that the natural environment can have its own legal rights is a recent and progressive idea (Stone, 1972).

Literature on conservation and cross-cultural relationships in Aotearoa New Zealand exists mostly at a state-iwi level. Therefore, research which does address comanagement centres around Māori and their rights to conservation under the Tiriti o Waitangi (the Treaty of Waitangi). Taiepa et al. (1997) comment on previous forms of 
consultation management in Aotearoa New Zealand, stating "'consultation' or a 'meaningful advisory role' is no longer a sufficient surrogate for true co-management involving Māori and Pākehā because it does not meet the constitutional principles articulated by the Treaty of Waitangi" (p. 237). Taiepa et al. (1997) also go further to state some basic prerequisites of what co-management for conservation might look like in Aotearoa New Zealand. Many of these are covered in the themes in this chapter. These are: the devolution of power over resource management from central and local governments, the establishment of community power and rangatiratanga (Māori authority and governance), and that structures must reflect the mana (influence, prestige, power, authority and control) of each iwi under the Treaty (Taiepa et al., 1997). Co-management processes that operate in this way recognise Māori as kaitiaki (environmental caretakers) and have a vested interest in ensuring that mauri (life force) is maintained or enhanced (Craig et al., 2013). Co-management in this form looks to incorporate Māori principles and values into co-management relationships. It is also in this form that co-management looks to accommodate for two types of management, and for iwi to reflect their own local needs and customs to environmental management (Craig et al., 2013). Moller (1996) states that a change in how research, management and funding priorities for collaborative relationships will empower and accelerate Māori resource management. Furthermore, research focusing on co-management must be increased (Craig et al., 2013).

In an attempt to identify gaps in the literature surrounding community conservation in Aotearoa New Zealand, this research asks:

What kinds of relationships form around community-based conservation on Māori land?

Additional sub-questions for this research are:

- Do these relationships around community-based conservation contribute to a decolonising understanding of nature?

Using an ethnographic study of the Manawa Karioi Ecological Restoration project in Island Bay, Wellington, this thesis will explore the relationships which exist for community-based conservation. 


\section{6 - Summary}

Many of the themes of conservation and community self-determination presented in this literature review are contested and debated. As research continues to develop, such concepts and perceived best practices for conservation develop and evolve as well (Berkes, 2009). Community-based conservation has emerged out of a wider conservation movement that seeks for power and self-determination for communities. It has emerged out of a history of conventional land and resource management, which has influenced current ways in which society views nature (Otto et al., 2013). The way in which nature is constructed is dependent on diverse epistemologies. Epistemologies shape the way in which our worldview perceives nature. In the Global North, it is often Western discourses which stabilise knowledge, language and power in regard to nature (Escobar, 1996). Discursive structures play an important part in the way we understand nature and the environment, and therefore how we look to conserve it.

Cross-cultural relationships for community-based conservation have the ability to empower local communities, on the proviso that centralised institutions devolve power in decision making to them. Self-determination is a large factor for Indigenous communities and environmental management in this regard, and therefore is a core theme discussed in co-management literature (Armitage et al., 2009). Poststructuralism and political ecology are two areas that allow for insight to be shed in these areas, as they look beyond conventional structures and analyse the diverse power relations of such relationships (Braun \& Wainwright, 2001). The conceptual frameworks of Poststructuralism and political ecology will look to extend understandings of the complexities of relationships within community-based conservation and co-management.

This chapter has focused on key relationships within conservation, particularly communities, Indigenous communities, and potential partners and volunteers working at a local scale. I have also discussed the fluid nature of communities, and the way they may be informed by different identities and knowledges. Political ecology and poststructuralism provide valuable frameworks to approach the politics and power relations that are entrenched in nature and its preservation. The following chapter will introduce the methodology utilised for this research and in doing so, will present the case-study for this research of the community-based conservation project at the Tapu Te Ranga marae in Island Bay, Wellington. 


\section{Chapter 3 - Methodology}

This chapter will describe the research methodology that shapes this research and how it is appropriate for examining community-based conservation and cross-cultural relationships. Social constructivism will be introduced as the epistemology which underpins this research. Social constructivism is a contemporary theory which places an emphasis on acknowledging culture within a given context (Kim, 2001). A constructivist understanding of culture and context assumes that reality is a belief that is socially constructed, and therefore supported by invented societal norms (Kim, 2001). Knowledge in this regard is also considered to be a humanised product where learning is a social process (Kim, 2001). Using a social constructivist epistemology for this research means that all knowledge, perspectives and culture are considered subjective. No one truth is considered to be true. Social constructivism is helpful for analysing the case-study for this research, where the relationships which flow within the space play significant roles in constructing the identity of place (Packer \& Goicoechea, 2000).

Space and place are integral aspects in theorising human geography. As Human Geographers seek to analyse relationships between people and the world through experience, conceptions of space and place become essential to the way in which analyses occurs (Cresswell, 2012). This research focuses on a case study in which space and place play key roles in how relationships have been formed and shaped over time. Massey (1992) asserts that there are many varied definitions of space. Such definitions have conflicting meanings which often "deprive it of politics and the possibility of politics; they effectively depoliticise the realm of the spatial" (p. 66). The relationships which occur in the space of the marae will be deconstructed through a poststructural and political ecology lens, as will how the political nature of the relationships shape the space of the marae, and contribute to shaping a sense of place.

Finally, I will detail the methods used for this research, and how information was analysed. Given the importance of reflexive thought in doing qualitative research in Human Geography, I also reflect on my place within this research and within the conservation initiative. This thesis will specifically analyse my own positionality. An insider - outsider perspective will be conveyed to highlight how as a long-standing member of the community of Island Bay in Wellington, I have been both an insider and an outsider to this research. The different power that is exchanged due to my 
own positionality in this research will also be nuanced in this section. The first section of this research will further detail the epistemology of social constructivism.

\section{1 - Epistemology of Social Constructivism}

This research takes a social constructivist approach. In the context of this topic, this means that I am interested in exploring the various truths that relate to communitybased conservation in Aotearoa New Zealand. A social constructivist approach is appropriate as an epistemology as it considers the importance of "culture and context in understanding what occurs in society and constructing knowledge based on this understanding" (Kim, 2001, p. 2). Creswell (2014), states that the "researcher seeks to establish the meaning of phenomena from the views of participants. This means identifying a culture-sharing group and studying how it develops shared patterns of behaviour over time" (p.8). In the context of the case-study for this research, the Tapu Te Ranga marae and the Manawa Karioi Society, a social constructivist epistemology acknowledges that all qualitative data collected is based on multiple views of relationships occurring in a singular space. Therefore, the way in which participant perspectives give meaning to the diverse relationships allows the researcher to look for the "complexity of views rather than the narrow meanings into a few categories or ideas" (Creswell, 2014, p. 8). The participants' perspectives portray how the relationship between the Tapu Te Ranga marae, the Manawa Karioi Society and the Sisters of the Home of Compassion have contributed to developing a sense of place at the marae.

A poststructuralist approach to studying the environment understands nature as a socially constructed entity. Poststructuralism as a conceptual framework seeks to address how perspectives of nature become objects of knowledge (Braun \& Wainwright, 2001). How ideas and perspectives of nature are represented, and come to be 'stabilised' as objects of knowledge by the Tapu Te Ranga marae and the Manawa Karioi Society, may have "substantial effects, both socially, politically and ecologically" (Castree \& Braun, 2001, p. 41). A poststructural conceptual framework is particularly useful given the cross-cultural aspects of this project; people rooted in Eurocentric thought may have very different ideas about nature compared to people rooted in Māori worldviews. 
Political ecology complements poststructuralism by seeking to understand how relations of power shape who has access to and control over nature, and the ways it's defined. Political ecology supports poststructural examinations of ways of knowing about nature by exploring ways in which different subjectivities - related to class, gender, culture and ethnicity - also shape relationships with and definitions of nature (Robbins, 2000). In doing so it accounts for context. Political ecology looks to take into account the ways in which interactions over nature are impacted by 'relations of power' (Escobar, 2002). 'Relations of power' often drive the way in which ecological issues are formed, but also drive the way that politics are embedded within ecological issues (Bryant, 2001). Political ecology, as the second conceptual framework for this research, will complement a poststructural examination. It supports not only how the concept of nature is constructed at Manawa Karioi, but also the way in which the political sphere of ecology has been formed to construct such thinking.

\section{2 -The Case Study - The Manawa Karioi Ecological Restoration Project}

The case-study this research uses is the Manawa Karioi Ecological Restoration Project to discuss community-based conservation, and the possibilities for crosscultural relationships. At Tapu Te Ranga marae, there are three groups who have been operating over a long time period in a particular space. The relationships which flow between the three groups in the space creates and enables the space to become place. The political relationships by which each group asserts their identities contributes to this sense of place (Cresswell, 2012). Cresswell (2012), describes place as the "central humanistic engagement with "being in the world"' (p. 113). Space and place in the context of human geography are illustrated in the relationship between the Tapu Te Ranga marae and the Manawa Karioi Society in Island Bay, Wellington. These terms will be used to explain how a sense of place has been created where these organisations reside.

Manawa Karioi is an ecological restoration project that is situated at the Tapu Te Ranga marae, in Island Bay, south Wellington. Manawa Karioi was established in 1990 and is a society which was invited to conduct community-based conservation at the marae (Manawa Karioi Society, 2019). Although the Manawa Karioi Society is a Western, Pākehā centred organisation, its membership is not strictly Pākehā. Members of all cultures are welcome to participate. Currently some members are Māori and one in particular has a close relationship with the whānau of the marae. 
The type of the community-based conservation conducted by Manawa Karioi is ecological restoration through revegetation of native trees, shrubs, and other native ecologies (Manawa Karioi Society, 2019). This community-based conservation project takes place on Māori land. The relationship which the marae holds with the Manawa Karioi Society is unique in Aotearoa New Zealand. The space in which the Tapu Te Ranga marae and the Manawa Karioi Society exist has been formed by a network of relationships, including with the Sisters of the Home of Compassion (Tapu Te Ranga marae, 2019). Since the 1970s, the relationships between these three organisations has developed to create a unique identity for the area.

The Tapu Te Ranga marae was established in the 1970s with the help of mainly young Māori, many of whom were passing through seeking shelter and food (Tapu Te Ranga marae, 2019). The Tapu Te Ranga marae land originally belonged to the Sisters of the Home of Compassion. In the 1970s, Bruce Stewart, the founder of the Tapu Te Ranga marae, was concerned for many of the local young Māori in the area of south Wellington, as many were becoming increasingly involved in crime (Tapu Te Ranga marae, 2019). Bruce Stewart was also Māori and wanted to create a support avenue for the young local Māori who were getting into trouble (Tapu Te Ranga marae, 2019). Bruce was living in the street next to land which the Sister of Compassion owned. Bruce approached the Sisters with a proposal to build a marae, built by local Māori, for local Māori. The Sisters agreed with Bruce's vision and sold the land to Bruce to build the marae (Tapu Te Ranga marae, 2019). In 1977 the Tapu Te Ranga Trust was formed, predominantly led by Bruce. Bruce became the rangatira and kaumātua of the Tapu Te Ranga marae.

The land originally purchased by Bruce is where the marae resides today. Bruce was the rangatira and kaumātua of the marae kaupapa (vision) which was community focused, especially for Māori in Wellington (Tapu Te Ranga marae, 2019). In particular, it was disadvantaged Māori youth who were supported through the Tapu Te Ranga marae. The marae was built from 1977 to 1983, with recycled material, and remains a unique structure with the backdrop of the Manawa Karioi whenua (land) situated behind it (Tapu Te Ranga marae, 2019).

In 1987, the Sisters offered to sell Bruce the remaining hillside of land behind the marae. The Tapu Te Ranga Trust had considered the idea of a project which would return the hillside back to its native state, and agreed to purchase the remaining land from the Sisters (Tapu Te Ranga marae, 2019). It was the intention of the Trust that 
the land would become a bird and bush reserve. The hillside is steep terrain, and at the time it was purchased from the Sisters it was mainly covered in gorse, blackberry bushes and other non-native species of trees (Tapu Te Ranga marae, 2019). The land covers a large space where there are five kilometres of different walking tracks and is typical of the steep hills of Wellington (Manawa Karioi Society, 2019). Although most of the land is a steep hillside, there are also flat areas where horses graze in paddocks and beehives are kept. The two photos below highlight the positive impacts ecological restoration has had at Manawa Karioi. The first photo was taken in 2007 where the hillside is still mainly low-lying bush and the gorse is in flower. The second photo was taken in 2018 and shows how the bush has been regenerated.

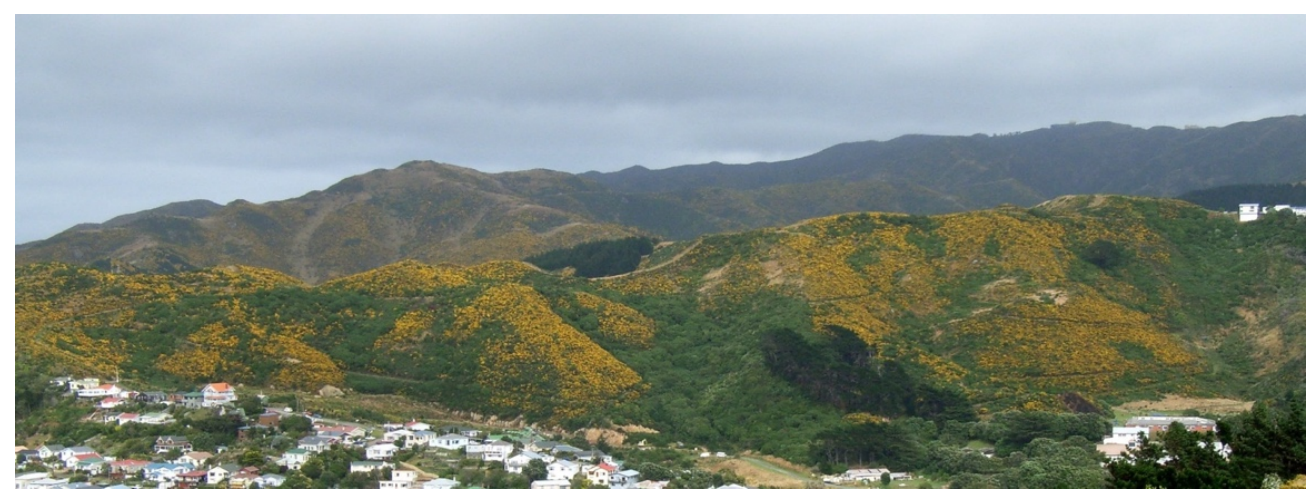

Figure 3: Photo of Manawa Karioi taken in 2007 (Photo credit; the Manawa Karioi Society)

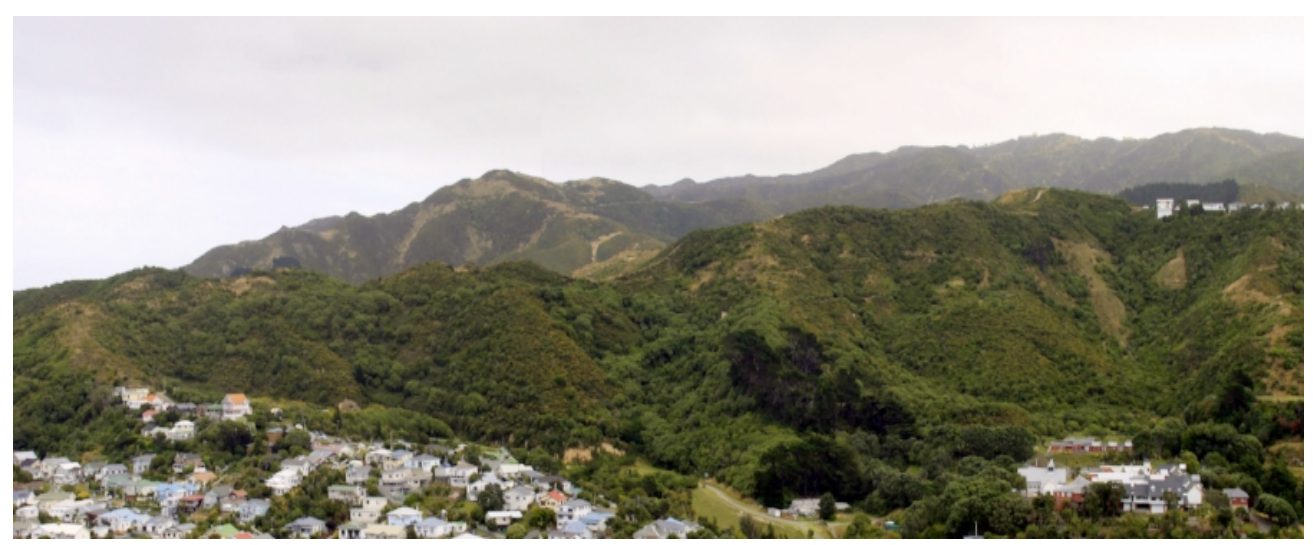

Figure 4: Photo of Manawa Karioi taken in 2018 (Photo credit; the Manawa Karioi Society)

The Sisters agreed with the Tapu Te Ranga Trust that a native bush reserve was a good idea. The remainder of the land was purchased in 1987 by the Tapu Te Ranga Trust, and in 1990 the Manawa Karioi Society was formed (Tapu Te Ranga marae, 2019). Manawa Karioi is the society who manages the ecological restoration and revegetation (Manawa Karioi Society, 2019). The Manawa Karioi Society was 
originally made up of people of the south Wellington community who were environmentally and conservation minded (Manawa Karioi Society, 2019). They all had an interest in volunteering to restore the hillside of Manawa Karioi. Communitybased conservation and ecological restoration projects were not as prevalent in 1990 and therefore Manawa Karioi is thought to be one of the older community-based conservation projects in Aotearoa New Zealand. In 1991, the first seedlings were planted (Manawa Karioi Society, 2019).

The Tapu Te Ranga Marae is a key part of the Island Bay community. The marae will often host visitors and events such as hui, meetings and other activities such as overnight school stays (Tapu Te Ranga marae, 2019). The Tapu Te Ranga marae provides a tūrangawaewae (a safe place to stand) for many Māori who do not whakapapa (affiliate) to an iwi of Wellington. The marae's tipuna whare, the main meeting house of the marae, is known as the Pare Hinetai No Waitaha and includes nine levels, all with specific names. The tipuna whare is made completely from recycled materials, lending a rustic, contemporary look to this urban marae. The marae also has its own gardens, Wāhi Whenua and Wāhi Pangarehu.

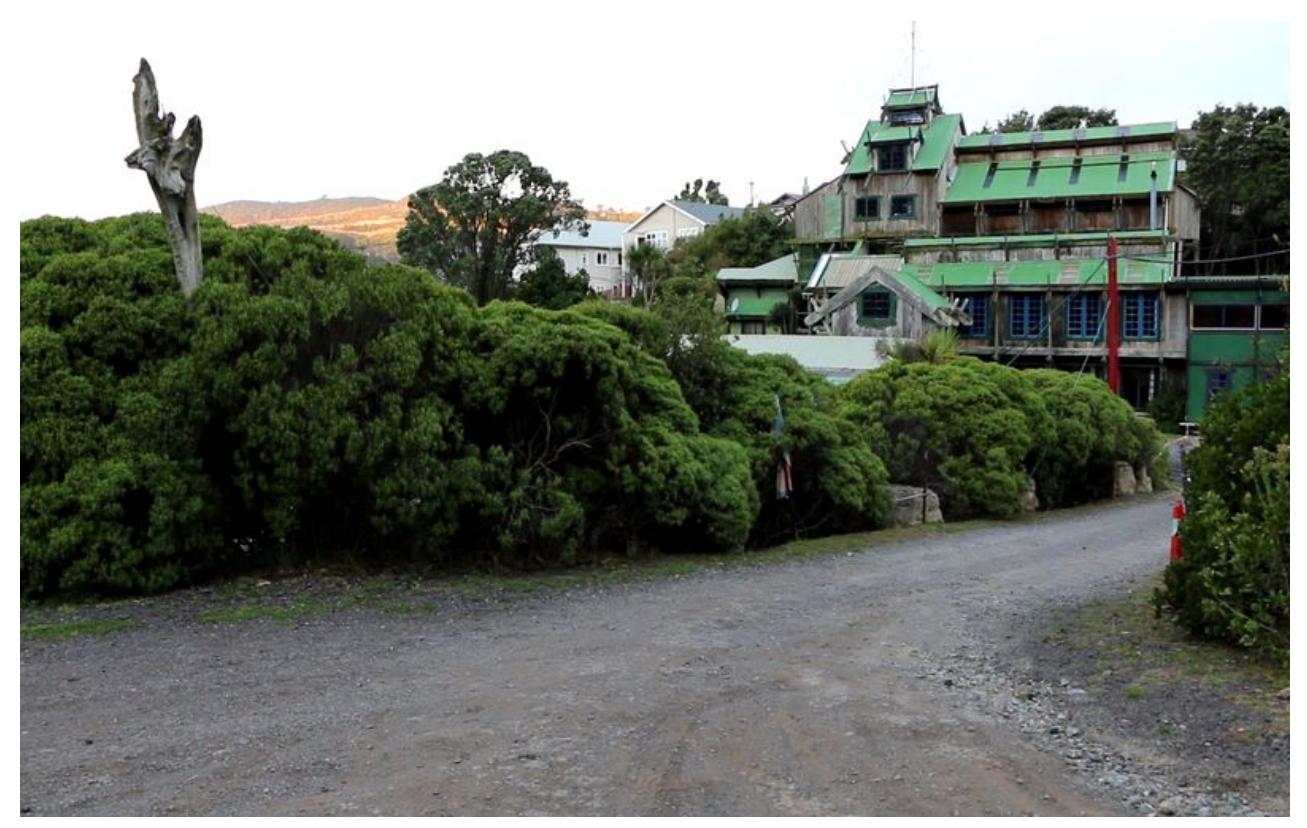

Figure 5: Tapu Te Ranga marae, 2019 


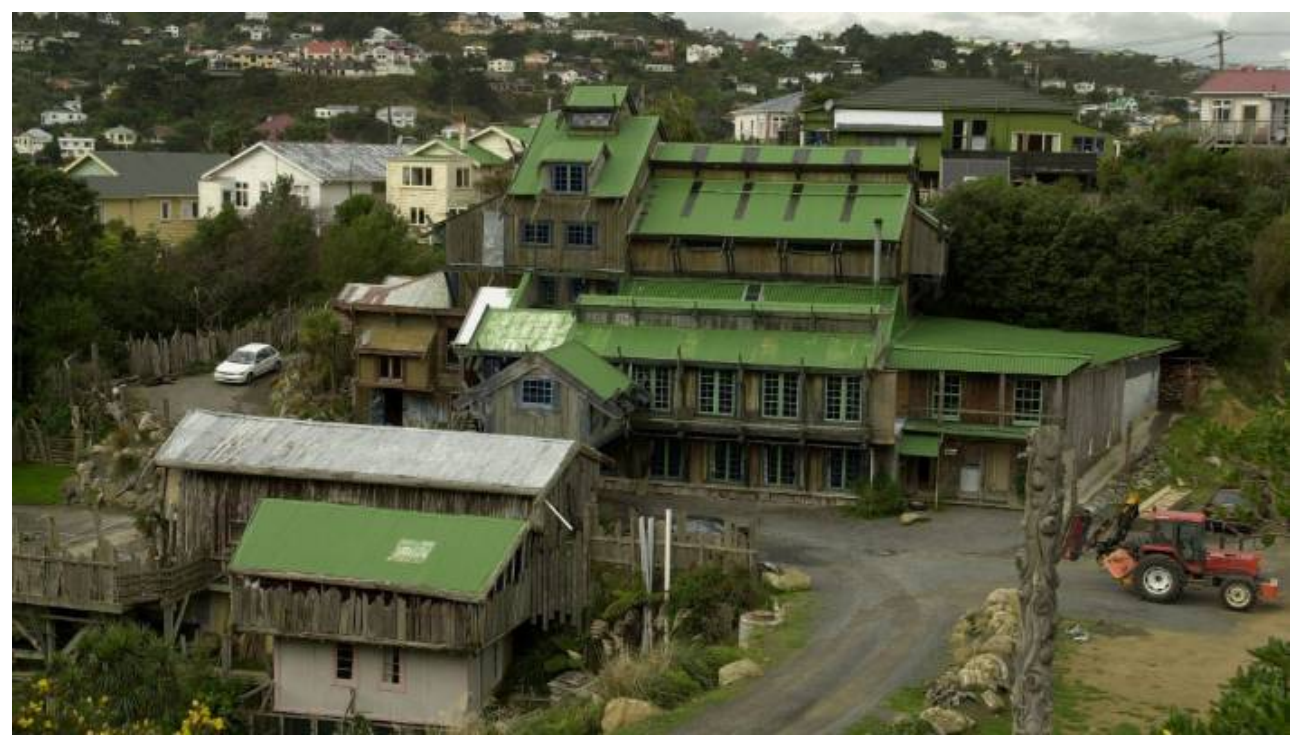

Figure 6: Tapu Te Ranga marae, 2019

Bruce passed away in June 2017. However, at the Tapu Te Ranga marae and Manawa Karioi his vision and legacy remain through the kaupapa he has left behind, and is carried on by his whānau. The Manawa Karioi Society also remains undertaking conservation, as their relationship with the marae has carried on. Bruce is now buried in the newly established urupā situated at the marae (Tapu Te Ranga marae, 2019). Bruce's passing was a significant moment for the marae and Manawa Karioi, as he had always acted as a central figure in its operations. For the Manawa Karioi Society, Bruce had always been the main representative of the Tapu Te Ranga Trust komitee, and therefore his passing could have left the marae and Manawa Karioi in difficult circumstances. However, the relationship between the Tapu Te Ranga marae and the Manawa Karioi Society remains strong thanks to Bruce's whānau and mokopuna (children). This relationship will be further explored in the discussion chapter.

Manawa Karioi is a society of which many of its participants are from a Pākehā background. Ecological restoration of Manawa Karioi has been greatly improved with the support and collaborative efforts of the Manawa Karioi Society. The relationship that has been built between Bruce and the Manawa Karioi Society has been effectively between Māori and Pākēhā, and therefore diverse pieces of knowledge have been brought in by the different stakeholders. The collaborative relationship between the Manawa Karioi Society and the Tapu Te Ranga Marae has provided a space for two existing "knowledges" to co-exist and improve the environment. 


\section{3 - The recruitment and interviews of participants}

The Manawa Karioi Society conducts two months of planting days every year, usually in the months of May and August. During these months planting days are held every Sunday from $1 \mathrm{pm}$ till $3 \mathrm{pm}$. Planting days gather many volunteers from the community from families, clubs and groups, to local community members who regularly utilise Manawa Karioi recreationally. Although I attended most of the working days during May, it was in the month of August that I was ready to start engaging with people for this research. In order to recruit interview participants, I attended the planting days in August too.

It was my intention to recruit between ten to fifteen participants for this research. I wanted to interview people who are large contributors to the Manawa Karioi Society. I also wished to interview members of the Tapu Te Ranga marae for their perspectives on the community-based conservation project. Speaking with such people would allow for an accurate portrayal of the history of the area at the Tapu Te Ranga marae, and give insight into how the two groups have been established in the space. Those who have had long-term involvement were able to shed light on other key persons who have made large contributions to the marae and Manawa Karioi.

This research was approved by the Victoria University Human Ethics Committee. Information and consent forms are attached in the appendices. For this research, I have agreed with all individual participants, as well as the Tapu Te Ranga marae and the Manawa Karioi Society, that all information provided will remain confidential. That is, all participants who contributed to the semi-structured interviews for this research shall not be named or described in such a way as to make their identity clear to a reader. Pseudonyms have been used where names are stated in this research.

On the first planting day in August, it was my intention to give a brief talk to introduce myself and my research, and then to invite volunteers to come and speak with me if they thought they might be interested in taking part. In attending the working days, I got to know many of the core members of the Manawa Karioi Society. I was also provided with an email list of current and past members, and with this I sent out personalised emails. I gained positive responses from most of the people I emailed. I came to know many of the current participants through the planting days, however, I also met with people who have had extensive past experience but who no longer take part. Out of fifteen emails I sent to potential interview participants there were only two who did not reply. 


\subsection{1 - Research Participant Characteristics}

The participants I interviewed had common perspectives and environmental values, but were also diverse in other ways. I interviewed participants who, similar to myself, had only recently started volunteering. Others who I spoke to had been there at the beginning when Manawa Karioi was first established, or otherwise early on in the project. Overall, I conducted twelve semi-structured interviews with different participants. Ten of the interviews conducted with participants were from the Manawa Karioi Society. They were participants who had prior long-term experience working with Manawa Karioi but have subsequently moved on. Other participants have had a long experience working with the Manawa Karioi Society and still perform key roles on the committee. The remaining participants were generally casual volunteers who enjoyed utilising Manawa Karioi recreationally outside the working days, or who were volunteers who engaged less with the society, but who also enjoyed giving their time for community-based conservation.

The remaining interviews were with two members of the whanau of the Tapu Te Ranga marae. A possible limitation of this research is that I have not been able to engage more with the marae. The opportunity to interview additional members of the whanau may have provided for a more in-depth perspective, as well as experiences they have within the cross-cultural relationship with the Manawa Karioi Society. Below is a table 1 , which provides a brief description of each participant and the role they play with the Manawa Karioi Society and the Tapu Te Ranga marae.

Table 1: Table of research participants

\begin{tabular}{|l|l|}
\hline Participant & Participant's relationship with Manawa Karioi \\
\hline Participant 1 & $\begin{array}{l}\text { Manawa Karioi member. Not on the Manawa Karioi Society committee, but } \\
\text { keeps in close contact and does attend meetings. }\end{array}$ \\
\hline
\end{tabular}




\begin{tabular}{|c|c|}
\hline Participant 2 & $\begin{array}{l}\text { Former volunteer and Society member. One of the founding members of the } \\
\text { Manawa Karioi Society. Was an active member on the committee for many } \\
\text { years. }\end{array}$ \\
\hline Participant 3 & $\begin{array}{l}\text { Casual volunteer. Not on the Manawa Karioi Society committee. Comes to } \\
\text { working days frequently. Enjoys using Manawa Karioi recreationally. }\end{array}$ \\
\hline Participant 4 & $\begin{array}{l}\text { Casual volunteer. Not on the Manawa Karioi Society committee. Comes to } \\
\text { working days frequently. Enjoys using Manawa Karioi recreationally. }\end{array}$ \\
\hline Participant 5 & $\begin{array}{l}\text { Manawa Karioi Society member. On the Manawa Karioi committee. Role on } \\
\text { committee as a person for public engagement and has increased volunteer } \\
\text { participation for working days. }\end{array}$ \\
\hline Participant 6 & $\begin{array}{l}\text { Manawa Karioi Society member. On the Manawa Karioi committee. Role on } \\
\text { committee as ecological expert. Facilitates and leads planting days, helps } \\
\text { with extra work required i.e. track maintenance, weeding, track making, etc, } \\
\text { and a key leader for Manawa Karioi. }\end{array}$ \\
\hline Participant 7 & $\begin{array}{l}\text { Manawa Karioi Society member. On the Manawa Karioi committee and } \\
\text { regular volunteer on planting days with knowledge of planting and } \\
\text { revegetation practices. }\end{array}$ \\
\hline Participant 8 & $\begin{array}{l}\text { Manawa Karioi Society member. On the Manawa Karioi committee. Role on } \\
\text { committee as ecological advisor when needed, a liaison between other } \\
\text { community-based conservation groups and a key leader for Manawa Karioi. }\end{array}$ \\
\hline
\end{tabular}




\begin{tabular}{|l|l|}
\hline Participant 9 & $\begin{array}{l}\text { Manawa Karioi Society member. On the Manawa Karioi committee. Role on } \\
\text { committee as one of the key leaders. A main point of contact between } \\
\text { Manawa Karioi and the Tapu Te Ranga Marae Trust. A person who was } \\
\text { present in the early years of Manawa Karioi being established. }\end{array}$ \\
\hline Participant & $\begin{array}{l}\text { Marae whānau member and representative of the Tapu Te Ranga Marae } \\
\text { Trust. Utilises the Manawa Karioi whenua for rongoā practices. Lives at the } \\
\text { Tapu Te Ranga marae. }\end{array}$ \\
\hline Participant & $\begin{array}{l}\text { Marae whānau member and the Tapu Te Ranga Marae Trust. Also lives at } \\
\text { Tapu Te Ranga marae. }\end{array}$ \\
\hline Participant & $\begin{array}{l}\text { A member of Manawa Karioi. Ecological advisor. Does not fully engage with } \\
\text { Society as infrequently present. Ex-committee member, former chairperson, } \\
\text { a person who was present in the early years of Manawa Karioi being } \\
\text { established. Also, a liaison between other community-based conservation } \\
\text { groups. }\end{array}$ \\
\hline
\end{tabular}

\section{4 - Research Methods}

In keeping with research frameworks that are interested in different knowledges and power, this research used an ethnographic, qualitative process. Ethnographic research describes a process of engaging and working with people and groups (Angrosino, 2007). It describes human behaviours and beliefs, the institutions people engage with, and the ways knowledge is created (Angrosino, 2007). For this project, qualitative data was collected through semi-structured interviews with participants from both the Manawa Karioi Society and the whānau of the Tapu Te Ranga marae.

\subsection{1 - Semi-Structured interviews}

Semi-structured interviews were used in this research. The nature of semi-structured interviews requires that the questions which are asked remain broad in nature to allow the participant to lead the conversation in the direction they choose (Longhurst, 2003). Longhurst (2003), also states that "this form of interviewing has some degree of predetermined order but still ensures flexibility in the way that issues are addressed by the informant" (p.145). Semi-structured interviews were the most appropriate form 
of data collection for this research, as this research is ethnographic in nature and looks to engage with various participants for their own perspectives and experiences.

The participants who I interviewed all were diverse in character. I sought to interview people who had long-term involvement at Manawa Karioi. The participants varied; there were casual volunteers, regular volunteers and also people who are highly involved on the Manawa Karioi committee. I also interviewed two members of the Tapu Te Ranga marae whānau. The variety of participants contributed to a large assortment of results based on their different perspectives of the relationships at the marae, as well as their own ideas of how community-based conservation should be in this space. As the participants all have different ways in which they engage with Manawa Karioi as a society, for conservation, for the enjoyment of being in nature or as a recreational resource, each has different views based on their relationship with Manawa Karioi. In this way, semi-structured interviews were apt for this methodology, allowing the participants agency in the research process to express their views based on their experiences. Attached in the appendices is the interview schedule used for interviewing the participants.

The duration of all interviews, apart from one, were approximately forty minutes to an hour. The last interview went for one hour and twenty minutes. Each interview was held in a different location including cafes and bars. I also was invited on numerous occasions to participants' houses, and two interviews were conducted at the Wellington Central Library. The two interviews with the whānau of the Tapu Te Ranga marae were conducted at the marae. All participants received a small koha for their time, typically in the form of food or drink. All interviews were recorded and transcribed by me.

Prior to conducting my fieldwork, I considered a range of risks to my and participant safety. For instance, I made sure to tell a specific person when I was going into the field, whereabouts the interview would be held and approximately how long it might take. Once the interview was finished, I would let the contact person know. Safety considerations underpin the formal university human ethics process. Ethical qualitative research requires full and informed consent from participants.

Participants who were interviewed also signed a consent form for this research. The consent form stated that if they were taking part in this research, they could withdraw until the 1st of November 2018. No participant contacted me to withdraw, however, 
as one of my interviews occurred after the 1st of November, I offered this person till the $1^{\text {st }}$ of January 2019 to withdraw. All participants have been de-identified by allocating them a number based on the order in which their interviews were conducted. The de-identified data is stored in secure locations. After three years all data will be deleted in accordance with the ethics application for this research.

\subsection{2 - Transcribing, coding and analysing}

The next phase in the research after the interviews was to transcribe each one. Before I transcribed each interview, I wrote a brief reflection of the interview and how I thought it went. I described the details of the interview, the areas covered, as well as some of the details that were not stated, and the reactions of some of the participants based on the perceived issues.

Transcripts were then analysed for themes. The coding process is a part of any qualitative methodology whereby the researcher takes steps to read, identify and order the ideas, concepts or themes that come out of the data (Given, 2008). This required me to read through the interview transcriptions thoroughly to start distinguishing the key themes which participants had expressed. Specifically, the coding procedure directs the research to identify or distinguish events, features, statements or behaviours and assign them a label (Benaquisto, 2008). In doing so, a researcher can start to piece together patterns and relationships within the data set which may not have been evident otherwise. It is important to recognise, however, that through a social constructivist epistemology, the nature of qualitative research is that all knowledge is socially constructed (Renner \& Taylor-Powell, 2003). The coding method for this research is based on my own subjective perspective, and therefore it is important to note this as part of a reflexive process. Attention will be given to reflection on this process in the next section of this chapter.

This research was examined through a thematic approach. A thematic analysis is common for ethnographic research, as it allows for flexibility in the patterns that emerge from the data and therefore for the creation of sub-themes (Creswell, 2014). Attride-Stirling (2001), states that "[t]hematic analysis seeks to unearth the themes salient in the text at different levels, and thematic networks aim to facilitate the structuring and depiction of themes" (p.387). The network of themes which came through from the data showed an array of intersecting themes. In organising thematic networks, themes are separated into a hierarchy (Attride-Stirling, 2001). Below, 
Attride-Stirling (2001) presents a diagram for detailing the global, organising themes and basic themes which are helpful for analysing thematic analysis.

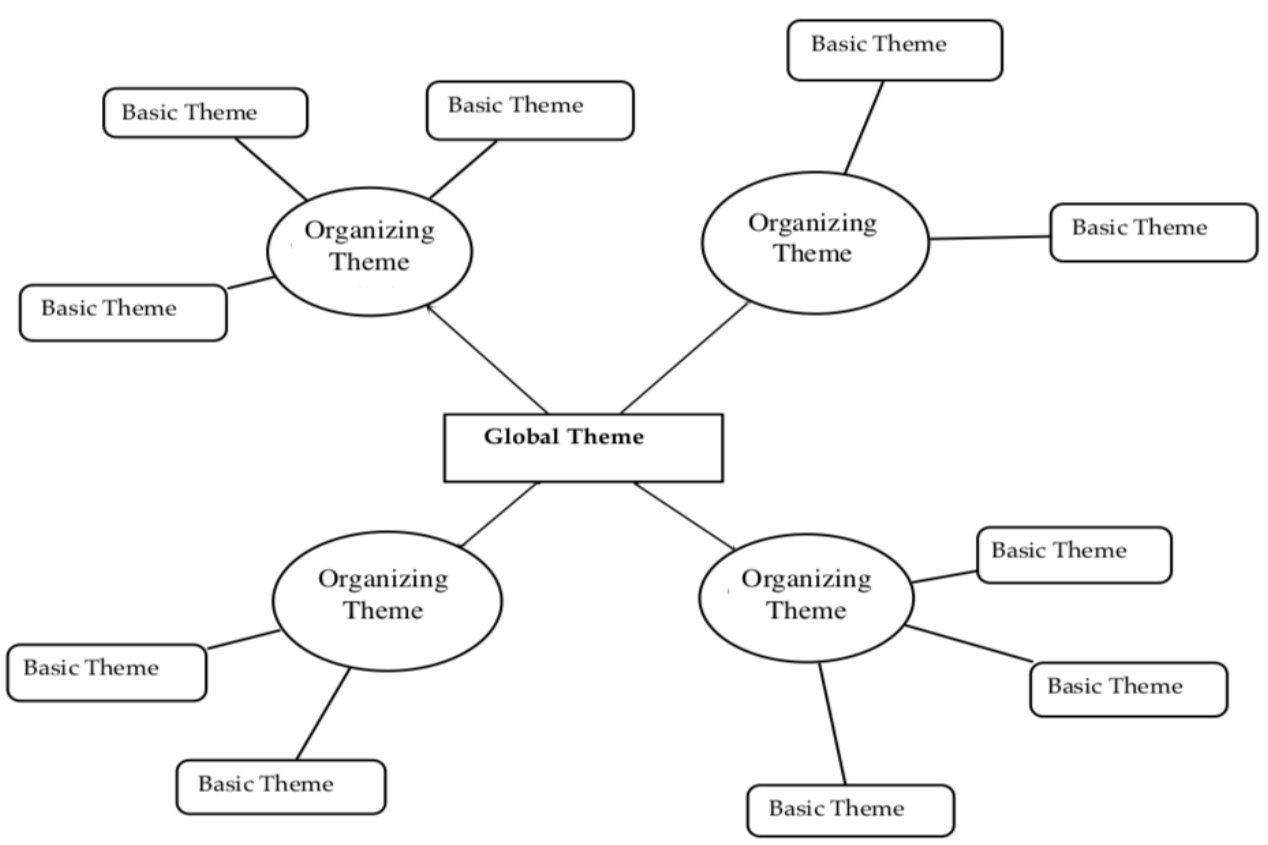

Figure 7: Network Analysis Map (Attride-Stirling, 2001)

The literature review presented in chapter two provides the large picture for this research. Based on my research questions I have identified key themes utilising a thematic analysis process as presented by Attride-Stirling (2001), which looks to separate themes into a global, organising and basic scale. By analysing this research through the lens of poststructuralism and political ecology, this thesis draws on the themes identified and seeks to apply them to how they fit into this space - place inquiry. In the next section of this methodology chapter, reflexive thought will be given to the process of this research. This will examine all aspects of myself as a researcher and how I have influenced this research, and the research context.

\subsection{Reflexivity, Positionality and Relations of Power in Cross-Cultural}

\section{Research}

Ethnographic research has a history of colonial bias which has been detrimental to Indigenous communities. Shaw, Herman, and Dobbs (2006) outline how there has been an increase in discussions for decolonising geography as a discipline within academia. In the context of Aotearoa New Zealand, Smith (1999) supports the arguments against colonial versions of ethnography. She states that ethnographers 
who have conducted cross-cultural research have often displayed a cultural ignorance (Smith, 1999). Louis (2007) asserts that "[f]rom an Indigenous perspective, research is linked to colonialism and oppression and must be decolonised" (p. 131). Inequalities have occurred as Western researchers have analysed Indigenous people through Western perspectives and therefore accounts of Indigeneity have been limited in their understanding of the worldview in question (Louis, 2007). England (1994) asserts that qualitative studies must "demand greater reflection by the researcher with the aim of producing more inclusive methods sensitive to power relations in fieldwork (p. 80). Such efforts and practices are known as being reflexive.

England (1994) states that qualitative research is a process and not just an outcome. The various actors involved in the process, including the researcher themselves, all influence the research in different ways (May \& Perry, 2010). The positionality of the researcher is especially important to consider, as identity, race, gender, sexuality, class, as well as other qualities play a role in the way the participants relate to them (May \& Perry, 2010). (Sultana, 2007) supports this by saying that "being reflexive about one's own positionality is not to self-indulge but to reflect on how one is inserted in grids of power relations and how that influences methods, interpretations, and knowledge production" (p. 376).

Research which involves the researcher having a relationship with the research context is described as 'insider-outsider research' (Greene, 2014). Breen (2007) defines insider researchers as those who do research with a group they belong to, while outsider research is conducted with groups that people do not belong to. Ethnographic research can also be tricky. Merriam et al. (2001) describe the complexities of those who straddle both the inside and outside of groups they research; the boundaries they negotiate are rarely clearly defined. Insider - outsider dynamics "The reconstructing of insider / outsider status in terms of one's positionality vis-á-vis race, gender, culture or other factors, offer us better tools for understanding the dynamics of researching within and across one's culture (Merriam et al., 2001, p. 405). For researchers who are the same as the participants in terms of commonalities of culture, gender and so forth, it is assumed that access is more easily granted, and meanings and validity of findings shared (Merriam et al., 2001). Outsider researchers who do not share common characteristics with participants often face the complexities of navigating access, meanings and validity in their understandings of the research (Le Gallais, 2008). 
In undertaking insider-outsider research it is important for a researcher to consider that "her or his membership status in relation to those participating in the research, is an essential and ever-present aspect of the investigation" (Dwyer \& Buckle, 2009, p. 55). In the context of this research based at the Tapu Te Ranga marae in Island Bay, Wellington, my positionality was both as an insider and an outsider researcher. On the one hand I was an insider; I've lived in Island Bay most of my life and have been heavily involved in the community here, including another community-based conservation project. On the other hand, because I had not previously been involved with the Manawa Karioi Society, I was an outsider at first.

I began as a consistent volunteer with the Manawa Karioi Society in 2017, when I was beginning to work with Manawa Karioi for my research. I decided it would be best practice to become a regular volunteer in order to build a reciprocal relationship with them. In September 2018, I became a member of the Manawa Karioi Society committee at the Annual General Meeting (AGM). Becoming a committee member meant that as well as being a researcher I was also becoming an insider within the society. It is possible my volunteering, and the fact that I was local, contributed to this too. It was also important for me to able to show that my research was supported, and that I had earned the trust from both the marae and Manawa Karioi (Sultana, 2007). As a committee member, reflexive considerations of the power relations involved when interviewing participants became even more important. I had to consider my positionality in the way I conducted myself when talking to the participants, the way I framed the questions, as well as how I interpreted their answers.

The unique context of this research at the Tapu Te Ranga marae meant that, despite being a member of the Island Bay community, my own Pākehā cultural identity meant that I was an outsider researcher. In initially attempting to engage with the marae, I was wary of imposing myself, and the research agenda, on the marae whānau. I attempted to initiate contact with the Tapu Te Ranga marae by sending an email. However, without a response after a period of approximately six weeks, I had to start considering other options for getting in contact. In reflection, I should have worked out a face-to-face meeting in the first instance. The trickiness of cross-cultural research is exemplified here; non-Māori wanting to invite input into research design from the outset, in order to do relevant, ethical research, while also trying to respect that Māori organisations are, generally, over-stretched and under-resourced. As I am now an insider researcher with Manawa Karioi and community member from Island Bay, this may have been why the marae whānau were eventually happy to speak with me. 
Overall, this experience of conducting cross-cultural, empirical research is a reflection of the fraught nature of doing so in a complex space such as this.

It was at the AGM that I was finally able to initiate appropriate contact with the marae. This may be poignant as it was at this time, I officially became an insider for this research. My engagement with the marae then consisted of visiting on a number of occasions and having kōrero (talking) with one of the participants. This participant was a key member of the whānau of the marae and became my key contact. I initially sought to ask this person if my research is something that the marae would be interested in, and if so, what sort of areas the whānau would like me to focus on. I also spoke with the whānau about myself, how I have lived in Island Bay all my life and how community is a really important value for me. After engaging with the whānau on various occasions both in and outside of a Manawa Karioi context, the marae said they were enthusiastic about me conducting this research.

Taking the time to appropriately engage with the Tapu Te Ranga marae was important for this research. It has meant that as I went to the marae and spoke with them on multiple occasions, a level of trust developed between us. I endeavoured to maintain the relationship through regular contact and visits throughout this research. Regular engagement has kept the whānau updated on the progress of the research, and the findings and results. During my visits to the marae, I was always aware of my positionality. I constantly needed to be aware of how my role as a Pākehā, male researcher influences the research process (Lenzo, 1995), and the deficiencies in my own knowledge given my upbringing within a non-Māori family. The way in which I conducted myself at the marae and with the whānau was also a very important part of this. Because of this, I always strived to respect marae protocol. I always brought a koha (offering), as a token of good will and to express my gratitude for having me.

I have attempted to acknowledge how histories of qualitative research have perpetuated inequalities, and therefore unequal relations of power for Indigenous communities. In light of this, I have also attempted to conduct thorough research in the most transparent and ethical way possible. Reflexivity in the research process is vital to acknowledging how a researcher impacts the research context they operate within, both in terms of power relations and positionality (Kobayashi, 2003). I may never know the extent of my positionality's effect, but it was vital to be mindful of it right throughout my time as a researcher (England, 1994). Although I will not claim to be an insider with the Tapu Te Ranga marae as I come from a non-Māori background, 
the general context of how the marae seeks to be community focused allows me to act as an insider as an active community member. It has taken time to develop relationships with both the Manawa Karioi Society and the Tapu Te Ranga marae. In doing so, I now walk a fine line straddling insider-outsider status with both parties. Reflexive thought has shown how maintaining such relationships is essential in conducting qualitative research.

\section{Summary}

This research uses qualitative methods to explore the topic of community-based conservation and cross-cultural relationships in Aotearoa New Zealand. These methods fit with my approach - underpinned by poststructuralism and political ecology. The aim of this research has been to discover what kinds of relationships form around community-based conservation on Māori land, and therefore how such connections function within a given space to shape a sense of place. While interviewing participants for this research there have been four significant themes to emerge. The next chapter describes the findings from this project and will present them in an order of significance. 


\section{Chapter 4 - Findings}

This chapter will explore the central findings from data collected from twelve semistructured interviews with research participants from the Manawa Karioi Society, and two members of the Tapu Te Ranga Trust. The findings for this chapter will be broken into four organising sections representing the key themes identified in the findings. I will discuss these themes and how they relate to the research questions, as well as linking them back to the literature reviewed in Chapter 2. At the Tapu Te Ranga marae, there are three groups who have been operating over a long temporal period in the space. The relationships which flow between the three groups, and the way in which each group asserts their identity, contribute to the sense of place at the marae (Cresswell, 2012).

The qualitative data for this research was analysed and separated into themes based on the network analysis diagram (Figure 7) by Attride-Stirling (2001)) in the Methods Chapter. As such, the 'global theme' for this research is community-based conservation, and the key themes of the findings will be referred to as the 'organising themes'. The term 'basic themes' will be used to describe any sub-themes which are discussed. The first section will describe the main organising theme of this research, the relationship between the Tapu Te Ranga marae and the Manawa Karioi Society. The remaining organising themes are: the volunteers who participate at Manawa Karioi, the additional community relationships which exist with Manawa Karioi, and the wider community benefits which are achieved through the cross-cultural relationship and the community-based conservation project. This systematic method of analysing qualitative themes allows for the depiction of salient themes and the relationships that link them together (Attride-Stirling, 2001). Lastly, although code numbers are used for all quotes by participants, where names are referred to in the quotes provided are pseudonyms and are therefore not the real names of people who currently work, or have done so with Manawa Karioi.

\section{1 - The Relationship between the Tapu Te Ranga marae and the}

\section{Manawa Karioi Society}

The connection between the Tapu Te Ranga marae and the Manawa Karioi Society is the most significant organising theme that concerns this research. The relationship between the Tapu Te Ranga marae and the Manawa Karioi Society dates back to 1990, when Manawa Karioi first began. The relationship is central to the community- 
based conservation occurring at the marae, which is the land which Tapu Te Ranga resides on. It demonstrates how there is a reciprocity of respect between the two groups.

This section will present a detailed history of how the relationship between the Tapu Te Ranga and the Manawa Karioi Society was first established. This history is contextually important as it shows how the relationship developed, and still exists today. It depicts the essence of the kaupapa of the Tapu Te Ranga marae, and describes how the community orientated notions of the Tapu Te Ranga marae transcend through Manawa Karioi as a society and a community-conservation project. It will detail how both groups have a symbiotic relationship through mutual benefits which are achieved. Therefore, the current relationship is reciprocal; both groups have a meaningful appreciation of each other.

\subsection{1 - The Tapu Te Ranga marae - Manawa Karioi Kaupapa of}

\section{Conservation:}

The community focus of Manawa Karioi is underscored by the community focused kaupapa of the Tapu Te Ranga marae. This was as a basic theme within the relationship and is described by setting the context of how the relationship between the two groups came about. Bruce Stewart was the rangatira, kaumātua and founder of the Tapu Te Ranga marae. With the marae well established, the Manawa Karioi Society was founded through a collaborative effort between the Bruce and people from the community in and around Island Bay. Participants who were involved in establishing the Manawa Karioi Society recalled that it was the collective vision to ecologically restore the hillside where the Tapu Te Ranga marae resides (Participant $2,6,9,12)$.

Bruce's vision was to bring back the birds, and the community participants were also focused on planting native trees. At this time, the hillside at the marae was predominantly over-grown with non-native trees and bushes. The space was identified by the Tapu Te Ranga marae and the Manawa Karioi Society as an area which could be transformed into an ecological restoration space. As the transformation has occurred, Manawa Karioi has contributed to creating a sense of place at the marae through the different ways that social interactions have been enabled. Despite some small differences between the vision of Bruce and the Manawa Karioi society, the collective desire for the hillside was very similar. The 
Manawa Karioi Ecological Restoration Project was not the only vision which Bruce Stewart had in mind for the marae and the whenua. It was also in Bruce's plan to build a papakainga housing area. This housing area would be designed on the same community orientated principles which founded the Tapu Te Ranga marae.

He wanted plants planted, and the native birds coming. But he also wanted to find an appropriate space and a place for people to, to live with them (Participant 2)

Although Bruce's plans of a papakainga housing area never eventuated, the collaboration between the Manawa Karioi Society and the Tapu Te Ranga marae still developed and evolved over time. The collective vision of the two groups has always been socially driven and therefore benefits have gone towards the community. For the marae, the large focus from its inception has been supporting young and vulnerable Māori. For the Manawa Karioi Society who share the space, the community-based conservation is led by community volunteers where many social benefits have become available through public access to Manawa Karioi as a space. Other values stated by Manawa Karioi reinforce this, they are:

- kaitiakitanga and environmental steward ship principles;

- to foster wider community involvement through recreation, education;

- to encourage the involvement of children in the society's activities ;

- To support other organisations in Aotearoa New Zealand with similar or compatible objectives;

- To establish a partnership of Māori and Pākehā in achieving the objects of the society (Manawa Karioi Society, 2019).

Although not all values and objectives of the Manawa Karioi Society may be consistent with other typical community-based conservation groups in the south coast of Wellington, their cross-cultural relationship provides an extension of the Tapu Te Ranga marae kaupapa into a conservation setting. In this sense, together the marae and the society enable different kinds of cultural interactions with the whenua and the plants

\subsection{2 - The Current Relationship}


The Tapu Te Ranga marae - Manawa Karioi relationship as it currently stands was another basic theme from the findings I explored. The relationship between the Tapu Te Ranga marae and the Manawa Karioi Society is fluid; it has existed differently at different times and is always changing. Despite this, the Manawa Karioi Society has always been welcome to practice community-based conservation throughout the year on the marae land. The society conduct most of their planting in the winter months, and invite community volunteers to participate on planting days or other working days. The Manawa Karioi Society also utilises the marae for meetings, hui and at times they are invited back to the marae to have a cup of tea after a working day. The relationship between the two groups is born out of these interactions that occur in the marae space, which contribute to creating a diverse sense of place as many volunteers enjoying spending their time there.

The fluid nature of the relationship between the two groups is exemplified by a participant who spoke of periods where volunteer numbers have not been high, and progress has been more difficult to maintain:

\begin{abstract}
Manawa Karioi went through a fairly, l'd call lean period in the sense that there wasn't a lot of community support and those folk who worked on the ground did a really good job and kept things ticking over. So by the time I came back three or four, or whatever it was years ago, relationships with the marae weren't bad. They were just very thin (Participant 9 )
\end{abstract}

The inconsistencies in volunteer support at this early period is reflective of the popularity of community-based conservation in the early 1990s. As aspects of environmental management and conservation have become more prominent in society, Manawa Karioi as a conservation project has also been able to grow. However, Manawa Karioi in the early periods was a project that required consistent volunteers in order to continue operating. In June, 2017, Bruce Stewart passed away. Despite this, the relationship between the marae and Manawa Karioi has stayed strong since. Although the emotion of the passing of Bruce is still very raw, the sense of unity between the two groups continued to grow, and the relationship is in a positive position going forward.

Since Bruce has died, everyone was worried that it was going to just fall apart because their leader or their head was gone, but it's 
actually, I've seen the opposite happen where the families are really united and they are doing a lot. They're really proactive and organised and seem to be getting along really well. And yeah, stuff's happening (Participant 5)

The history of the two groups shows that the relationship goes through different stages, often based on those who are able to engage in it. The fluid nature of the relationship is a large focus of this basic theme. It shows how perceptions of place can be fluid over temporal periods based on the natural flux of the relationship. Today the current relationship between the Tapu Te Ranga marae and the Manawa Karioi Society is in a healthy state where communication and engagement occur regularly. Participants from the Tapu Te Ranga marae stated:

It's a good relationship. In the last couple of years, the two or three years it's been a really good relationship. It helps that we're friends with the individuals who managed the group of volunteers. Stella in particular who has been a long-time friend, both Grant and Jamie are quite close to us. They've been really respectful of the taha Māori [Māori identity] aspect of reforestation, down to the names of tracks. All of those types of things. And I don't think we could have really asked for better, they've been so good to us in the last few years. Very organised and just respectful. It's a really good relationship, friendship (Participant 10)

This relationship and the networks of connection that flow between agents are seen here to be of a very supporting and reciprocal nature. This is perhaps one of the most important elements of the basic theme, as it exemplifies how Manawa Karioi participants recognise the value of community-based conservation taking place on the marae land. These diverse interactions contribute to creating the current sense of place at Manawa Karioi. The current strength of this relationship reflects the reciprocal benefits which are achieved between Tapu Te Ranga marae and Manawa Karioi. As Manawa Karioi is part of the community, many of the benefits go to the community, however, the dynamic of respect and appreciation between the two groups also significantly contributes to constructing a sense of place. This was exemplified by a participant who has a large involvement in at the society. 
I think we have a role and active duty to support the marae (Participant 8)

This statement by participant 8 shows how Manawa Karioi Society feel about the marae and Manawa Karioi as a place. Participant 8 feels a strong sense of place at Manawa Karioi and understands that this has been established through maintaining the relationship with the marae whānau. The relationship between the Tapu Te Ranga marae and the Manawa Karioi Society is the most significant organising theme for this research, in the way it has existed in the past, present and going forward. It is the mechanism which allows Manawa Karioi to operate. The values of both groups are reflected through this relationship; the community focused kaupapa of the marae, as well as the community focused nature of Manawa Karioi. These values converge through the community-based conservation operating at the Tapu Te Ranga marae.

\section{2 - Manawa Karioi Volunteers \& participants}

The second organising theme of this research relates to the volunteers and participants who contribute their time and effort to the Manawa Karioi Society. This is another basic theme of the relationship between the two groups. It should be noted here that many of these themes intersect with each other. The people from the community who participate and volunteer their time play a large role in many ways. This includes the way the physical landscape of Manawa Karioi appears through their conservation work, the way in which ecological restoration is undertaken, and also how the relationship between the society and the Tapu Te Ranga marae is positively maintained. Collectively, these aspects through volunteer and participant experiences and understandings of nature also shape a sense of place at Manawa Karioi.

One of the prominent basic themes from the interviews was that there was a clear and deep respect for the Tapu Te Ranga marae from the Manawa Karioi participants. They shared their experiences of volunteering and the appreciation they felt towards the marae. The appreciation was diverse, where participants expressed their gratitude for the opportunity to undertake ecological restoration on the marae land, but also for the diverse cultural experiences. One participant stated one of the reasons they wanted to be involved with Manawa Karioi: 
I guess it was actually the Mãori element to it. So really it was the only project that was going at the time and I was really interested in their relationship with the marae. So that's what drew me, that it was based around the marae. The land it's on is actually owned by the Tapu Te Ranga Trust. So that's what drew me in to Manawa Karioi as opposed to other conservation projects in the area. (Participant 2)

Another participant also shared their experiences of being involved:

It's the sort of thing where I have never been welcomed on to a marae before like that. It's the only marae I've been [to] and had anything to do with. For a lot of people it's probably the same experience. They come to plant trees, they get to go see an amazing marae and hear about Bruce, have food and some kai in there... And we've had older people who have never probably been on marae before, especially some of my work mates. l've dragged one along, and so you just go and have a cup of tea after [planting days] and this is like something quite special, and quite unique. (Participant 7)

Both participants belong, or have belonged, to the Manawa Karioi committee and have therefore been involved with the marae in management of some kind. After working days, it is not unusual for the marae to invite the volunteers from Manawa Karioi back to the tipuna whare of the marae. This often includes a powhiri. Both experiences expressed by the participants show a great appreciation for the Tapu Te Ranga marae. These participants were grateful of the support that the marae provides Manawa Karioi through being welcomed to conduct conservation, but also hospitality through a cup of tea and the reciprocal gratitude for the work they do. Volunteers who attend such gatherings show an interest, respect and appreciation for the marae whānau and their culture, which adds to their enjoyment in partaking in communitybased conservation. The reciprocal appreciation shown by both groups is another way in which the networks and connections have assisted in shaping the sense of place over a temporal period. Manawa Karioi is now not just a society. It is an area of space open to the public and belonging to the marae. It is a place where, through the relationship between the two groups, both the identity of the Tapu Te Ranga marae and the identity of Manawa Karioi as a conservation space are represented. 
Lastly, another longstanding member of the Manawa Karioi Society conveyed a similar gratitude for the relationship stating:

I think definitely yes, it was innovative and still is. And um, but it's fair to say that back then, we're about sort of early to mid-nineties. No I certainly didn't fully appreciate that but as I got re-involved with it, I've realised what an unusual thing it is and certainly one of the reasons why I really enjoy and feel motivated by the relationship. There's a significant group of people who are also attracted then to visit the marae and establish a relationship with the marae (Participant 8)

This participant indicates that conservation participation provides a pathway into greater cross-cultural exchange that may well extend beyond conservation, as volunteers are invited to develop their own unique relationships with the marae. Participants are aware that the project resides on the marae whenua and therefore holds a particular cultural significance. The appreciation and reciprocal respect between the two groups also contributes to the main research question: what kinds of relationships form around community-based conservation on Māori land?

Despite the healthy state of the current relationship between the two groups, the Manawa Karioi Society faces diverse challenges with regard to low volunteer numbers, and the resulting slow pace of conservation. The next section will detail the experiences of participants and the challenges of operating community-based conservation. Despite such challenges, there are improvements where participants with particular skills have brought about success. In this regard, Manawa Karioi is an example of one of the very well managed community-based conservation groups on the south coast of Wellington.

\subsection{1 - Challenges and Successes of Volunteers}

Since it began in 1990, there have been periods where Manawa Karioi has operated effectively and periods which have struggled to maintain consistent volunteer engagement. The challenges and successes of those who partake in communitybased conservation is another basic theme, related to the organising theme of the volunteers. Naturally, during times where volunteers were not as engaged with participation, restoration has been slow. A very experienced Manawa Karioi 
participant spoke of their experience during such times. This participant is a Manawa Karioi committee member and a central figure in leading planting days, and in the maintenance required such as weeding or track clearing.

Sometimes we've had only one or two in the core-group really and it's gone through bleak times like that. Some days you have had a committee that might comprise of six or seven people, but they're all so busy with lots of other things and at one point most of us had young kids so no one had time, you know, we'd have a meeting and discuss things to be done that we wouldn't actually get a lot done. Our volunteer support base was pretty minimal (Participant 6)

Manawa Karioi is situated on a large, ridged hillside. The hill has a steep incline and is covered by large areas of native trees. This means volunteer labour required for successful ecological restoration at Manawa Karioi is high. There are also various tools which are required for this kind of conservation project which incur costs. Low volunteer engagement meant that not only was it a challenge for the dedicated conservationists who were partaking in the physical aspects of tree planting, but also the management requirements for the committee. Another participant expressed the challenges of low numbers on the working days.

Jamie said that there was sometimes just him and maybe two other friends that were showing up for working bees. And it was really like a, like they needed to do so much work (Participant 5)

The times where volunteer engagement and support has been low run parallel to low levels of engagement between Manawa Karioi and the marae. However, as time has progressed, volunteer numbers have improved due in part to the efforts of some of the Manawa Karioi Society committee members. One participant has made a large difference to the challenges of retaining volunteers, through their role as social media and communications officer on the Manawa Karioi committee. This has been a success for Manawa Karioi as a community-based conservation project. When speaking to the person they told the story of how it was when they first got involved. Today, efficient communications through social media and the website is reinvigorating the working bee days: 
My career is in media, when I first started looking into it their media stuff it was a bit of a mess. I've revamped the whole thing and since then we've had some big working bees with between twenty to thirty volunteers show up. With that many people, more gets done, including track maintenance. Jamie works up there on his days off and mows the tracks. Now we have more volunteers and more of the tracks and weeds are getting done (Participant 5)

When speaking with volunteers who partake on a more casual basis, they too spoke of the success of volunteers engaging on planting days:

Okay so I found out about it last year first of all. I think just through Facebook. I didn't quite know what to expect, but everybody seemed really friendly. You know when you first turn up at an event you don't, you kind of assume that everybody knows everyone because you have just arrived and there are all these people there. But then you quickly realise that some of the people are new as well (Participant 3)

There is a fairly broad demographic of people. So older people, younger families with their kids and then like students or international students or backpackers or whoever (Participant 4)

However, as the success of social media has created renewed numbers for the Manawa Karioi Society, new challenges have arisen. Participant 4 also described the new challenges they perceived which came with having more volunteer engagement on the working days:

There was one day where they ran out of tools, and they ran out of trees and things, and you do the track work at the end but there's kind of the eight people standing around watching one person dig. In an ideal world it wouldn't happen but it's perfectly understandable because you've got no idea, I guess who will turn up on the and for one person like Jamie to manage twenty or thirty people and keep them gainfully employed the whole time. It's not really feasible or realistic (Participant 4) 
This participant's experience highlights that as Manawa Karioi have become more successful in bringing in new volunteers, there are also new challenges in facilitating new comers. Manawa Karioi is fluid in the sense that it exists differently over time due to the particular volunteers coming and going, and the skills they have. Having a larger volunteer base means that diverse views will be experienced by those who participate. Some of these were specifically voiced by another long-term active volunteer with in-depth knowledge of biodiversity and ecology:

I find a lot of people, although their heart is definitely in the right place, they're thinking from an anthropocentric perspective. It's about tracks and aesthetics. But you know [the idea that] most of the site was planted on the quality of work by volunteers is questionable. The species we were planting were already abundant. It's nice to engage people and give them an experience of nature, but should that be our priority while weeds are continuing to spread? I don't think so (Participant 12)

The quote by this participant suggests that there might be a misconception in people's expectations of what is required for ecological restoration. The challenges and successes of community-based conservation which occurs further demonstrates how volunteer engagement at Manawa Karioi shapes perceptions of nature, and therefore identify of place for participants. Although ecological restoration predominantly involves restoring the natural environment through planting native trees, maintenance is also required through pulling weeds, and clearing tracks and other areas. The new challenges associated with the successful engagement of volunteers has meant that Manawa Karioi as had to adapt to the diverse peoples who turn up to help, and the different ways they want to help. A part of this is acknowledging that the situation may never be perfect. However, as a community orientated conservation group, they must strike a balance between accommodating people contributing to the project, and striving for positive ecological outcomes. The way that participants experience the challenges and successes of volunteering at Manawa Karioi shapes the way they identify with the space, and how engaged they may wish to be moving forward. 


\section{3 - Wider Community Relationships}

Relationships that are formed from community-based conservation may be diverse and extensive. Many of the relationships which the Manawa Karioi Society or the Tapu Te Ranga marae have, or have had in the past, have often influenced the direction of the ecological restoration project at the marae. At times this has been inadvertent and other times has directly affected certain outcomes. The wider community relationships that the marae and Manawa Karioi have with other organisations or community groups is the third organising theme which stems from the central findings.

One integral relationship which has not been presented so far is the relationship with the neighbouring Home of Compassion, situated on the northern end of the Marae and Manawa Karioi. This basic theme will also detail a considerable event which has played a large role in the way that both the Tapu Te Ranga marae and the Manawa Karioi Society are today. It is part of the history of how Bruce Stewart acquired the marae land.

\subsection{1 - Aligned Values - Sisters of Compassion \& Tapu Te Ranga}

The Sisters of the Home of Compassion reside on the northern side of the Tapu Te Ranga marae. The Home of Compassion is a Catholic organisation who are, like the Manawa Karioi Society and the Tapu Te Ranga marae, community focused. The Sisters of Compassion have a long history of caring for the sick, elderly and those who are in vulnerable positions. The Sisters of Compassion originally owned the land where the Tapu Te Ranga marae is situated. When speaking with participants of the whānau of the Tapu Te Ranga marae they described the story of how Bruce had initially purchased the land for the marae and later Manawa Karioi:

By the time that he went in search of land to buy he saw an ad in the paper saying that the Sisters of the Home of Compassion was selling land. So he inquired, and they were selling fifty acres and they had fifty-two all together so kept two, sold fifty. (Participant 11)

The Tapu Te Ranga marae kaupapa was exemplified by Bruce in the way it was built with a community focus, but furthermore with the assistance of those seeking tūrangawaewae. As this was predominately vulnerable Māori in the area, the marae was a cultural support network for the community. 
So one of the proverbs that came out of the building was, Ko te ringa tangata i hanga $i$ te whare èngari ko te taura ōte whare $i$ whakatipu $i$ te tangata. So those that build the house, are built by the house. So they just kept on building till they were okay or healed enough to walk away (Participant 10)

The Sisters of Compassion identified with his community focused vision. Later, Bruce went on to purchase their remaining two acres; the hillside which now exists as Manawa Karioi. One of the most significant moments in the history of the Tapu Te Ranga marae came about in 2000. The Catholic Church was celebrating their millennium jubilee. The Catholic Church has traditionally promoted the value of forgiveness as a central principle of their belief system. The Sisters of the Home of Compassion forgave the remaining debt that Bruce owed for the marae land he had purchased.

[b]ecause of that time the marae, [Bruce], Home of Compassion, the sisters there, they have a very, very strong relationship, friendship going on for a long time. And that's why they approached him first and said we want you to have this land if you can do. They were in favour of him having it because they agreed with the kaupapa and what the old man was building, and they could see it was a good thing and was a good cause.

And then there was a point after two thirds of the principal had been paid off and then it came around to the jubilee year for the Catholic Church and the Home of Compassion according to their church, the year of jubilee, they wiped the debts. They wiped any debts they have, yeah which is quite an amazing thing. So the last portion of the debt, they wiped it and that was given as a koha to the marae which was huge, a huge win and blessing and my understanding is the Home of Compassion were given that land way back at the beginning of Mother Aubert, the whole land was given to them by the local Māoris (sic) at the time so it's kind of fitting that they give it back (Participant 11)

The forgiveness of the remaining debt that Bruce owed the Home of Compassion is significant moment in the history of the Tapu Te Ranga marae. It has contributed to 
shaping and forming the marae and Manawa Karioi into what it is today, and the wider community benefits that come from it.

Participant 11 also makes mention of the appropriateness of the return of the land to Māori. This is a small but important statement to consider. The Catholic Church, and the missionaries contributed to the British colonial regime at the time of European settlement between the years of 1815 and 1990 (Davidson, 2004). Along with the efforts by the Crown, the Catholic Church and other denominations of Christianity worked in conjunction to acquire land to support the Catholic mission of spreading the word of God (Davidson, 2004). This aspect of the history of the marae and the Home of Compassion is a significant part of history that is often overlooked. Dening (1989) explains that "[t]he past is never contemporary, but history always is. History is always bound to the present is some way. History always represents the present in the ways it re-presents the past" (p. 134). For Participant 11, the return of the land by the Sisters is a form of indirect reconciliation between the two parties, and therefore adds to Manawa Karioi's sense of place through the relationship with the Sisters of Compassion.

The significance of the role in which the Sisters have played within this space is highlighted by the relationship they have with the marae. It also contributes to the way in which the sense of place continues to be constructed for the Tapu Te Ranga marae and Manawa Karioi. One of the Sisters continued her involvement with the Manawa Karioi Society. Participant 2, one of the early volunteers at Manawa Karioi, reflected on how Sister Loyola from the Home of Compassion also continued to also be involved at Manawa Karioi for many years after the Sisters had gifted the remaining land to the marae:

That was big so we had a big celebration for that. And then after that, um, yeah, there was the Sister Loyola Galvin, and if you've seen that film about gardening with soul, that's sister Loyola. She was on the Manawa Karioi committee for quite a few years. She'd be with us. (Participant 2)

The way Sister Loyola maintained contact with the Manawa Karioi Society shows that the Home of Compassion also continued to support the kaupapa of the marae, and the community focus of the society. Additionally, it underscores that the Home of Compassion's relationship with the Tapu Te Ranga marae and the Manawa Karioi 
Society was based on a shared community-driven focus. This is one of the key aspects in how the three groups have been able to maintain their connections. Their common community interest adds to supporting a diverse sense of place for different people at the marae.

Although this research has focused so far on the key relationships between whānau of the Tapu Te Ranga marae, the Manawa Karioi Society, and the Home of Compassion, there are various other community-based conservation groups in the area of Island Bay and the south coast of Wellington. Over the recent past, there have been several hui (meeting) which the Tapu Te Ranga marae have hosted between these groups, along with Manawa Karioi. The relationship which Manawa Karioi have with these groups also plays a role in shaping identity and place in the marae space. The following section will address the other community groups, and how the relationships at the marae space also contribute to influencing relationships and community-based conservation on the south coast of Wellington.

\subsection{2 - Community-based conservation groups in Island Bay}

Wider community benefits are extended to other surrounding community-based conservation groups in Island Bay. Some of these groups conduct ecological restoration close to Manawa Karioi. The relationship which the marae and the Manawa Karioi Society have with these groups is the basic theme for this section, under the organising theme of wider community relationships. These groups are the Southern Environmental Association (SEA), the Paekawakawa Reserve, Oku Reserve for dune restoration at the Island Bay beach, Friends of the Owhiro Bay Stream, and Te Motu Kairangi on the Miramar peninsula. Other general conservation groups who have alternative focuses such as Predator Free Island Bay and Predator Free Newtown are also involved. Having a form of relationship with such groups is constructive for sharing knowledge around some of the common challenges and successes that everyone faces.

One of the committee members at the Manawa Karioi Society who has a long history of working with numerous conservation groups, as well as being an ecologist, acts as a liaison between many of the neighbouring groups. In 2017, this participant helped organise an environmental hui (meeting), hosted at the Tapu Te Ranga marae, where many of these surrounding groups from the south coast of Wellington assembled. 
I should say that both of these [restoration hui] were basically about restoration and conservation groups in the southern suburbs coming together to share their experiences. (Participant 8)

Another participant I spoke to with large involvement on the committee and work at Manawa Karioi spoke of the environmental hui, stating:

that was a case of just getting all the groups together to talk about what everyone is doing and how we might be able to work together on things. I guess the main thing there would be there's suddenly in the last year or two being quite a surge in community pest control work going on with Predator Free Newtown and Island Bay in that. So those groups. So that's kind of like separate groups stepping in and getting involved with established groups, which is quite good because that's a whole different set of skills that you need to have, you know, and we're spread fairly thin in terms of the amount of people we've got in our core group that it's hard to take on an extra level of what you're doing, but if there's already a group set up to do that, then you can just step in and do it. (Participant 6)

\begin{abstract}
Statements such as these articulate the increasing importance of maintaining relationships with other community-based groups. There has been a recent increase of smaller groups emerging who have specific skill sets to support ecological restoration initiatives. Predator Free groups are a great example as they act in a conservation context and produce benefits for other conservation groups.
\end{abstract}

The same participant spoke of the benefits they had experienced through other clubs and groups who wished to be involved in supporting conservation occurring at Manawa Karioi. Some of them were also at the environmental hui and others have contacted Manawa Karioi to be involved.

The first one was held in that marae. So that brought in a whole lot of other groups like Department of Conservation, Regional Council, things like that, yeah. So yeah, we're constantly working with new groups. Um, we have, this year we've had the Victoria University Tramping Club get involved and they want to come back several times a year. We're finding more groups like that, you know, as, as 
people learn about what we're doing, they come along, see it and they're like, wow, this is really cool to get involved too. So constantly learning how to manage and deal with groups because you know, we've had school groups come in. (Participant 6)

Many of the participants suggest that the relationship that community-based conservation groups have with each other provide community networks. Such relationships not only transfer the flow of knowledge through community engagement, but also provide flows of exchange between people. Many of the participants talked about prior experience of volunteering with other groups before discovering Manawa Karioi:

So I looked around to see what there was available in Wellington and that's when I found the group in Island Bay, which is called Island Bay Coast Care, and they were at the time working both on the sand dunes and on Okura Reserve, which is right at the very end of Island Bay (Participant 3)

Initiatives such as the environmental hui for local community-based conservation groups were an effective forum for sharing experiences, and advancing the cause of community-based conservation. The importance of community-based conservation relationships have been a recurring theme in the data. This suggests they are an important factor for Manawa Karioi in sharing specific skills and gaining support from other groups, as well as appealing for more volunteer engagement. The environmental hui that the Tapu Te Ranga marae host further enable cross-cultural interactions with community-based conservation groups outside of the marae space. This further illustrates a cross-cultural sense of place in the Manawa Karioi space.

\subsubsection{Wellington City Council \& other institutions}

The Wellington City Council and various other groups play a role in supporting the Manawa Karioi Society. This is the final basic theme for the wider community relationships the marae and Manawa Karioi have. Many of the participants with longterm experience mentioned the relationship the society has with the council in one way or another. One of the main forms of support which the Wellington City Council provides for Manawa Karioi is supplying subsidised native seedlings. Although the relationships with external but local institutions contributes less to the identity of place 
and the marae-Manawa Karioi space, the equity of support goes a long way in allowing community-based conservation to occur. They are therefore necessary supporting relationships but are far more subtle in the way they contribute to the space. One of the long-term participants of Manawa Karioi spoke of the council's support.

People don't have the resources and the knowledge [for communitybased conservation] whereas nowadays, it's a lot of community groups with lots of keen hands and networks now, you know, local councils are really supportive and provide a lot of the trees to groups, which helps immensely. I don't think anywhere near as much could be done if it wasn't for that. (Participant 6)

The comment by Participant 6 illustrates the way in which community-based conservation groups are limited in the way of resources and volunteers with in-depth knowledge of restoration. These factors are often barriers for progress for conservation projects and often highlight that additional support is needed through wider relationships.

There have also been other institutions in the past who also support Manawa Karioi. Some of these groups have been previous partners with the society, whilst others still actively provide assistance today. Participants spoke of organisations such as Forest and Bird who have a nursery and, in the past, have also provided native seedlings.

Forest and Bird had been supplying us with plants for quite a long time now. I think it was Naturally Wellington or something is a project they set up with their nursery up in the Highbury to supply plants to community groups. They're quite good for supplying more unusual plants. There's a guy who is there and does a lot of their seed collecting and he's got of wide knowledge of what plants are around and where to collect the seeds from. So that's one group we worked with (Participant 6)

Such wider community relationships are seen by many participants as being a large contributor to the success of Manawa Karioi. They signify that as a community group, resources, time and knowledge are often scarce and are required in order to maintain the cross-cultural relationship as well as the restoration. The final section of this 
chapter will present fourth significant theme: the wider community benefits from crosscultural relationships and community-based conservation.

\section{4 - Wider Community Benefits from C.B.C and cross-cultural} relationships

Through the cross-cultural relationship with the Tapu Te Ranga marae space, many social and environmental benefits are created. This section will detail how the relationship between the Tapu Te Ranga marae and the Manawa Karioi Society create these benefits for community use. The wider community benefits for community-based conservation is the final organising theme to be presented for this research. As the Tapu Te Ranga - Manawa Karioi relationship makes possible crosscultural interactions with the whenua and the ngahere (bush), these benefits come in the form of increased opportunities for community engagement, as well as the regularly used recreational activities. How sense of place for the community is enabled at Manawa Karioi and the Tapu Te Ranga marae is through the many ways that people choose to engage with them.

\subsection{1 - Cross-Cultural Engagement in Space and Place}

Fundamentally, the Manawa Karioi Society was developed for ecological restoration within the space of the marae. The cross-cultural relationship between the marae and Manawa Karioi and how it contributes to the space for interaction and collaboration is the basic theme here. It contributes to the wider organising theme of community benefits by detailing the diverse and cross-cultural forms in which the community may engage with the marae or Manawa Karioi. Despite the way that knowledges may differ between the two gruops, interactions and collaboration have constructed the identity of the marae and Manawa Karioi as a place. One participant who has been involved with Manawa Karioi since its inception stated:

We adopted a strict eco-sourcing policy and took a more holistic approach, so yeah, the initial idea came from a deep, genuine appreciation of nature, but it was still a bit limited, but you know, it's one of the earliest restoration projects in the country (Participant 12)

It's likely that the original members of the Manawa Karioi Society, with their objective of ecological restoration and revegetation, will not have foreseen the co-benefits that have emerged from the relative success of Manawa Karioi. These successes extend 
to the Tapu Te Ranga marae as a result of the collaborative relationship, therefore the bi-cultural community space has the potential to command parallel benefits for both groups. This was observed from one interview where the participant from Manawa Karioi expressed why they became so heavily involved;

\begin{abstract}
I haven't been to my own tribal marae so I used to really enjoy going to Tapu Te Ranga marae. The marae is really contemporary, inclusive for the community - Ngā hau whā so it's for everybody. I just affiliated with it, and it was in my neighbourhood, so I just used to go there all the time (Participant 5)
\end{abstract}

As the two organisations of the Tapu Te Ranga marae and the Manawa Karioi Society create a space together, this enables a cultural exchange through community-based conservation and having a shared, caring relationship with the whenua and ngahere (bush). This quote supports the reciprocal appreciation between the two groups but also further highlights the importance of interactions and collaboration in constructing a sense of place. For Participant 5, the Tapu Te Ranga marae contributes greatly to their own perception of identity at Manawa Karioi, as it ties into their own cultural worldview. The relationship between the two groups not only serves as a space for cross-cultural interaction, but as a space that also facilitates cross-cultural collaboration. When I spoke to participants from the marae, they spoke of the importance of Manawa Karioi and the significance of their relationship with the whenua:

That's really the heart of [Māori environmental relationships]. That's really the heart of it, of our attitude towards the land, and attitude towards the people (Participant 11)

We do rongoā workshops where we take people up the maunga [mountain], identify different rongoā Māori, Māori medicine, um all thanks of course to Manawa Karioi. So it's a free clinic that we run every week where members of the community who need help but want to go back to using traditional, sourcing the rongoā (Participant 10) 
Yeah. I think the ngahere (forest) plays a huge part in reconnecting

Māori to their Māoritanga in so many different ways (Participant 10)

These quotes by members of the marae detail an insight into the opportunities the marae presents for Māori. It also prevents opportunities for other individuals who do not identify with Western perspectives on environmental management, and who are seeking new opportunities to engage with the environment in a different cultural setting. Furthermore, a history of colonialism has created a large disconnect for Māori and their cultural connections with the environment (B. Coombes, 2003). As stated in the second quote, the whānau of the Tapu Te Ranga marae enjoy providing and promoting rongoā clinics, not only as a form of connecting with their own tikanga values, but to allow others from the community to do the same.

The relationship between the Tapu Te Ranga marae and Manawa Karioi, the whenua and the society, shapes opportunities for cross-cultural learning. Volunteers from the Manawa Karioi Society, particularly volunteers who may be from other ethnic groups are able to expand their knowledge. This is not only through learning Western techniques for biodiversity and ecological restoration, but also the in the embedded tikanga that informs the relationship between the Tapu Te Ranga marae and the whenua of Manawa Karioi. Learning opportunities for the community such as these, allow for broader understandings of the environment, as well as the promotion of Indigenous environmental values in society. Place is further formed through these opportunities for the community to engage with nature. Cross-cultural interactions allow for such engagements to take place, and to shape different ideas of nature. Through these practices identities of place are formed.

\subsection{2 - Recreational opportunities}

Manawa Karioi is utilised by many members of the community. This is the final basic theme from the organising theme of the wider community benefits. The Tapu Te Ranga marae and therefore the Manawa Karioi Society are happy to allow for recreational activities in addition to the walking tracks; dog owners are especially encouraged to bring their dogs to Manawa Karioi. In this situation the Tapu Te Ranga marae still hold authority over the whenua, however, due to their collective community kaupapa, both groups agree that Manawa Karioi should be publicly accessible. 
I think the fact that we are actively looking to encourage people to recreate there. I'll tell you one specific thing that I really love is that the fact that we feel confident enough to actually invite people with walking dogs because there are a lot of conservationists that hate dogs and think that people with dogs are kind of like the enemy. And that's such a destructive attitude because dog walkers probably make up about half the visits to our natural areas. And this was one of the nice things that came about having interaction between the different southern groups. So there are some areas in particular the dune areas where dogs are really bad news and some of the dune groups have had terrible experiences with dog owners. So, we can actually encourage dog walkers and say, look, how about bringing your dogs here? We welcome you and we'd rather that you came here than that you walked your dogs on the beach or in the dune areas. And I think that's really neat and it's one of the real, really tangible benefits of looking wider than just group by group (Participant 8)

Recreational use of Manawa Karioi was also portrayed in the interviews to influence volunteer participation for the society. Two participants stated that using Manawa Karioi as a space for running has sparked their interest in the ecological restoration and thus, they decided to attend the working days:

Yes, so I've been flatting in Newtown, Berhampore, and so it was really close to my house. I could just bike around there really easily, and I already knew the area from running there as well. So, I'd already felt I guess an affinity with that land from running around the outside of the area up through the Mornington hills on some of the tracks (Participant 3)

Other events that have been held at Manawa Karioi in recent times have been a Matariki guided tour, as well as the Mental Health Awareness Picnic. Matariki is now a widely celebrated event in Aotearoa New Zealand as it culturally recognises the changing of seasons. This too also supports the cross-cultural nature of Manawa Karioi and the interactions which shape place through the networks of relationships. The participant who helped organise the Matariki guided tour spoke of their experience: 
Oh yeah, the guided walk. Yeah so we've done guided walks maybe three or four times since I've been there and they're quite popular. The first one we did, I find them easier to promote. But the first one we had it was a really nice day and it was in conjunction with the Island Bay festival and we got 90 people. I was just going crazy promoting it because I kind of enjoy the challenge (Participant 5)

The recreational benefits which Manawa Karioi provide are diverse. For the community, Manawa Karioi acts as a form of a public good where people are able to enjoy the bush by walking, running or biking. It also remains accessible for dog walkers which in turn takes pressure off other community-conservation projects. The events hosted by the marae or the Manawa Karioi Society provide social benefits where people may come and enjoy learning.

\section{5 - Summary}

The findings presented for this research detail the four significant organising themes to come out of the qualitative semi-structured interviews: the Tapu Te Ranga marae - Manawa Karioi relationship, the volunteers of Manawa Karioi, wider community relationships and the wider community benefits. The Manawa Karioi relationship has been identified as the most significant theme for cross-cultural community-based conservation. The remaining basic themes have been identified as significant as they link in diverse ways to this relationship. The participants of the interviews all spoke of aspects of their experiences volunteering at Manawa Karioi and their personal reflections on the relationship with the Tapu Te Ranga marae. The research question, what kinds of relationships form around community-based conservation on Māori land? is answered through the participants' expressions of their experiences. The examples provided through the themes display a brief snapshot of how Manawa Karioi interacts with the Tapu Te Ranga marae, as well as the Sisters of Compassion and other community and local institutions. The experiences detailed by participants are but a few of the many people who have had input at the marae or the Manawa Karioi Society. 
In the following discussion chapter these themes will be analysed to provided nuanced detail as to how they feed into the Tapu Te Ranga marae - Manawa Karioi relationship. The themes are diverse and therefore give weight to the relationship in diverse ways. Additionally, not all the remaining basic themes give equal weight to the relationship, yet still remain integral as inputs. The discussion chapter will present the ways in which the Tapu Te Ranga marae-Manawa Karioi relationship and these remaining basic themes play a larger role in decolonising community-based conservation. Analysis through the lens of poststructuralism and political ecology will also highlight how the altered perception of nature which the relationship engenders heavily contributes to decolonisation. 


\section{Chapter 5 - Discussion}

The purpose of this discussion chapter is to analyse the key findings of my research on community-based conservation at Manawa Karioi and connect these key findings with existing literature. The unique and important relationship between the Tapu Te Ranga marae and the Manawa Karioi Society is a key organising theme prominent within this research. Additional organising themes identified in this research are also important and are a part of this relationship. Additional organising themes include: the volunteers of Manawa Karioi, the wider community relationships which are formed and lastly, the wider community benefits. These themes contain specific elements to support the relationship between Tapu Te Ranga marae and the Manawa Karioi Society, and play a role in forming place out of space.

This discussion chapter will utilise the conceptual frameworks of poststructuralism and political ecology, stated in the methodology chapter (3), to analyse the significance of the Tapu Te Ranga marae - Manawa Karioi relationship. The various organising themes for this research are constructed out of smaller basic themes in relation to the network analysis map as presented in Figure $\mathbf{7}$ in the methodology chapter. This research will describe how each aspect feeds into the central theme of the relationship. In doing so, I will explore the importance of collaborative relationships; especially ones providing cross-cultural opportunities, and the significance for community-based conservation.

A Poststructuralist approach to nature enables an examination of how different common sense(s) are stabilised at different times how other truths form the constitutive outside (Braun \& Castree, 2005; Escobar, 1996). This is particularly apparent in (post)colonial contexts where Indigenous knowledges have been sidelined (B. Coombes, Johnson, \& Howitt, 2013). This research with the Tapu Te Ranga marae and the Manawa Karioi Society allows for insights as to how different networks of connection between different relationships has constructed sense of place. Such connections are fluid and have existed differently through temporal periods. Therefore, place also exists fluidly over temporal periods (Cresswell, 2012). The interviews I conducted with participants from the Manawa Karioi Society and the Tapu Te Ranga marae, provided diverse insights and perspectives about many aspects of the Manawa Karioi Ecological Restoration Project. Viewed through a political ecology lens, Escobar (1996) maintains that it is the politics and power 
relations involved in such relationships which assist in framing connections between society and nature.

The first section that will be discussed for this chapter will be on the relationship between the Tapu Te Ranga marae and the Manawa Karioi Society. This part will look to address the current relationship connections which have occurred and exist within the Tapu Te Ranga marae - Manawa Karioi space, and how such connections contribute to construct a sense of place there. The remainder of the chapter will detail aspects from the other key themes and how they have played a role for the relationship, in the past or currently.

\section{1 - Decolonising Practices: The Tapu Te Ranga - Manawa Karioi}

\section{Relationship}

This research seeks to address the colonial environmental history in Aotearoa New Zealand. It has done this so far at a community level. As introduced in chapter 2.3.1 of the Literature Review, Global trends in the late 19th century influenced the establishment of many protected areas (Büscher \& Whande, 2007). Aotearoa New Zealand followed in this fashion. Many national parks have been established since this form of fortress conservation was first implemented by the government. Today Aotearoa New Zealand has thirteen different national parks across the country (Blue \& Blunden, 2010). As a result of protected areas under the Aotearoa New Zealand conservation estate, many Māori have suffered, have been marginalised, and have been subordinated (Blue \& Blunden, 2010). It is important to acknowledge that due to colonial imperialism, conventional conservation in most forms in Aotearoa New Zealand is informed by Western knowledge and technocracy (Ginn, 2008).

The participants from the Manawa Karioi Society who took part in this research also demonstrated strong in-depth knowledge of biodiversity and ecologies, fields underpinned by Western epistemologies of nature and science. Such knowledge and the way it is represented in space is a reflection of the relationship between the marae and the society (Murdoch, 2005). This reflection and the way that knowledge is represented constructs the identity of place at the marae - Manawa Karioi space.

The relationship between the Tapu Te Ranga marae and the Manawa Karioi Society demonstrates ways in which decolonising practises take place through communitybased conservation. All Manawa Karioi participants who took part in the research 
spoke about their appreciation for the marae in enabling the society's activities and the chance to engage in conservation. Perhaps most significantly though, all Manawa Karioi participants acknowledged that conservation occurs on private marae land, and therefore are grateful to be invited and hosted by the marae to undertake it. Similar views were also stated when speaking with the whānau members of the Tapu Te Ranga marae. They spoke of their gratitude towards the volunteers of Manawa Karioi, for all their work for ecological restoration. This rich and unique cross-cultural relationship between the Tapu Te Ranga marae and the Manawa Karioi Society is the most significant theme to come from the research findings.

The theme of the cross-cultural relationship at Manawa Karioi is the most significant, as it provides an example which conflicts with many of the discursive constructs formed through Aotearoa New Zealand's colonial history of conservation. Many of the fundamental dynamics of the Tapu Te Ranga marae - Manawa Karioi relationship illustrate this, such as how conservation occurs on Indigenous, Māori land, but is undertaken by a different organisation. Furthermore, the relationship exemplifies a cultural reciprocity whereby both groups contribute to and gain from the relationship in diverse ways. The relationship as it exists in this way represents a set of decolonising practises within the marae - Manawa Karioi space as it shifts power and resources away from Pākehā and Western centred norms towards Indigenous people, worldviews and institutions.

Decolonisation can be defined as a process by which power and self-determination is transferred back to cultures or ethnicity who have been subordinated under historical colonial and neo-colonial regimes (Rothermund, 2006). Huygens (2011) describes, in her work "Decolonisation work for settler colonisers", key practices on how 'settler coloniser decolonisation' could appear (p.73). The practices presented include:

1 "Revisiting the history of the settler coloniser relationship with Indigenous people;

2 Sharing and supporting emotional responses to a shift in worldview about the colonial relationship;

3 Building a critical sense of cultural collectivity among settler colonisers;

4 Working towards accountable, mutually agreed relationship between Indigenous and settler coloniser peoples" (Huygens, 2011, pp. 73-74). 
Based on Huygens' (2011) key practices above, and from the identified key themes in the literature, the Tapu Te Ranga - Manawa Karioi relationship exemplifies aspects of a decolonised relationship. Although specifically, I have not learned that the Tapu Te Ranga - Manawa Karioi relationship has addressed the first aspect (1) 'revisiting the history of the settler coloniser', the remaining aspects (2) 'sharing and supporting responses to a shift in worldview about the colonial relationship, (3) building a critical sense of cultural collectively among settler colonisers, and lastly, (4), working towards accountable, mutually agreed relationship between Indigenous and settler coloniser people, all seem to have occurred to a certain extent at the Tapu Te Ranga - Manawa Karioi space.

Nkrumah (1966) describes a broad definition of neo-colonialism as colonial practices which still remain prevalent in society. Although the marae exists in what can be still considered a neo-colonial society, the Tapu Te Ranga - Manawa Karioi relationship has aspects of decolonising practices. Hence, the case study of the Tapu Te Ranga marae and the Manawa Karioi Society addresses the main research question, by showing that community-based conservation can form decolonising relationships through community-based conservation on Māori land. It also goes further in that knowledge which is formed and generated by one group is seen as being equal to that of the other. However, in making this argument I acknowledge that, as a Pākehā researcher with limited relationships to the Tapu Te Ranga whānau, it is not for me to adjudicate or diagnose decolonisation. Rather, by drawing on Huygens' (2011) "practices", this research does demonstrate a decolonising process at work.

The Tapu Te Ranga - Manawa Karioi relationship is significant as it challenges (post)colonial conservation norms by acknowledging cultural knowledge and land tenure within community-based conservation. In addressing barriers and bridges for co-management, Spaeder and Feit (2005) speak of land tenure arrangements and social relations of land users as key themes in literature. When speaking with one of the whānau participants of the Tapu Te Ranga marae, this person expressed their appreciation of the work that is done at Manawa Karioi:

Yeah. I think the ngahere [trees] plays a huge part in reconnecting Māori to their Māoritanga in so many different ways. (Participant 11)

Another participant also spoke of the community workshops hosted at the marae for education in Māori rongoā Gardens: 
Rongoā in my head is really simple. We've been using it for a long time, in the last, since the fifties when everyone moved to the city, we lost touch with it and we are just starting to reconnect. What's interesting about rongoā is that it will grow wild wherever the people need it. There was rongoā here before Manawa Karioi and the reforestation project, but what they've done is created an environment where it absolutely thrives. (Participant 10)

Participant 11 from the marae also spoke of land ownership and the appropriate way the land has been returned back to Māori:

[t]he whole land was given to them by the local Māori's (sic) at the time so it's kind of fitting that they give it back. (Participant 11)

Land tenure and social relations of land users as stated by Spaeder and Feit (2005) also act as key themes in the marae - Manawa Karioi space. Whānau Participant 10 states the impacts of colonial and neo-colonialism for Māori culture through previous disconnection from the ngahere (trees). This statement is a reflection of Māori disconnection from cultural relationships with the environment produced by colonial and neo-colonial constructs (B. Coombes et al., 2013). Participant 10 also expresses however that the decolonising practices which occur at Manawa Karioi contribute to reconnecting Māori to their Māoritanga (Māori cultural worldview). Moreover, the reference by Participant 11 in regard to the return of land tenure also supports that decolonising practices have been occurring through the relationship with the Sisters of Compassion and the marae.

Again Huygens' (2011) settler decolonising framework may be applied here. The second and third features of "[s]haring and supporting emotional responses to a shift in worldview about the colonial relationship (p. 74)" and also "[b]uilding a critical sense of cultural collectively among settler colonisers (p. 74), are exemplified through the decolonising practices in the marae space. The whānau utilise rongoā as a way to reconnect Māori to back to the whenua (land). While small, this example is significant, as it is recognised by all groups that the land belongs to the marae. Manawa Karioi support this by contributing to decolonising practices through the work and cultural understanding that community-based conservation serves at the marae. The theme of social relations and land tenure presented by Spaeder and Feit (2005) also occurs 
through this second and third aspect of decolonising practices presented by Huygens (2011) in the marae - Manawa Karioi space.

In addition, reconnecting Māori with their environmental relationships through examples of rongoā, Participant 10 also addresses the way decolonising practices enable traditional Indigenous practices. The rongoā gardens are another example of the way that the marae asserts their own traditional values to the whenua of the Manawa Karioi space. Although the Manawa Karioi Society do not play a role in the rongoā workshops, the relationship and therefore the decolonising components of their relationship further enables the marae to be self-determining in the way they wish to apply traditional practices. Huygens' (2011) third aspect of building a sense of cultural collectivity is again relevant here. Both groups respectfully interact in the same space and contribute to decolonising practices in the overall space of the marae, Manawa Karioi land.

Sense of place is created at the marae through such small but significant aspects of decolonising practices. Cresswell (2012) refers to how place is formed by asserting that it "is constructed through relations to an outside that is always simultaneously part of it (p. 221). The way in which the relationships between the Sisters of Compassion, the Tapu Te Ranga marae, and the Manawa Karioi Society have been maintained and existed over time has contributed to constructing an identity of place. Place may exist differently for those who engage with the marae or Manawa Karioi. In this sense, the networks of connections support how decolonising practices enable, the marae - Manawa Karioi space constructs place.

Community-based conservation and co-management relationships that enable decolonising practices as demonstrated, have the ability to address the colonial and neo-colonial constructs for conservation in society (Castro \& Nielsen, 2001). Moving away from centralised fortress conservation to methods which empower communities and promote self-determination for Indigenous peoples, as described by Huygens (2011), are forms of addressing histories of inequality and pave paths for better participation for diverse cultures in local community-based conservation projects. The next section of this discussion chapter will explore the notion of the Tapu Te Ranga Manawa Karioi relationship as a decolonising process. In doing so I will examine through poststructural and political ecology ideas, what a decolonised relationship means for constructed notions of nature at Manawa Karioi. 


\section{$\underline{5.2 \text { - Poststructural and Political Ecology Analysis at Manawa Karioi }}$}

Perceptions of nature at Manawa Karioi are constructed through its own diverse sets of discursive practices. The relationship which Bruce Stewart and the Tapu Te Ranga marae have had with the Sisters of Compassion has influenced these discursive outcomes. The relationship and the networks of connection between the two neighbouring groups has contributed to forming place out of space at the marae. The concept of geometries of power is described by Massey (2012), as the way we seek to analyse how diverse groups or individuals are placed in relation to flows of connection. Massey (2012) also goes further to detail that a progressive sense of place may have certain character of its own, yet it is far from a single sense of place which everyone shares. Rather, a progressive sense of place is related to a person's sense of identity towards sense of place. "If it is now recognized that people have multiple identities, then the same point can be made in relation to places (Massey, 2012, p. 65). At the marae and Manawa Karioi, this is very applicable in the way that many people utilise the space differently based on their own identity and relational connection to the whenua.

The relationship between the marae and Manawa Karioi illustrates a power dynamic where the marae holds full autonomy over their whenua, while also devolving a certain degree of power to Manawa Karioi. Power in this form for the Manawa Karioi Society allows them to implement conservation in a self-sufficient way. However, this form of power is not fully autonomous. The Manawa Karioi Society demonstrates a respect for the relationship they have with the mare. All decision making concerning the marae is always a collaborative process between both groups. The geometries of power between the marae and Manawa Karioi are balanced; the society is free to work but also respects the marae space it operates within.

Support from wider community relationships come into political ecology examinations here. In supporting Bruce and the kaupapa of the marae, the Sisters of Compassion demonstrate a supportive role in enabling the marae to be self-determining and autonomous. The relationship between the marae and the Sisters was described by one interviewee who was heavily involved in the establishment of Manawa Karioi. This participant spoke of how one of the Sisters was also involved on the Manawa Karioi committee: 
Sister Loyola was the only who really got involved. I mean, we had good relationships with sister Margaret and Sister Anne. But it was Sister Loyola, she was the one who would come to the meetings and be involved. (Participant 2)

Contributions by the Sisters, and specifically the support of Sister Loyola, demonstrates the significance of the reciprocal relationship with the marae. The geometries of power (Massey, 2012), within this relationship have contributed towards constructing a sense of place at the marae. The acceptance, respect, and acknowledgement for the marae kaupapa (principles or ideas) shown by the Sisters has in itself been one of the first decolonising practices. Additionally, the gesture of the Sisters in gifting the remaining land to the marae has allowed a shift in neo-colonial power over the whenua.

Examples of how these relationships have contributed to different understandings of nature are evident, as often the marae plays host to visitors who also engage with Manawa Karioi. This may be primary schools who stay at the marae and are taken for a guided tour of Manawa Karioi. As such, visits are entangled with cross-cultural learning; children are exposed to different knowledges that contribute to building and constructing social perceptions of nature. The marae and Manawa Karioi are not limited to school visits. Other visitors who might engage are manuhiri (guests) who are often invited to engage with the whenua of Manawa Karioi. Participants during the interviews told of how some manuhiri even take part in a working bee as a koha back to the marae. Engagement opportunities for community members highlight the way in which visitors are able to engage in different forms at Manawa Karioi, as well as the diverse people who also play a role in constructing a sense of place.

A cross-cultural representation of nature at the Manawa Karioi is significant as it allows for many community benefits. It can influence other community groups and provide alternative avenues for environmental engagement for people. It could be argued that the Tapu Te Ranga - Manawa Karioi relationship provides cultural and social equity through bi-cultural engagement. An example of this is a Māori member of the Manawa Karioi committee who became involved while looking for a cultural space with which to engage. Other examples include community engagement through the rongoā garden workshops hosted by the marae, visiting schools, or other visiting manuhiri. Furthermore, drawing attention to Māori knowledge and environmental 
relationships may aid 'decolonising practices' for other community-based conservation projects in Aotearoa New Zealand.

The Manawa Karioi Ecological Restoration Project provides ways in which crosscultural relationships for community-based conservation may reconstruct perceived notions of nature. For many of the community-based conservation groups, Manawa Karioi represents a nature in which both cultural values and Western practices are instilled. In the following section, I will briefly detail how the key findings of the Tapu Te Ranga marae - Manawa Karioi cross-cultural relationship, as well as the additional themes which feed into the relationship, challenge or confirm findings from existing literature. Examination of the diverse findings from a poststructural and political ecology perspective, both affirm and challenge literature on conservation

\section{3 - How do these key findings confirm or challenge existing literature?}

The case study of Manawa Karioi is a unique example of community-based conservation in Aotearoa New Zealand. The key findings drawn from this research both support and challenge existing literature surrounding community-based conservation and cross-cultural relationships. Global conservation for comanagement and collaborative relationships is explored extensively by many academics. Waylen, Fischer, Mcgowan, Thirgood, and Milner-Gulland (2010), also state that successful community-based conservation, which engages in cross-cultural relationships, is greatly influenced by local and cultural contexts. Local and cultural context plays a large role in relationships and conservation outcomes. Waylen et al (2010) assertions holds true for the Manawa Karioi case-study. The Tapu Te Ranga marae space has been influenced through the local context and culture, the relationships with the Sisters and a community-based conservation society which all shape how sense of place is perceived by people.

How and why empowering communities though conservation is necessary is determined by Armitage et al. (2009). Building trust with communities through development and social learnings is a key way of improving understandings of complex socio-ecological systems and ways to respond to them (Armitage et al., 2009). Communities who have close bonds with their environments often demonstrate in-depth understandings to the complexities of local socio-ecological systems (Berkes, 2009). This research also found similar themes, confirming the importance 
of the volunteers who not only participate in the project, but who also convey adequate knowledge in both the cultural and ecological context.

\subsection{1 - Volunteers and the cultural context}

The second organising theme to support the wider cross-cultural relationship theme is the importance of the people who give their time to partake in community-based conservation at Manawa Karioi. Natcher et al. (2005) emphasise the importance of re-centering Indigenous peoples and communities in conservation in the wake of ever-growing globalisation and environmental degradation. At Manawa Karioi the volunteers are a vital aspect of maintaining a cross-cultural relationship, confirming existing literature (e.g. Waylen et al., 2010), which states that project engagement within the cultural context can be an integral aspect of cross-cultural relationships. Waylen et al. (2010) state that "interventions are more successful if they can understand and respond to local institutions and culture. Interventions which ignore traditional values and beliefs are less likely to succeed" (p. 1126). The Manawa Karioi committee relies on a core of volunteers and their inputs to operate and respond to institutions and culture. Such inputs include: a cultural respect and appreciation for the marae and the opportunity to partake in community-based conservation, knowledge of biodiversity and ecology, and administration skills to contribute to the direction of Manawa Karioi as a restoration project. It is these volunteers who maintain engagement with local institutions for support in enacting conservation. They respect and acknowledge the Tapu Te Ranga marae in these engagements, and this means institutions respond in ways that are culturally appropriate for the marae and Manawa Karioi. Perhaps most important, however, is having volunteers who have the ability to contribute to and maintain the cross-cultural relationship.

The Tapu Te Ranga - Manawa Karioi relationship possesses characteristics of effective volunteer support, as well as a reciprocal respect for the knowledge and effort by both groups. Such aspects of the Tapu Te Ranga - Manawa Karioi relationship are also supported by Huygens' (2011) practices for developing a decolonisation approach for settler colonisers. The relationship has witnessed challenging times when the described aspects have not been as well maintained. As volunteer capabilities change over time, cross-cultural relationships within community-based conservation appear to be fluid and take on different forms over time. 
The theme of volunteers at Manawa Karioi supports Natcher et al. (2005), who state that understandings of cultural values in cross-cultural co-management is essential for relationships, and conservation success. However, the specific case of the Manawa Karioi case study highlights significant aspects of how such a relationship occurs, which are not acknowledged within the literature. J. S. Brooks, Waylen, and Mulder (2012), maintain that because of the diverse nature of community-based conservation, the national context, community characteristics and project design, specific aspects that are often subtle may remain understated. Although many of the dynamics of the Tapu Te Ranga - Manawa Karioi relationship remain specific to the context, they might be applicable as a point of reference for other community groups in New Zealand who wish to undergo or partake in cross-cultural relationships.

\subsection{2 - Community relationships for conservation}

The theme of community relationships is the third prominent organising theme produced in the findings of this research. Again, literature considering this theme demonstrates the specific and unique context of this case study. Berkes and Ross (2013) introduce the concept of socio-ecological resilience as the ability of complex social and ecological systems to adapt to, or endure, disturbances. A system's ability to absorb or adapt to such disturbances may determine the degree of resilience it has (Walker, Holling, Carpenter, \& Kinzig, 2004). The community relationships that have been developed with the Tapu Te Ranga marae and the Manawa Karioi Society demonstrate socio-ecological resilience.

Socio-ecological resilience is apparent through the co-managed relationship at the marae - Manawa Karioi space, where conservation is carried out with diverse knowledge. The understanding that conservation there plays a part not only for advancing ecology and biodiversity but also the social systems which assist or gain from them (Berkes \& Ross, 2013). The relationships developed with other communitybased conservation groups in the area illustrate how knowledge sharing and the support for one another can build 'horizontal' resilience across communities (Berkes, 2004). These wider relationships through networks of connection formed in the marae space build collective support for community-based conservation in the area and therefore also form resilience for community-based conservation. Other institutions in the area like the Wellington City Council and Forest and Bird have also contributed through the regular donation of native seedlings and therefore add to the networks of connection. 
Berkes (2004), supports Walker et al. (2004), and goes further by stating that social systems, as well as ecological systems, are inherently intertwined and therefore both must be resilient in order to maintain sustainability. As presented in the findings, the cross-cultural relationship between the Tapu Te Ranga marae and Manawa Karioi is one which holds various versions of knowledge.

Resilience is embedded in the relationship through the diversity of such knowledge which underpins the relationships and therefore community-based conservation remains resilient too. The kaupapa of the marae acknowledges that their social and environmental relationships are also inherently intertwined and therefore they seek to maintain both at the marae space. This can be seen in the next section where community benefits have been evident through bi-cultural outcomes.

\subsection{3 - Community Benefits for conservation}

The final theme is the community benefits from cross-cultural community-based conservation. Brockington et al. (2012), explore aspects of greater democratic and ecological outcomes through the devolution of power and decentralisation for resource management. Devolved power to communities provides equitable distributions of benefits for those communities, brings more local knowledge to management decisions, reduces transactions costs for resource management, and promotes an environmental consciousness within communities (Brockington et al., 2012). Other benefits include outcomes for volunteers, for the environment and for wider communities, the benefits of collaboration with other community groups, as well as the self-determination it provides (Higgs, 2012). Although the Tapu Te Ranga marae - Manawa Karioi relationship exemplifies many of these themes, there are various contextual and tangible benefits for the Island Bay community which are not covered in literature on conservation and natural resource management.

Many of the community benefits stated by Brockington et al. (2012), and Higgs (2005) in 2.4.4, are relevant for this case study. However, the aspects which will be discussed in regard to the marae - Manawa Karioi present additional insight to academic understandings of the benefits of community-based conservation. One such key aspect that supports the marae - Manawa Karioi relationship is the reciprocity of learning and acknowledging the cultural values of the relationship. At Manawa Karioi, the marae and the society host community events such as the Matariki guided tour of 
Manawa Karioi held in the month of June 2018. The mental health awareness picnic is another example. Events such as these continue to engage people in the Island Bay community and to develop their relationship with nature. In doing so, the relationship adds to the cultural dimension of the socially constructed perception of nature at Manawa Karioi.

Additional significant community benefits that have been identified in the findings are the recreational opportunities to engage with Manawa Karioi. Dog walkers, runners, mountain bikers and casual walkers are welcome and regularly use the space. Literature in the context of Māori-Pākehā relationships for conservation has mainly considered the relationship between Iwi and the New Zealand Government (B. Coombes, 2005). Taiepa et al. (1997), further support this by explaining that in Aotearoa New Zealand many co-management relationships have occurred at a state - iwi level, as this has been the most efficient form of addressing Treaty settlement grievances. The specific context of cross-cultural community relationships between Māori and Pākehā, on (private) marae land and how it differs to existing literature, could be expanded on in future studies. The more successful the community-based conservation at Manawa Karioi, the more volunteers have engaged, the more the cross-cultural relationship has become evident, and the more the marae has been able to express their cultural values. This is seen in some of the workshops the marae holds for the community such as the rongoā gardens mentioned in the findings. In this way, the relationship, in its various stages, is an example of the cross-cultural and ecological success that has been achieved within the marae space between the Sisters of Compassion, the Manawa Karioi Society and the Tapu Te Ranga marae.

This research aligns with existing literature by highlighting specific ways in which community-based conservation has opportunities for cross-cultural relationships in Aotearoa New Zealand. In this sense, the context of the case-study is meaningful in that it shows the way that relationships occur in a particular space. Moreover, the example of Tapu Te Ranga, as an urban marae is unique and therefore may provide a context which might be very different to any other community cross-cultural relationship. The skills and knowledge which communities have to maintain engagement, the time and resources for volunteers and the ability to develop relationships with other community groups and institutions, also play key roles. 


\section{4 - Poststructural, political ecology - relationship with existing}

\section{literature}

A poststructural analysis of the relationship between the Tapu Te Ranga marae and the Manawa Karioi Society sheds light on how knowledge is situated within this collaborative partnership. This analysis highlights how through language, knowledge and their own set of discursive structures that have taken place, a socially constructed view of nature at the marae is shaped. The gap in the literature which this research fills is the cross-cultural nature of the relationship being integral to its success, as well as the many wider benefits community-based conservation produces. The dynamics of respect and reciprocity advance this relationship greatly. It is these aspects of political ecology occurring at the marae and Manawa Karioi that this research responds to. They both confirm and challenge existing literature in poststructuralism and political ecology.

Political ecology is a body of theory which seeks to examine how contrasts in power relations often drive ecological issues. Moreover, political ecology also considers how ecological issues exist within politics (Bryant, 2001). B. Coombes et al. (2012) consider the domain of Indigenous and postcolonial geographies, as many Indigenous communities struggle for autonomy and land rights over environmental resource management. They argue the political interactions between governments, large (sometimes corporate) institutions and Indigenous communities, often illustrate Western policies in advancing capital flows and trade, or in the establishment of protected areas for conservation (B. Coombes et al., 2012). Such institutions are often ambivalent towards Indigenous people's culture and land rights, and therefore advance social inequalities and environmental degradation (B. Coombes, 2007). Examples of case studies within political ecology literature often focus on countries and Indigenous communities of the Global South (Bailey \& Bryant, 2005). Manawa Karioi provides a different context. New Zealand is a colonial state, and therefore has neo-colonial characteristics of environmental management.

The first aspect of the findings to consider in relation to literature on political ecology is the security of tenure which the Tapu Te Ranga marae has over the land. Sole ownership of the land has meant that the Tapu Te Ranga marae holds full autonomy over their whenua. Conservation occurs because the marae hosts the Manawa Karioi Society. The relationship highlights how cross-cultural relationships can be achieved. 
This challenges the examples provided by political ecologists, which usually show difficulties caused by power relations.

The Sisters of Compassion and the role they have played in forgiving the marae debt, are a unique feature of this research and not found the academic literature. Reparative treaty settlements are a process of redress for Māori in Aotearoa New Zealand who have suffered land loss and cultural marginalisation (Lashley, 2000). Treaty claims and settlement processes are administered by the Waitangi tribunal not only for land reparation but also for self-determining rights (Taiepa et al., 1997). Debates on whether the conservation estate in Aotearoa New Zealand adequately serves Māori through Treaty grievances is argued by Taiepa et al. (1997) as still ongoing. B. Coombes et al. (2012) assert that "environments which are implicated in co-management are often complex or subject to rapid change (p. 813). Despite many settlements for Māori, community aspirations for resource management are rarely addressed (B. Coombes et al., 2012).

The outcomes of the relationship between the marae and the Sisters has meant that the whānau has avoided such complex engagements with state institutions. The security of land tenure at the marae demonstrates that the co-management is less than conventional in this space. The reciprocal relationship they have with the Manawa Karioi Society is a further reflection of the respectful partnership they have. The reciprocal relationships between the groups highlights how decolonising understandings of nature are facilitated through the marae.

Ownership of the land allows full autonomy and self-determination for the marae whānau. This finding is consistent with the literature studied. B. Coombes et al. (2013) describe the importance of autonomy and self-determining values by maintaining "[w]hile they will not always achieve broader solidarity, Indigenous conceptions of responsibility and autonomy provide lessons about how to ground activism in placebased politics, a basis for alliance-building and shared visions of decolonization ( $p$. 693). The Tapu Te Ranga marae's relationships demonstrate autonomy through the alliance-building with the Manawa Karioi Society and the Sisters of Compassion. The marae also has additional projects which enable them to exercise their selfdetermination. This research supports ideas in the literature such as Berkes (2004) who promotes autonomy for Indigenous communities in local resource management through the additional benefits outlined. 
Although this case study, which is located in the Global North, and does not necessarily align with research examples of the Global South, it does support themes in the literature specifically around community-based conservation success. The case study for this research provides a unique context for community-based conservation in Aotearoa New Zealand. While marae in many parts of Aotearoa New Zealand provide and contribute to communities in many different forms, Kenney and Phibbs (2015) state that existing literature in Aotearoa New Zealand has not as yet examined how community relationships support community-based conservation or the community benefits which are produced.

\section{Summary}

This discussion chapter details the key findings in relation to the conceptual theories of poststructuralism and political ecology. The findings provide an insight into what kinds of relationships form around community-based conservation on Māori land, through the relationships between the Tapu Te Ranga marae, the Manawa Karioi Society and the Sisters of Compassion in Island Bay, Wellington. The context of the case-study means that the key findings for this research are distinctive. Research on cross-cultural relationships for community-based conservation in other areas may result in very diverse findings. What could be consistent, however, is the way in which nature is constructed cross-culturally within space to create a sense of place. The research therefore provides a means for diverse cultural aspects to be included in how this takes place. This may provide similar outcomes to the findings of this research, where the cross-cultural relationship is identified as being the most significant.

In this chapter I addressed the sub-question for this research: do these relationships around community-based conservation contribute to a decolonising understanding of nature? The kaupapa of the marae is central to decolonising understandings of nature. The marae and the Manawa Karioi Society have a series of different relationships with wider community groups which form networks of connection. These relationships are reciprocal and are underpinned by diverse knowledges. The reciprocity of the relationships and the diversity of knowledges contribute to the decolonising understandings of nature. In the following conclusion chapter, reflection of this research process will present the strengths and weaknesses, as well as what implications this investigation may have. 


\section{Chapter 6 - Conclusion}

In conducting this research, I have set out to understand how community-based conservation may provide for diverse relationships which exist on Māori land. The social constructivist epistemology which frames this research has supported the analysis of these relationships as socially constructed in a particular space, and over a temporal period. The additional themes to come out of this research are the volunteers of the Manawa Karioi Society, the wider community relationships, and the community benefits which are achieved at the marae.

The discussion chapter highlights the decolonising practices which are enabled through the relationship between the Tapu Te Ranga marae and the Manawa Karioi Society. The reciprocal relationship means that all volunteers understand that conservation occurs on Indigenous land, and this is a key driver for decolonising methods taking place. The long-term reciprocal relationship allows for cross-cultural views to be shared, and thus community perceptions of nature are transformed.

Te Tiriti o Waitangi (the Treaty of Waitangi) consists of principles which have the potential to underpin positive Pākehā and Māori relationships. However, Aotearoa New Zealand's colonial history has not always realised this potential. Attempts at establishing more decolonising practices within community-based conservation in Aotearoa New Zealand may contribute to reflecting such Treaty principles in society.

This research responds to the research question, what kinds of relationships form around community-based conservation on Māori land?, by highlighting the importance of various significant themes. The case study of the Manawa Karioi Ecological Restoration Project is unique as it is hosted by the Tapu Te Ranga marae. Both marae whānau and Society members described a mutually respectful relationship that has developed through conservation on marae land. This relationship has changed over time but, at the moment, it is a resilient partnership that enables knowledge sharing about nature and conservation.

Volunteers play a significant role as the Manawa Karioi committee continues to grow and transform. An understanding of the marae culture is essential for appropriate engagement and collaborative decision making. Furthermore, relationships flow out from and also through the conservation efforts, through links with other organisations 
such as wider community groups, Forest and Bird and the Council, with whom knowledge and resources are shared.

\section{1 -Reflection of the research process - Strengths and Limitations}

One limitation of this research is that I am of a Pākehā cultural background. While not in and of itself a problem, it means that I came to this research with some knowledge about working cross culturally, but with limited connections and knowledge of te ao Māori. As such, this research was framed in a particular way. I attempted to adopt a cross-cultural methodology drawing on Smith's (1990) model, where communities are deeply involved in formulating the research. Power sharing models seek to provide in-depth input by, and tangible benefits for, Māori communities (Cram, 1997).

However, due to the limitations highlighted above, my initial discussions with the marae whānau were limited. Their later involvement with this project shaped my focus and enabled me to explore themes related to cross-cultural relationships I wouldn't have been able to explore otherwise. I have sought to maintain consistent engagement with the marae throughout this research, and to cultivate strong relationships (Cram, 1997). However, I acknowledge that someone steeped in knowledge of this marae and Māori conservation approaches would have reached different findings than me, both through their greater understanding of the subject and potentially through the different kinds of knowledge that would have been shared with them.

As a result of this research process I also have become a member of the Manawa Karioi committee. Being on the committee has allowed me to gain unique insights into the relationships that surround and flow through this case study. Through this work, and my earlier contributions as a volunteer, I have also attempted to give back to the project. I hope that by providing a greater understanding of the relationship, the history, and the culture of the community-based conservation that takes place in the marae space, this research adds value to the committee and to the future of the Tapu Te Ranga marae and Manawa Karioi. 


\section{2 - Implications of this Research}

This research highlights some important features of what makes community-based conservation significant. The focus of the research is specifically on community-based conservation, yet the kind of cross-cultural relationship in this case study is not necessarily limited to conservation. This research may provide insights to other relationships or groups who seek to engage in community decolonising practices. Future research looking to explore community-based projects may seek to widen its scope through, for example, comparative studies that explore different arrangements within communities that enable decolonising practices.

This thesis has sought to uncover how particular relationships may operate within a space to form a sense of place. It sheds light on the way community relationships between Māori and Pākehā can move towards decolonising ways of being. Decolonising is always an ongoing process. Future research may further explore the idea of communities working together towards relationships which share cultural beliefs and practices, for shared benefits and outcomes. Marae in many parts of Aotearoa New Zealand provide and contribute to communities in many forms. Security of land tenure for Māori has been evident as an ultimate form of decolonisation, and an ultimate form of the self-determining principle of tino rangatiratanga. Cross-cultural community relationships that are practiced in such circumstances, which reflect shared values and provide examples of progressive relationships, may advance literature and promote examples of decolonisation.

This study of space and place, and the relationships which occur and enable social processes, is one way of attempting to understand how co-management relationships and community-based conservation are able to work together. However, future studies may wish to assess what could be further explored through a space and place analysis of relationships and community-based conservation. Possible research might wish to ask:

How can relationships advance while maintaining decolonising methods in the wake of future environmental challenges? 


\section{Summary}

Community-based conservation has much to offer local communities and their ecologies in Aotearoa New Zealand. On a global scale, community-based conservation has emerged out of alternative perspectives of resource management, which seek to divest away from centralised state-management of the environment (Berkes, 2004). The social aspects to community-based conservation mean that communities have agency in the way they engage with their natural environment (Natcher et al., 2005). For Indigenous communities, this may mean community-based conservation is a way of asserting their own cultural view of nature, and potentially gaining autonomy and sovereignty (B. Coombes et al., 2012). However, this research goes further to analyse what relationships may form around community-based conservation on Māori land. As land tenure at Manawa Karioi is held by the marae, the relationship between the whānau and the Manawa Karioi Society has been able to develop through the reciprocal elements of their connection.

The Tapu Te Ranga - Manawa Karioi relationship is underscored by reciprocal respect and recognition. Through this relationship, benefits have flowed across the wider conservation and Island Bay community. Importantly, this relationship has established a promising community based conservation scheme that enables different worldviews to coexist in space. Practices have emerged that go some way towards decolonising conservation there. There is potential to further this work, and continue to try to build on the trust that already exists. The relationship between Manawa Karioi and Tapu Te Ranga is an interesting and useful case study for thinking about the future of conservation in Aotearoa New Zealand. 


\section{Bibliography}

Adger, W. N., Brown, K., \& Tompkins, E. L. (2005). The political economy of crossscale networks in resource co-management. Ecology and Society, 10(2).

Agrawal, A., \& Bauer, J. (2005). Environmentality: technologies of government and the making of subjects.

Agrawal, A., \& Gibson, C. C. (1999). Enchantment and disenchantment: the role of community in natural resource conservation. World development, 27(4), 629649.

Agrawal, A., \& Gibson, C. C. (2001). Communities and the environment: ethnicity, gender, and the state in community-based conservation. New Brunswick, NJ: Rutgers University Press.

Angrosino, M. (2007). Doing ethnographic and observational research. London, UK: Sage.

Armitage, D. R., Plummer, R., Berkes, F., Arthur, R. I., Charles, A. T., Davidson-Hunt, I. J., . . . Marschke, M. (2009). Adaptive co-management for social-ecological complexity. Frontiers in Ecology and the Environment, 7(2), 95-102.

Attride-Stirling, J. (2001). Thematic networks: an analytic tool for qualitative research. Qualitative research, 1(3), 385-405.

Benaquisto, L. (2008). Codes and coding. The Sage encyclopedia of qualitative research methods, 1, 85-83.

Berkes, F. (2002). Cross-scale institutional linkages: perspectives from the bottom up. The drama of the commons, 293-321.

Berkes, F. (2004). Rethinking community-based conservation. Conservation Biology, 18(3), 621-630.

Berkes, F. (2007). Community-based conservation in a globalized world. Proceedings of the National Academy of Sciences, 104(39), 15188-15193.

Berkes, F. (2009). Evolution of co-management: role of knowledge generation, bridging organizations and social learning. Journal of environmental management, 90(5), 1692-1702.

Berkes, F., \& Ross, H. (2013). Community resilience: toward an integrated approach. Society \& Natural Resources, 26(1), 5-20.

Blue, L., \& Blunden, G. (2010). (Re) making space for kiwi: beyond 'fortress conservation'in Northland. New Zealand Geographer, 66(2), 105-123.

Braun, B. (2002). The intemperate rainforest: nature, culture, and power on Canada's west coast. Minneapolis, MN: University of Minnesota Press.

Braun, B., \& Castree, N. (2005). Remaking reality: nature at the millenium. New York, NY: Routledge.

Braun, B., \& Wainwright, J. (2001). Nature, poststructuralism, politics: Theory, Practice, Politics. In Social Nature: Theory, Practice, Politics: Basil Blackwell.

Breen, L. (2007). The researcher'in the middle': Negotiating the insider/outsider dichotomy. The Australian Community Psychologist, 19(1), 163-174.

Brockington, D., Duffy, R., \& Igoe, J. (2012). Nature unbound: conservation, capitalism and the future of protected areas. London, UK: Routledge.

Brockington, D., Igoe, J., \& Schmidt-Soltau, K. (2006). Conservation, human rights, and poverty reduction. Conservation Biology, 20(1), 250-252. 
Brooking, T., \& Pawson, E. (2010). Seeds of empire: The environmental transformation of New Zealand (Vol. 4). New York, NY: IB Tauris.

Brooks, J., Waylen, K. A., \& Mulder, M. B. (2013). Assessing community-based conservation projects: a systematic review and multilevel analysis of attitudinal, behavioral, ecological, and economic outcomes. Environmental Evidence, 2(1), 2.

Bryant, R. L. (2001). Political ecology: a critical agenda for change. Castree, Noel/Braun, Bruce (2001)(Eds.): Social Nature. Theory, Practice, and Politics, 151-169.

Büscher, B., Sullivan, S., Neves, K., Igoe, J., \& Brockington, D. (2012). Towards a synthesized critique of neoliberal biodiversity conservation. Capitalism nature socialism, 23(2), 4-30.

Büscher, B., \& Whande, W. (2007). Whims of the winds of time? Emerging trends in biodiversity conservation and protected area management. Conservation and Society, 5(1), 22-43.

Campbell, L. M., \& Vainio-Mattila, A. (2003). Participatory development and community-based conservation: Opportunities missed for lessons learned? Human Ecology, 31(3), 417-437.

Carlsson, L., \& Berkes, F. (2005). Co-management: concepts and methodological implications. Journal of environmental management, 75(1), 65-76.

Carter, J. L., \& Hill, G. J. (2007). Critiquing environmental management in indigenous Australia: two case studies. Area, 39(1), 43-54.

Castree, N. (2001). Socializing nature: Theory, practice, and politics. Social nature: Theory, practice, and politics, 1-21.

Castree, N. (2003). Environmental issues: relational ontologies and hybrid politics. Progress in Human Geography, 27(2), 203-211.

Castree, N. (2006). From neoliberalism to neoliberalisation: consolations, confusions, and necessary illusions. Environment and Planning A, 38(1), 1-6.

Castree, N., \& Braun, B. (2001). Social nature theory, practice, and politics.

Castro, A. P., \& Nielsen, E. (2001). Indigenous people and co-management: implications for conflict management. Environmental Science \& Policy, 4(4-5), 229-239.

Colchester, M. (2004). Conservation policy and indigenous peoples. Environmental Science \& Policy, 7(3), 145-153.

Coombes, B. (2003). The historicity of institutional trust and the alienation of Maori land for catchment control at Mangatu, New Zealand. Environment and History, 333-359.

Coombes, B. (2007). Defending community? Indigeneity, self-determination and institutional ambivalence in the restoration of Lake Whakaki. Geoforum, 38(1), 60-72.

Coombes, B., Johnson, J. T., \& Howitt, R. (2012). Indigenous geographies I: Mere resource conflicts? The complexities in Indigenous land and environmental claims. Progress in Human Geography, 36(6), 810-821.

Coombes, B. L., \& Hill, S. (2005). "Na whenua, na Tuhoe. Ko DoC te partner"Prospects for Comanagement of Te Urewera National Park. Society and Natural Resources, 18(2), 135-152. 
Corbeil, M.-C. (2015). Conservation institutions as agents of change. Studies in Conservation, 60(sup2), 32-38.

Craig, J., Moller, H., Saunders, D., \& Williams, M. (2013). Enhancing our heritage: Conservation for 21st century New Zealanders: Ways forward from the Tahi group of concerned scientists. Pacific Conservation Biology, 19(4), 256-269.

Cram, F. (1997). Developing partnerships in research: Pākehā researchers and Māori research. Sites, 35, 44-63.

Cresswell, T. (2012). Geographic thought: a critical introduction. West Sussex, UK: John Wiley \& Sons.

Creswell, J. W. (2014). Research design: Qualitative, quantitative, and mixed methods approaches. Thousand Oaks, CA: Sage publications.

Cronon, W. (1996). The trouble with wilderness: or, getting back to the wrong nature. Environmental History, 1(1), 7-28.

Davidson, A. K. (2004). Christianity in Aotearoa: A history of church and society in New Zealand: Education for Ministry.

Demeritt, D. (2002). What is the 'social construction of nature'? A typology and sympathetic critique. Progress in Human Geography, 26(6), 767-790.

Dening, G. (1989). History" in" the Pacific. the contemporary pacific, 134-139.

Dwyer, S. C., \& Buckle, J. L. (2009). The space between: On being an insider-outsider in qualitative research. International journal of qualitative methods, 8(1), 5463.

England, K. V. (1994). Getting personal: Reflexivity, positionality, and feminist research. The Professional Geographer, 46(1), 80-89.

Escobar, A. (1996). Construction nature: Elements for a post-structuralist political ecology. Futures, 28(4), 325-343.

Escobar, A. (1998). Whose knowledge, whose nature? Biodiversity, conservation, and the political ecology of social movements. Journal of political ecology, 5(1), 53-82.

Escobar, A. (1999). After nature: Steps to an antiessentialist political ecology. Current anthropology, 40(1), 1-30.

Escobar, A. (2002). Constructing Nature Elements for a poststructural political ecology: Elements for a poststructural political ecology Introduction: The Discourse of Nature and the Nature of Discourse. In Liberation Ecologies (pp. 58-80). New York, NY: Routledge.

Feeny, D., Berkes, F., McCay, B. J., \& Acheson, J. M. (1990). The tragedy of the commons: twenty-two years later. Human Ecology, 18(1), 1-19.

Fletcher, R. (2010). Neoliberal environmentality: towards a poststructuralist political ecology of the conservation debate. Conservation and Society, 8(3), 171-181.

Foucault, M. (1990). The history of sexuality: An introduction, volume I. Trans. Robert Hurley. New York: Vintage.

Gadgil, M., Berkes, F., \& Folke, C. (1993). Indigenous knowledge for biodiversity conservation. Ambio, 151-156.

Given, L. M. (2008). The Sage encyclopedia of qualitative research methods. Thousand Oaks, CA: Sage Publications.

Greene, M. J. (2014). On the inside looking in: Methodological insights and challenges in conducting qualitative insider research. The qualitative report, 19(29), 113. 
Grese, R. E., Kaplan, R., Ryan, R. L., \& Buxton, J. (2000). Psychological benefits of volunteering in stewardship programs. Restoring nature: perspectives from the social sciences and humanities, 265-280.

Hardin, G. (1968). The tragedy of the commons. Science, 162(3859), 1243-1248.

Hartter, J., \& Goldman, A. (2011). Local responses to a forest park in western Uganda: alternate narratives on fortress conservation. Oryx, 45(1), 60-68.

Heatherington, T. (2012). Remodeling the fortress of conservation? Living landscapes and the new technologies of environmental governance. Paper presented at the Anthropological forum.

Hetherington, K. (1996). Identity formation, space and social centrality. Theory, Culture \& Society, 13(4), 33-52.

Holling, C. S., \& Meffe, G. K. (1996). Command and control and the pathology of natural resource management. Conservation Biology, 10(2), 328-337.

Igoe, J., \& Brockington, D. (2007). Neoliberal conservation: a brief introduction. Conservation and Society, 5(4), 432-449.

Kim, B. (2001). Social constructivism. Emerging perspectives on learning, teaching, and technology, 1(1), 16.

Kleymeyer, C. D. (1993). Cultural traditions and community based conservation.

Kobayashi, A. (2003). GPC ten years on: is self-reflexivity enough? Gender, Place and Culture, 10(4), 345-349.

Le Gallais, T. (2008). Wherever I go there I am: reflections on reflexivity and the research stance. Reflective practice, 9(2), 145-155.

Lenzo, K. (1995). Validity and self-reflexivity meet poststructuralism: Scientific ethos and the transgressive self. Educational Researcher, 24(4), 17-24.

Little, P. D. (1993). The link between local participation and improved conservation: $A$ review of issues and experiences. Paper presented at the Conservation Workshop18-22 Oct 1993Airlie, Va.(EUA).

Longhurst, R. (2003). Semi-structured interviews and focus groups. Key methods in geography, 117-132.

Louis, R. P. (2007). Can you hear us now? Voices from the margin: Using indigenous methodologies in geographic research. Geographical research, 45(2), 130139.

Mairi Jay, \& Morad, M. (2009). Conservation and ecology. International Encyclopedia of Human Geography Elsevier., 259-267.

Manawa Karioi Society. (2019). Manawa Karioi Home Page Retrieved from https://www.manawakarioi.nz

Massey, D. (1992). Politics and space/time. New Left Review, 65-65.

Massey, D. (2005). For space. Thousand Oaks, CA: Sage.

May, T., \& Perry, B. (2010). Social research and reflexivity. Thousand Oaks, CA: Sage.

Menzies, C. R. (2006). Traditional ecological knowledge and natural resource management. Lincoln, NE: University of Nebraska Press.

Merriam, S. B., Johnson-Bailey, J., Lee, M.-Y., Kee, Y., Ntseane, G., \& Muhamad, M. (2001). Power and positionality: Negotiating insider/outsider status within and across cultures. International Journal of Lifelong Education, 20(5), 405416.

Murdoch, J. (2005). Post-structuralist geography: a guide to relational space: Sage. 
Nadasdy, P. (1999). The politics of TEK: Power and the" integration" of knowledge. Arctic Anthropology, 1-18.

Nadasdy, P. (2005). The anti-politics of TEK: the institutionalization of comanagement discourse and practice. Anthropologica, 215-232.

Nash, C. (2002). Cultural geography: postcolonial cultural geographies. Progress in Human Geography, 26(2), 219-230.

Natcher, D. C., Davis, S., \& Hickey, C. G. (2005). Co-management: managing relationships, not resources. Human Organization, 64(3), 240-250.

Oakley, P. (1991). Projects with people: The practice of participation in rural development. Geneva, Switzerland: International Labour Organization.

Otto, J., Zerner, C., Robinson, J., Donovan, R., Lavelle, M., Villarreal, R., . . Kleyneyer, C. (2013). Natural connections: perspectives in community-based conservation (D. W. a. R. M. Wright Ed.). Washington, D.C.: Island Press.

Packer, M. J., \& Goicoechea, J. (2000). Sociocultural and constructivist theories of learning: Ontology, not just epistemology. Educational psychologist, 35(4), 227-241.

Renner, M., \& Taylor-Powell, E. (2003). Analyzing qualitative data. Programme Development \& Evaluation, University of Wisconsin-Extension Cooperative Extension.

Robbins, P. (2000). The practical politics of knowing: state environmental knowledge and local political economy. Economic Geography, 76(2), 126-144.

Ruru, J. (2008). A Maori Right to Own and Manage National Parks? Journal of South Pacific Law, 12(1), 105-109.

Sallenave, J. (1994). Giving traditional ecological knowledge its rightful place in environmental impact assessment. Northern Perspectives, 22(1), 16-19.

Sayer, A. (1979). Epistemology and conceptions of people and nature in geography. In Qualitative Change in Human Geography (pp. 19-44): Elsevier.

Schroeder, H. (2000). The motivations and values of ecosystem restoration volunteers: an analysis of stewardship group newsletters. Restoring nature: perspectives from the social sciences and humanities.

Shaw, W. S., Herman, R. D. K., \& Dobbs, G. R. (2006). Encountering indigeneity: Reimagining and decolonizing geography. Geografiska Annaler: Series B, Human Geography, 88(3), 267-276.

Singleton, S. (2000). Co-operation or capture? The paradox of co-management and community participation in natural resource management and environmental policy-making. Environmental Politics, 9(2), 1-21.

Singleton, S. G. (1998). Constructing cooperation: the evolution of institutions of comanagement. Ann Arbor, MI: University of Michigan press.

Smith, L. T. (1999). Decolonising methodologies. Research and Indigenous peoples.

Spaeder, J. J., \& Feit, H. A. (2005). Co-management and indigenous communities: barriers and bridges to decentralized resource management: introduction. Anthropologica, 47(2), 147-154.

Stevenson, M. G. (2004). Decolonizing co-management in northern Canada. Cultural Survival Quarterly, 28(1), 68-72.

Stevenson, M. G. (2006). The possibility of difference: rethinking co-management. Human Organization, 167-180. 
Stone, C. D. (1972). Should Trees Have Standing--Toward Legal Rights for Natural Objects. S. CAI. I. rev., 45, 450.

Sultana, F. (2007). Reflexivity, positionality and participatory ethics: Negotiating fieldwork dilemmas in international research. ACME: An international journal for critical geographies, 6(3), 374-385.

Taiepa, T., Lyver, P., Horsley, P., Davis, J., Brag, M., \& Moller, H. (1997). Comanagement of New Zealand's conservation estate by Maori and Pakeha: a review. Environmental Conservation, 24(3), 236-250.

Tapu Te Ranga marae. (2019). Tapu Te Ranga Kõrero. Retrieved from https://www.taputerangamarae.org.nz/1 17 k-rero.html

The World Bank. (1999). Report from the International Workshop on CommunityBased natural Resource Management (CBNRM). Retrieved from URL:http://www.worldbank.org/wbi/conatrem/

Tipa, G., \& Welch, R. (2006). Comanagement of natural resources: issues of definition from an indigenous community perspective. The Journal of Applied Behavioral Science, 42(3), 373-391.

Vermeulen, S., \& Sheil, D. (2007). Partnerships for tropical conservation. Oryx, 41(4), 434-440.

Warren, S. (2016). Whanganui River and Te Urewera Treaty Settlements: Innovative developments for the practice of rangatiratanga in resource management.

West, P., Igoe, J., \& Brockington, D. (2006). Parks and peoples: the social impact of protected areas. Annu. Rev. Anthropol., 35, 251-277.

Western, D. (1994). The background to community-based conservation. Natural connections: Perspectives in community-based conservation, 1-12.

Wyatt, S. (2008). First Nations, forest lands, and "aboriginal forestry" in Canada: from exclusion to comanagement and beyond. Canadian Journal of Forest Research, 38(2), 171-180.

Wynn, G. (1979). Pioneers, politicians and the conservation of forests in early New Zealand. Journal of Historical Geography, 5(2), 171. 


\title{
Appendices
}

\section{Appendix 1: Participant Information Sheet}

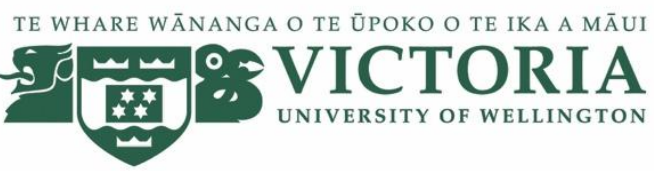

\section{Community-Based conservation; ideas and perspectives of conservation}

\author{
VUW Human Ethics Committee (HEC) number; 0000026126 \\ INFORMATION SHEET FOR PARTICIPANTS
}

You are invited to take part in this research. Please read this information before deciding whether or not to take part. If you decide to participate, thank you. If you decide not to participate, thank you for considering this request.

\section{Who am I?}

My name is Jerry van Lier and I am a Masters student in Environmental Studies at Victoria University of Wellington. This research project is working towards my thesis.

\section{What is the aim of the project?}

This project will analyse community-based conservation and how experiences as volunteers shape our knowledge and ideas around conservation.

I will be interviewing participants and volunteers of community-based conservation of the Manawa Karioi Restoration Project. These interviews will explore how our practical experiences of community-based conservation shape our perspectives.

The Manawa Karioi Society also has a collaborative relationship with the Tapu Te Ranga marae. As well as different ideas about conservation, this research will also explore the role of the marae in this restoration project, and perceptions of this role. 
Your contribution will provide insight into how people feel about conservation in Aotearoa, New Zealand. These feelings will reflect the different ideas and perceptions that shape how conservation is applied in community projects such as the Manawa Karioi.

\section{How can you help?}

If you agree to take part, I will interview you based on your experience of being involved with the Manawa Karioi Society, or as a volunteer during working days at the Manawa Karioi Restoration Project. If you have other experiences in community-based conservation these may also be applicable too. I will ask you questions about your experience and perceptions of community-based conservation occurring and what challenges and success you have faced and how the conservation project has evolved over time.

\section{The Interview Process}

Interviews will occur in the location of preference of the interviewee. This may be in the comfort and privacy of your own home, at a café or any other location which provides a comfortable setting.

The interview will take approximately 30-60 minutes. I will record the interview and write it up later. You can stop the interview at any time, without a given reason. You can withdraw from the study by contacting me anytime up to and including the $1^{\text {st }}$ of November, 2018. If you withdraw, the information you provided will be destroyed or returned to you.

\section{What will happen to the information you give?}

The information that you provide for this research will be confidential. Pseudonyms will be used for information provided to all identifiable research data.

Access to the information you give will also be de-identified when stored to ensure confidentiality. The storage of the (electronic) information will be locked in a secure server with pass-word protection. All hard copy material will be converted to an electronic format and destroyed. Electronic information will be destroyed on the $5^{\text {th }}$ of March, 2021.

You may also request to see a summary of the findings of the research and comment before any research is formally published. You may also provide input of assessing how information will be used and presented

\section{What will the project produce?}

The information from my research will be used to produce my Masters thesis and may be used in future articles or conference presentations. A findings report will also be produced and will be given to both the Manawa Karioi Society and the Tapu Te Ranga marae. If you are interest, you may request a copy of this findings report too.

\section{If you accept this invitation, what are your rights as a research participant?}


You do not have to accept this invitation if you don't want to. If you do decide to participate, you have the right to:

- $\quad$ choose not to answer any question;

- $\quad$ ask for the recorder to be turned off at any time during the interview;

- $\quad$ withdraw from the study anytime and up to and including $1^{\text {st }}$ of November 2018 after the interview;

- $\quad$ ask any questions about the study at any time;

- $\quad$ receive a copy of a summary of the findings and offer input as to how the research will be presented.

\section{If you have any questions or problems, who can you contact?}

If you have any questions, either now or in the future, please feel free to contact either:

Student:

Name: Jerry van Lier

University email address:

Jerry.vanlier@vuw.ac.nz

Phone: 0273239214

\section{Supervisor:}

Name: Dr. Amanda Thomas

Role: Lecturer

School: Geography, Environment and Earth

Sciences

Phone: 044636117

Amanda.Thomas@vuw.ac.nz

\section{Human Ethics Committee information}

If you have any concerns about the ethical conduct of the research you may contact the Victoria University HEC Convenor: Dr Judith Loveridge, email hec@vuw.ac.nz, phone (04) 4636028. 


\title{
Community-Based conservation; ideas and perspectives of conservation
}

\author{
VUW Human Ethics Committee (HEC) number; 0000026126 \\ CONSENT TO INTERVIEW FOR CONSERVATION PARTICIPANT
}

This consent form will be held for 1 year.

Researcher: Jerry van Lier, School of Geography, Environment and Earth Sciences, Victoria University of Wellington.

- I have read the Information Sheet and the project has been explained to me. My questions have been answered to my satisfaction. I understand that I can ask further questions at any time.

- $\quad$ I agree to take part in an audio recorded interview.

I understand that:

- I may withdraw from this study anytime up to and including the date of the $1^{\text {st }}$ of November, 2018, and any information that I have provided will be returned to me or destroyed.

- $\quad$ The identifiable and de-identifiable information I have provided will be destroyed two years past the research project on the $5^{\text {th }}$ of March, 2021. 
- $\quad$ I understand that the results will be used for a Masters report may be used in academic reports and/or presented at conferences.

- $\quad$ I understand that pseudonyms will be used in the report for confidentiality at all times and consent to information or opinions which I have given to be used in any Yes $\bigcirc$ No $\bigcirc$ reports on this research.

- $\quad$ I would like a copy of the summary of findings and the chance to comment on it Yes $\bigcirc$ No $\bigcirc$ with the option of assessing how information will be used and presented:

- $\quad$ I would like to receive a copy of the final report and have added my email address Yes $\bigcirc$ No $\bigcirc$ below.

Signature of participant:

Name of participant:

Date:

Contact details: 


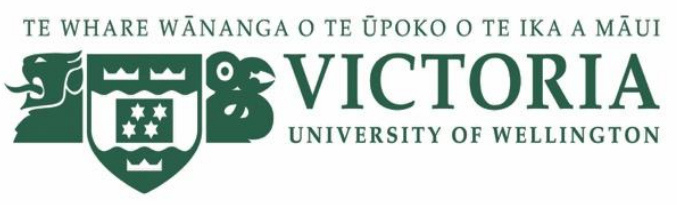

\section{Community-Based conservation; ideas and perspectives of conservation}

\section{Interview Schedule}

\section{Semi-Structured interviews with participants of the Manawa Karioi}

\section{Society}

1. What is your relationship with the Manawa Karioi Ecological Restoration Project?

a. How long have you been involved with the Manawa Karioi Ecological Restoration Project?

b. Do you have a specific role in this relationship?

2. What initially made you want to get involved with conservation or more specifically ecological restoration?

a. So why did you start volunteering at Manawa Karioi specifically?

b. Have you had any experiences with other conservation projects in New Zealand that you would like to share?

c. Have your experiences of conservation shaped an opinion of conservation in New Zealand in general. I.e. the state of conservation in general?

3. Do you know much about co-management relationships of conservation in New Zealand?

a. Have you had any experience working within a co-management relationship? 
b. Can you tell me what they often might look like?

4. What are some of the challenges you perceive the Manawa Karioi Ecological Restoration Project have been confronted with through its history?

a. Do these challenges still exist for Manawa Karioi?

5. Can you tell me about some of the successes you have achieved through these challenges?

a. Have these been large influences on the knowledge of conservation at Manawa Karioi?

6. In June, there was a Matariki guided tour of Manawa Karioi event.

a) did you go? Tell me about your experience.

b) what other forms of knowledge sharing take place at Manawa Karioi?

c) can you tell me about the relationship between the society and Tapu Te Ranga marae, and how this relationship shapes the kind of conservation you do?

7. Can you tell me a bit about the different things you have learnt about conservation from being a part of the Manawa Karioi Society? 


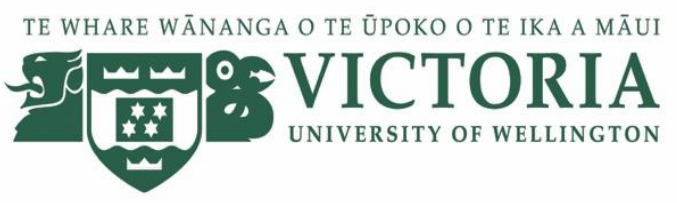

\section{Community-Based Conservation; ideas and perspectives of conservation}

\section{Interview Schedule}

\section{Semi-Structured interviews with volunteers of the Manawa Karioi Ecological Restoration Project}

1. What is your relationship with the Manawa Karioi Ecological Restoration Project?

a. How long have you been involved with the Manawa Karioi Ecological Restoration Project?

b. Do you have a specific role in this relationship?

2. What initially made you want to get involved with conservation or more specifically ecological restoration?

a. So why did you start volunteering at Manawa Karioi specifically?

b. Have you had any experiences with other conservation projects in New Zealand that you would like to share?

c. Have your experiences of conservation shaped an opinion of conservation in New Zealand in general. I.e the state of conservation in general?

3. Do know much about co-management relationships of conservation in New Zealand?

a. Have you had any experience working within a co-management relationship?

b. Can you tell me what they often might look like? 
4. Can you tell me a bit about the different things you have learnt about conservation from volunteering at Manawa Karioi or others?

5. In June, there was a Matariki guided tour of Manawa Karioi event.

c) did you go? Tell me about your experience.

d) what other forms of knowledge sharing take place at Manawa Karioi?

c) can you tell me about the relationship between the society and Tapu Te Ranga marae, and how this relationship shapes the kind of conservation you do? 
Appendix 4: Memorandum from Human Ethics

TE WHARE Wánanga o TE OPOKO O TE IKa A Mãu

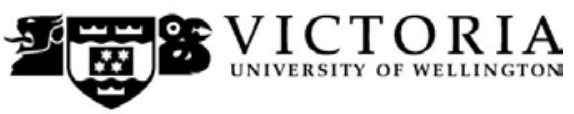

MEMORANDUM

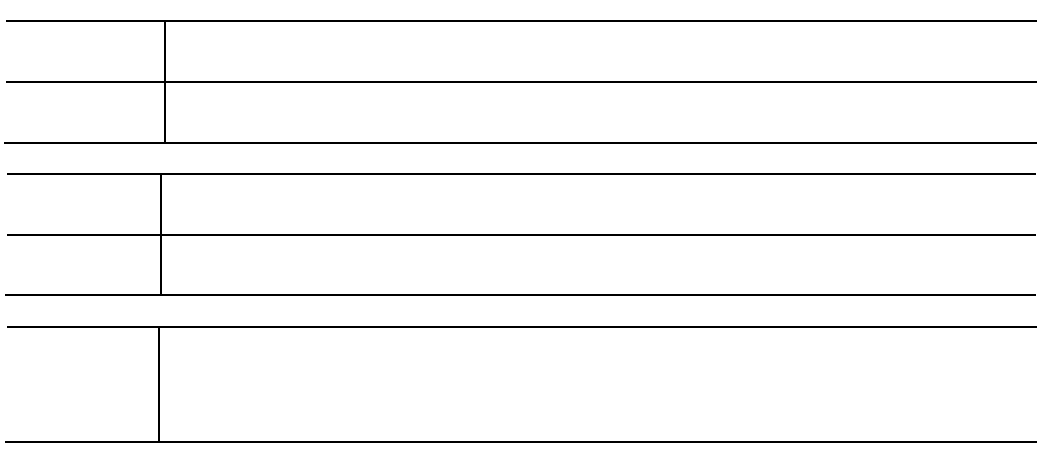

g.A.honeidge 